\title{
LABORATORY DETECTION LIMITS OF POTENTIAL HUMAN DECOMPOSITION PRODUCTS UNDER A VARIETY OF SOIL CONDITIONS
}

\author{
A Thesis \\ Presented to \\ The Graduate Faculty of The University of Akron
}

\author{
In Partial Fulfillment \\ of the Requirements for the Degree \\ Master of Science
}

Sarah E. Travaly

August, 2016 


\title{
LABORATORY DETECTION LIMITS OF POTENTIAL HUMAN DECOMPOSITION PRODUCTS UNDER A VARIETY OF SOIL CONDITIONS
}

\author{
Sarah E. Travaly
}

Thesis

Approved:

Accepted:

Advisor

Dr. Linda R. Barrett

Interim Dean of the College

Dr. John Green

Faculty Reader

Dr. Timothy Matney

Faculty Reader

Dr. John M. Senko

Department Chair

Dr. James McManus
Dean of the Graduate School

Dr. Chand Midha 


\begin{abstract}
This study is part of a larger project titled, "In Situ Shallow Subsurface Spectroscopy (S4 Initiative)" which is focused on furthering the research on shallow subsurface spectroscopic and geochemical prospecting of archaeological deposits in situ. The long term goal is to create a geochemical instrument for subsurface prospection and characterization of soil conditions in an archaeological and forensic context. The specific purpose of this study was to establish laboratory detection limits of four potential human decomposition products (leucine, calcium pyrophosphate, oleic acid, and palmitic acid) under a variety of soil conditions and demonstrate their applicability to human burial analogues under field conditions.

Detection limits were determined under laboratory conditions by collecting ATRFTIR spectra on soil samples to which known concentrations of the four human decomposition products had been added. The soil used was collected from three locations representing a variety of texture classes (particle size) and organic matter contents. A similar process was utilized to detect the compounds in soil samples taken from two sites where pigs had been buried as human analogues. Soil cores taken from the "pig dig” sites allowed for the effectiveness of the detection limits to be tested using sample analogues of human burials under field conditions.

All four of the human decomposition products were detected in the samples to which they had been added, though no significant relationships to either particle size or organic matter content were observed. Detection limits ranged from 1.0\% - 0.04\% for leucine,
\end{abstract}


4.0\% $-0.05 \%$ for calcium pyrophosphate, $0.10 \%-0.01 \%$ for oleic acid, and $1.0 \%$ 0.01\% for palmitic acid in all samples.

ATR-FTIR spectral peaks representative of one or more fatty acids were present in some of the cores in both of the human burial analogues, however peaks representative of leucine and calcium pyrophosphate were not present in any of the cores from either human burial analogue. The detection limits of leucine and calcium pyrophosphate were too high to adequately distinguish the presence of either product in the human burial analogue samples, which contained only trace amounts of each product. However, the detection limits of both oleic and palmitic acid were low enough that both were present in samples taken from each of the human burial analogues. One sample which contained visible pig tissue decomposition, contained spectral peaks indicative of approximately $1.0 \%$ oleic acid and/or $1.0-4.0 \%$ palmitic acid.

The results from this study suggest that fatty acids will be beneficial decomposition products for further research by the S4 Initiative in their pursuit to create a geochemical instrument for subsurface archaeological prospection. 


\section{ACKNOWLEDGEMENTS}

I would like to thank the members of the S4 Initiative for inviting me to work on this project and sharing their knowledge of all things soil, archaeological, chemical, and forensic. Thank you to my advisor, Dr. Linda Barrett, my committee member, Dr. Timothy Matney, my honorary committee member, Dr. David Perry, and Dr. Linda Whitman for all of their input over the last two years, for calming me down when I became overwhelmed, and for all of the research experience on our trip to Kansas.

Thank you to my committee member, Dr. John Senko, for his help in the laboratory and for letting me borrow materials from his lab.

A very big thank you to Thomas Quick for help in the field, help with the computers, help with everything! Tom's selflessness and willingness to help everyone in the department with any problem is truly inspirational and is not taken for granted by any of us.

Another big thank you to Elaine Butcher for her constant help throughout the whole process, especially with posters, InDesign formatting, and general knowledge of the department. Elaine looks after every single professor and student in the department and we would be lost without her.

Thank you to Corinne Lally and Bo Montanye for helping me take cores, even though I was the only one forced to wear a hard hat.

Thank you to the Delaney family for letting me dig a large hole in their yard.

Thank you to both sets of my parents, Cathy and Scott Lawrence, and Andrew Travaly and Carla Welch, for always believing in me and encouraging me to persevere 
throughout my undergraduate and graduate career. They also let me vent my frustrations to them any time of the day or night which was also appreciated.

Thank you also to both sets of my grandparents, Dona and Jack Croto, and Marie and Augie Travaly, for always telling me how proud they are of me and supplementing my financial aid.

Shout out to my best friend, Bryan Murray, for always telling me I'm awesome, even when I'm having a bad day and for asking to read this when it's all finished. Thank you.

Lastly, I would like to thank Adam Delaney, Corinne Lally, Stephanie Mitchell, Annie Hartwell, and all of my fellow graduate students for laughing with (at?) me and keeping me sane throughout this entire process.

Thank you all for the love and support you have given me throughout my time at graduate school and my life in general.

Thanks! 
TABLE OF CONTENTS

Page

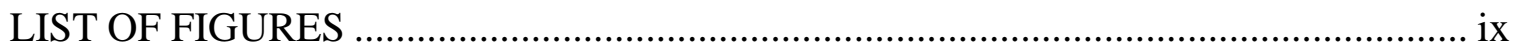

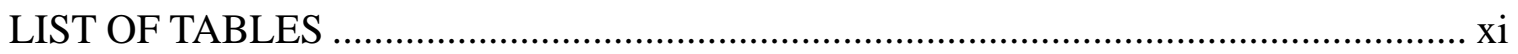

\section{CHAPTER}

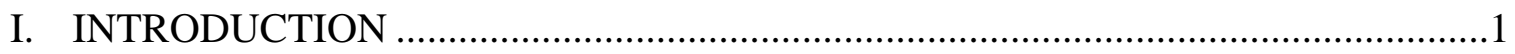

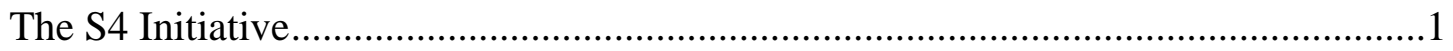

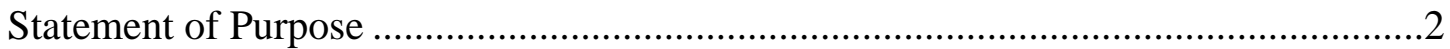

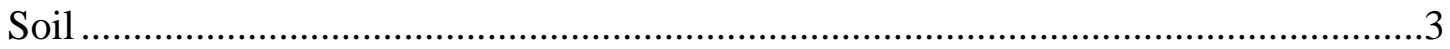

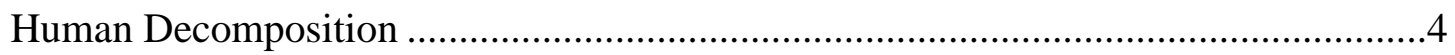

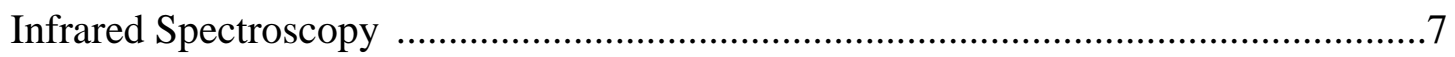

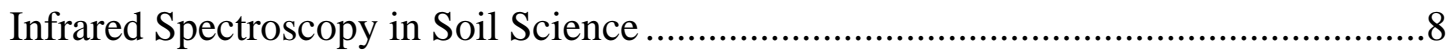

Human Decomposition Product Detectability .....................................................9

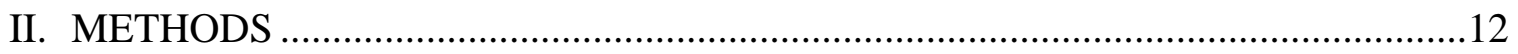

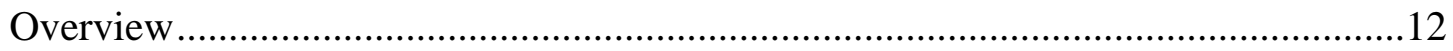

Soil Sample Collection and Preparation ............................................................... 12

Leucine and Calcium Pyrophosphate..................................................................15

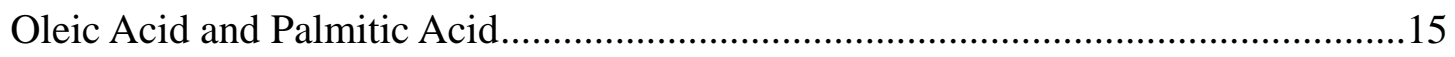

Laboratory Spectroscopy and Analysis..............................................................

Application of Laboratory Spectra to Field Conditions..........................................17

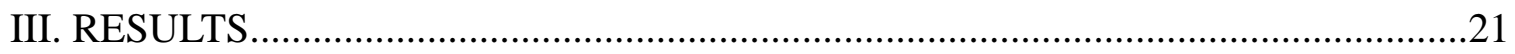

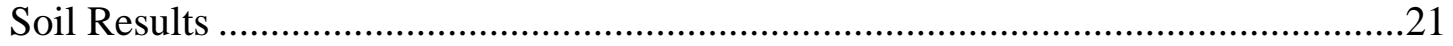

Decomposition Product Spectra - Leucine ............................................................28 
Decomposition Product Spectra - Calcium Pyrophosphate ................................33

Decomposition Product Spectra - Oleic Acid .....................................................33

Decomposition Product Spectra - Palmitic Acid ................................................38

Human Burial Analogue 2011 - Soil Results ...................................................38

Human Burial Analogue 2011 - Spectra Results ..............................................44

Human Burial Analogue 2015 - Soil Results ......................................................55

Human Burial Analogue 2015 - Spectra Results ...............................................55

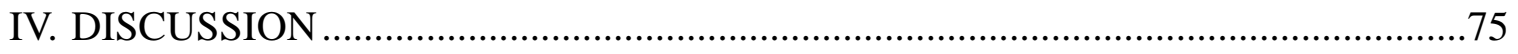

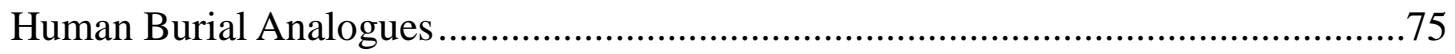

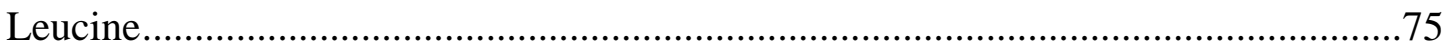

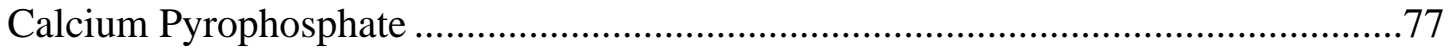

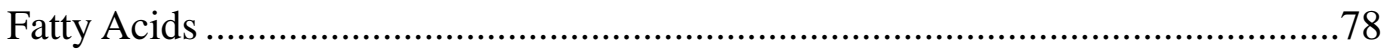

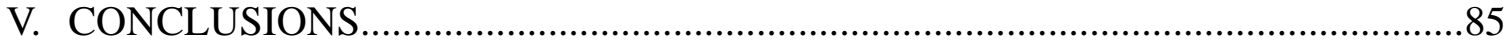

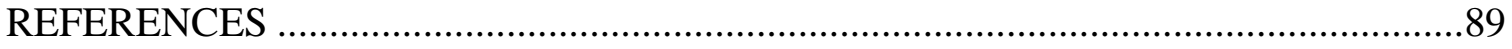

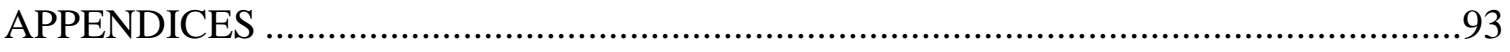

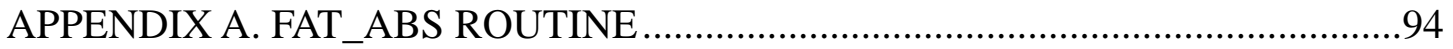

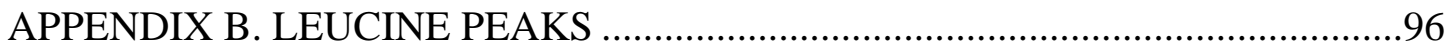

APPENDIX C. CALCIUM PYROPHOSPHATE PEAKS.....................................100

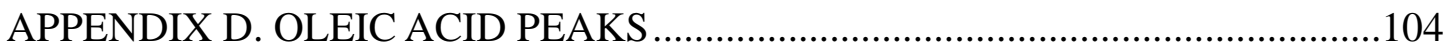

APPENDIX E. PALMITIC ACID PEAKS.........................................................108 


\section{LIST OF FIGURES}

Figure Page

1 Overview of human decomposition processes (Dent et al., 2003)

2 Chemical formulas and structures for the four decomposition products used in this study.

3 Location map of the three sample soils

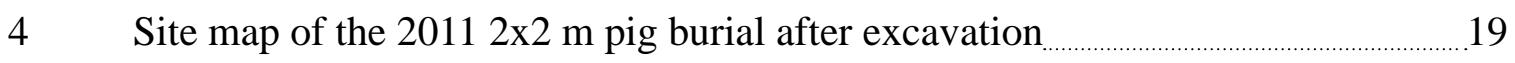

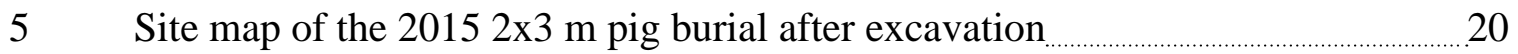

$6 \quad$ Photograph of the Steiner Property soil profile

$7 \quad$ Texture triangle showing particle size distribution of the three soils _........................... 24

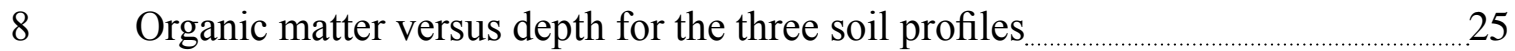

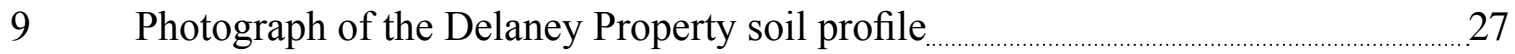

10 Leucine peaks in the Steiner Property S1 sample 30

11 Leucine detection limits plotted against particle size and plotted against organic matter in the three soils 32

12 Calcium pyrophosphate peaks in the Steiner Property S1 sample

13 Calcium pyrophosphate detection limits plotted against particle size and plotted against organic matter in the three soils.

14 Oleic acid peaks in the Steiner Property S1 sample

15 Oleic acid detection limits plotted against particle size and plotted against organic matter in the three soils...

16 Palmitic acid peaks in the Steiner Property S1 sample..

17 Palmitic acid detection limits plotted against particle size and plotted against organic matter in the three soils

18 Photographs of the 2011 cores. 
19 Texture triangle showing the particle size distribution of the 2011 cores

20 Spectra results of the 2011 cores, on
(a) MC1 - MC3

(b) MC4 - MC5

21 Spectra results of the 2011 cores compared to the Steiner Property palmitic acid spectra and oleic acid spectra, on

(a) MC1 - MC3

(b) MC4 - MC5

22 Site map of the 2011 cores compared with the spatial differences in the amounts of fatty acid present in the cores

23 Photographs of the 2015 cores 59

24 Texture triangle showing the particle size distribution of the 2015 cores …................6

25 Spectra results of the 2015 cores, on

(a) C1D1 - C3

(b) $\mathrm{C} 4$ - $\mathrm{C} 6$

26 Spectra results of the 2015 cores compared to the Steiner Property palmitic acid spectra and oleic acid spectra, on

(a) C1D1 - C3

(b) $\mathrm{C} 4$ - $\mathrm{C} 6$

27 Photograph of the adipocere present in C2 at a depth of $10-20 \mathrm{~cm}$

28 Site map of the 2015 cores compared with the spatial differences in the amounts of fatty acid present in the cores

29 The 2015 pig carcass after it had been exposed

30 Comparison of unaltered calcium pyrophosphate spectra from S1 with pure water spectra

31 S1 calcium pyrophosphate peaks transposed over Klee's and Engel's (1969) Figure 1

32 Comparison of oleic acid and palmitic acid spectra from S1 compared with adipocere spectra from C2. 


\section{LIST OF TABLES}

Table

Page

1 Soil properties for the Steiner Property soil

2 Soil properties for the Delaney Property soil

3 Soil properties for the North Kingsville Property soil

$4 \quad$ Leucine peak $2\left(\sim 2950 \mathrm{~cm}^{-1}\right)$ measurements on
(a) Peak heights
(b) Peak areas

5 Calcium pyrophosphate peak $2\left(\sim 1090 \mathrm{~cm}^{-1}\right)$ measurements on
(a) Peak heights
(b) Peak areas...

$6 \quad$ Oleic acid peak $3\left(\sim 2925 \mathrm{~cm}^{-1}\right)$ measurements on
(a) Peak heights
(b) Peak areas.

$7 \quad$ Palmitic acid peak $3\left(2915 \mathrm{~cm}^{-1}\right)$ measurements on
(a) Peak heights
(b) Peak areas

8 Soil properties for 2011 core MC1 47

$9 \quad$ Soil properties for 2011 core MC2 $\quad 48$

10 Soil properties for 2011 core MC3 49

11 Soil properties for 2011 core MC4

12 Soil properties for 2011 core MC5

132011 cores peak $2\left(\sim 2915 \mathrm{~cm}^{-1}\right)$ measurements on
(a) Peak heights
(b) Peak areas.

14 Soil properties for 2015 cores C1D1 and C1D2

15 Soil properties for 2015 core C2

16 Soil properties for 2015 core C3

17 Soil properties for 2015 core C4 
19 Soil properties for 2015 core C6

202015 cores peak $2\left(\sim 2915 \mathrm{~cm}^{-1}\right)$ measurements on

$\begin{array}{ll}\text { (a) Peak heights } & \text { (b) Peak areas }\end{array}$ 


\section{CHAPTER I}

\section{INTRODUCTION}

\section{The S4 Initiative}

This study is part of a larger project with the long term goal of creating a geochemical instrument for subsurface prospection and characterization of soil conditions in an archaeological and forensic context. The project, titled “In Situ Shallow Subsurface Spectroscopy," shortened to "The S4 Initiative," is focused on furthering the research on shallow subsurface spectroscopic and geochemical prospecting of archaeological deposits in situ. Aside from surface survey and excavation, most common archaeological prospecting involves subsurface geophysical survey, specifically remote sensing. Remote sensing in an archaeological context refers to the use of some form of electromagnetic energy to detect and measure characteristics of an archaeological target (Kelly and Thomas, 2013). Typical remote sensing techniques include magnetic gradiometry, soil resistivity survey, and ground penetrating radar, which are used to narrow locations and potentially identify archaeological features before excavation (Kelly and Thomas, 2013).

Archaeologists would benefit by supplementing geophysical prospection techniques with a geochemical approach, such as diffuse reflectance spectroscopy. Although the current remote sensing technologies aid in the mapping of archaeological features, the instrument proposed by the S4 Initiative would allow for real-time chemical analyses of subsurface features before excavation. It would also allow archaeologists to determine areas with the highest potential for positive results before beginning an expensive excavation. This would be executed with a minimally invasive probe which would 
determine subsurface soil conditions through the use of visible to near-infrared or midinfrared spectra.

Research by the S4 Initiative team has begun (Matney et al., 2014) to demonstrate the feasibility of using an in situ subsurface infrared spectroscopy method to locate archaeological remains. Matney et al. (2014) used a truck-mounted probe delivery system and an integrated spectrometer to view the visible and near-infrared spectra of the subsurface soil of a certain area in Kansas, to detect the presence of known anthropogenic features left behind by Native American peoples. They were attempting to see spectral signatures indicating the presence of three aspects of the archaeological soil: hearth soil, carbon content, and phosphorus content (Matney et al., 2014). Though the objectives of the S4 Initiative's proposed instrument are intended to further archaeological techniques, the fields of forensics, national security, agriculture, and environmental science would benefit as well.

\section{Statement of Purpose}

My purpose as part of the S4 Initiative is to establish laboratory detection limits of potential human decomposition products under a variety of soil conditions and demonstrate their applicability to human burial analogues under field conditions. In order to establish an in situ method to determining the presence of human remains within a recent or archaeological "gravesoil” (Tibbett and Carter, 2009), the aspects of a decomposing body which are detectable under laboratory conditions must be ascertained. The products must be chemically different than substances naturally present in a soil in order to be distinguishable from the soil, thus inferring they only entered the soil through human or animal decomposition processes. The four decomposition products analyzed in this study are leucine, calcium pyrophosphate, oleic acid, and palmitic acid. The specific laboratory technique utilized is attenuated total reflectance-Fourier transform infrared 
spectroscopy (ATR-FTIR) which involves analyzing unique reflective signatures of soil substances by viewing and comparing their mid-infrared spectra. The simulated human burial sites were represented by soil cores taken from the burial sites of two pigs, as pigs and humans have similar tissues and decomposition processes (Notter et al., 2009).

\section{Soil}

Soil is a three dimensional body composed of unconsolidated mineral and organic material which forms at the earth's surface and is a growth medium for plants (Buol et al., 2003; Schaetzl and Anderson, 2005). The main components of soil are inorganic mineral matter, organic matter, water, and air, referred to by Stenberg et al. (2010) as a "complex matrix." The mineral component of soil is often referred to by its particle size, the most important being the fine earth fraction: sand, silt, and clay (Schaetzl and Anderson, 2005; Stenberg et al., 2010). The sand particles are primarily more resistant minerals such as quartz and feldspar, while the clay particles are the end products of various degrees of weathering (Stenberg et al., 2010).

Soil has much variability laterally, vertically, and across even small distances, due to the nature of its formation. Jenny (1941) described soil as a function of climate, organisms, relief, parent material, and time. Climate includes the temperature, precipitation, and water availability of the environment in which the soil forms (Schaetzl and Anderson, 2005). Organisms refer to the flora and fauna present during the formation and maturation of a soil (Schaetzl and Anderson, 2005). Relief includes the topography, slope, and drainage of the developing soil (Schaetzl and Anderson, 2005). Parent material refers to the substrate in which the soil formed; it is commonly based on the geology present in the area of the forming soil. The texture and composition of the parent material has much influence over the soil type (Schaetzl and Anderson, 2005). Finally, the last factor of soil formation is time, which refers to the amount of time a soil has had to form. 
This influences the maturation of the soil and the development of horizons within the soil profile (Buol et al., 2003).

\section{Human Decomposition}

Decomposition of human remains begins almost immediately after death (Dent et al., 2003). The first postmortem processes to occur are autolysis and putrefaction (Dent et al., 2003; Janaway et al., 2009). Together these bacterially induced processes breakdown soft tissue, altering its carbohydrate, protein, and fat constituents (Dent et al., 2003). If the decomposition process continues, putrefaction is followed by liquefaction and disintegration, leaving the body in a skeletonized state; only the bone, teeth, and cartilage remain to be subjected to inorganic chemical weathering (Figure 1; Dent et al., 2003). When a cadaver decomposes, decomposition products are released into the surrounding soil (gravesoil) creating a localized surge of nutrients referred to as a cadaver decomposition island or a concentrated island of fertility (Carter et al., 2008; Stokes et al., 2009). This pulse of nutrients provides the soil with a medium for increased growth of soil microbial biomass and microbial activity (Stokes et al., 2009).

During putrefaction, enzymes break down proteins in the body through the process of proteolysis (Evans, 1963). Proteolysis does not occur at uniform rates, resulting in some proteins being destroyed in the early stages of decomposition while others are not destroyed until later stages (Dent et al., 2003). The less resistant proteins (destroyed first) are those of the neuronal and epithelial tissues (ie. the gastrointestinal tract lining) and the more resistant proteins (destroyed last) include the epidermis (skin), collagen, and muscle protein (Dent et al., 2003). Proteolysis yields proteoses, peptones, polypeptides, and amino acids (Dent et al., 2003).

During the deamination of amino acids, nitrogen is released in the form of ammonia (Dent et al., 2003). The ammonia is either used by plants or microbes in the soil, 


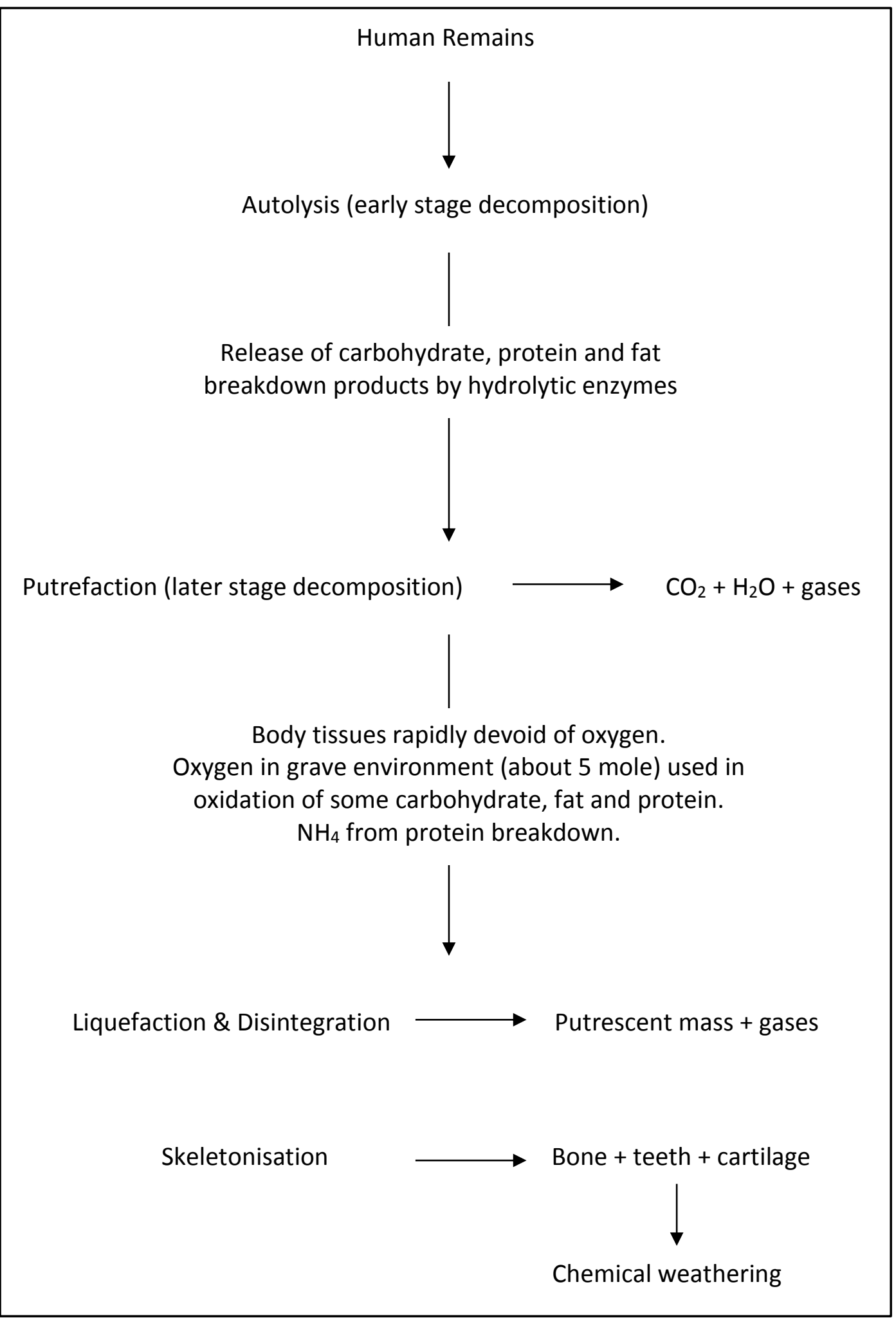

Figure 1. Overview of human decomposition processes (Dent et al., 2003). 
converted to nitrate by soil organisms under oxic conditions, accumulated in the soil, or removed from the soil by the groundwater system (Dent et al., 2003). Nitrogenbased compounds are among the most common decomposition products of cadaver protein components (Stokes et al., 2009; Swan et al., 2010). Leucine, the nitrogen-based compound used in this study, is an essential amino acid found in human blood plasma (Van Slyke and Meyer, 1912; Stein and Moore, 1954) as well as skeletal and cardiac muscle tissue (Morgan et al., 1971; Buse and Reid, 1975; Garlick, 2005).

Phosphorus is another element present in animal biomass, stored in the components of nucleic acids, phospholipids, and bones (Anderson, 1996; Dent et al., 2003). Phosphorus is liberated during decomposition through many complex pathways (Dent et al., 2003) and tends to accumulate in soil rather than being removed or leached out (Matney et al., 2014). Stokes et al. (2009) suggested that phosphorus-based compounds are among the most common byproducts of cadaver decomposition and are detectable in the soil for a period of time after decomposition, offering good potential as "forensic tools." Rather than staying in its elemental form (Dent et al., 2003), phosphorus is likely to exist in soils as insoluble inorganic complexes associated with iron, calcium, magnesium, and aluminum (Higgins and Burns, 1975). Inorganic pyrophosphate is metabolized intracellularly during the synthesis of several major cell constituents, such as those of proteins, lipids, nucleic acids, urea, and glycogen, as well as metabolized extracellularly in body fluids such as serum, plasma, urine, saliva, and synovial fluid (Caswell et al., 1983; Ryan and McCarty, 1995). Calcium pyrophosphate, the inorganic phosphorusbased compound used in this study, is usually found adsorbed to bone mineral in large quantities, but can also be found pathogenically in the synovial (soft joint tissue) membrane (Caswell et al., 1983).

Another human decomposition process is the breakdown of adipose (fat) tissue (Dent et al., 2003) into adipocere, or “corpse wax” (Ubelaker and Zarenko, 2011). 
Adipose tissue is primarily comprised of 5-30\% water, 2-3\% proteins, and 60-85\% lipids, by weight (Reynold and Cahill, 1965). 90-99\% of the lipids (fats) are triglycerides, composed of one glycerol molecule attached to three fatty acid molecules (Reynold and Cahill, 1965; Dent et al., 2003). After death, the neutral fat of the adipose tissue undergoes hydrolysis, yielding fatty acids which then may undergo hydrogenation or oxidation (Dent et al., 2003). The hydrogenation of oleic, linoleic, and palmitoleic acids yields stearic, oleic, and palmitic acids, respectively (Dent et al., 2003; Forbes et al, 2005a,b). Evans (1963) suggests that continued hydrolysis and hydrogenation increases the amount of saturated fatty acids in the decomposing neutral fat, while subsequently decreasing the amount of unsaturated fatty acids. Therefore, palmitic acid and stearic acid, both saturated long-chain fatty acids, would be the primary fatty acid components of adipocere when all of the neutral fat has decomposed. Comparatively, Dent et al. (2003) suggested that shorter chain fatty acids begin to decompose before longer chain fatty acids; inferring that the presence of short-chain fatty acids may be indicative of a recently buried cadaver, while the presence of long-chain fatty acids may be indicative of a cadaver with a longer residence time. The fatty acids used in this study, oleic acid (a medium-chain unsaturated fatty acid) and palmitic acid (a long-chain saturated fatty acid), are both found in adipocere, the end product of adipose decomposition (Dent et al., 2003; Forbes et al., 2005a,b).

\section{Infrared Spectroscopy}

Infrared spectroscopy involves creating the infrared spectrum of a sample by passing an infrared light beam through the sample and allowing some of the beam to be absorbed by the sample and some to be reflected back to the machine. Absorbance of the infrared light occurs when the frequency of the infrared light is the same as the vibrational frequency of a bond in the sample. Infrared spectroscopy is a useful technique 
in chemical analysis because it is impossible for two different molecules to produce identical infrared spectra (Chang and Thoman, 2014).

Attenuated total reflectance-Fourier transform infrared spectroscopy (ATR-FTIR) refers to a specific method of infrared spectroscopy. In the ATR-FTIR method, a beam of several frequencies of infrared light is shone at a sample and a computer records how much of the beam is reflected by the surface of the sample and how much of the beam is internally absorbed by the sample. This process is repeated several times using different combinations of wavelengths. The computer is able to use this data to determine the absorbance at each wavelength and create a spectrum for the sample, plotting absorbance versus wavelength (Griffths, 1983).

\section{Infrared Spectroscopy in Soil Science}

Infrared spectroscopy has proved to be very useful in the chemical analysis of soil samples. Chang et al. (2001) stated that, "Near-infrared reflectance spectroscopy is a simple and nondestructive analytical method that can be used to predict several soil properties simultaneously.” Since the 1980s, visible and near-infrared diffuse reflectance Fourier transform spectrometry (DRIFTs) techniques have been extensively developed in agriculture and soil science, with particular emphasis on soil organic and inorganic carbon content and iron-bearing minerals (Bellon-Maurel and McBratney, 2011; Stenberg, 2010; Leifeld, 2006). DRIFTs differs from ATR-FTIR in that it collects information from the bulk matrix of a sample; the rough edges reflect the light in all directions to be collected by an ellipsoid or paraboloid mirror (Fuller and Griffiths, 1978). DRIFTs is often favored because it is inexpensive, involves minimal sample preparation, and is nominally invasive to samples (Morgan et al., 2009; Stenberg et al., 2010). However, in a comparison of spectra, Beasley et al. (2014) stated that DRIFTs produced much lower resolution and less reliable results than ATR-FTIR. 
Soil studies using diffuse reflectance spectroscopy commonly measure reflectance in the visible ( 400 to $700 \mathrm{~nm}$ ) to near-infrared (700 to 2,500 nm) wavelengths, though some have begun utilizing the mid-infrared (2,500 to 25,000 nm) wavelengths (Reeves, 2010; Viscarra Rossel et al., 2006). An advantage of mid-infrared spectra is that many materials, such as quartz, have their fundamental vibrations in the mid-infrared wavelengths, allowing them to have a strong mid-infrared signal even though they have a weak nearinfrared signal (Reeves, 2010). Although mid-infrared spectra may be easier to interpret than near-infrared spectra in complex materials such as soil, the instruments are often more expensive and not intended for use in the field (Reeves, 2010; Bellon-Maurel and McBratney, 2011; Janik et al., 1998). Due to the cost and lack of available equipment utilizing mid-infrared spectroscopy, previous S4 Initiative studies have been limited to an instrument capable of producing visible to near-infrared spectra (Matney et al., 2014).

\section{Human Decomposition Product Detectability}

The human decomposition products tested in this study (leucine, calcium pyrophosphate, oleic acid, and palmitic acid) are detectable using infrared spectroscopic techniques. Leucine, the nitrogen-based compound I am using (Figure 2), has been detected in the mid-infrared range by Aleese et al. (2006). Aleese et al. (2006) used mid-infrared multiphoton dissociation (IRMPD) spectroscopy, a technique used to fragment molecules in the gas phase in order to determine the structural analysis of the original molecule (Little et al., 1994). Although the technique is different from FTIR, both utilize mid-infrared spectra. Resolution enhanced FTIR was used by Rey et al. (1990) to characterize pathological deposits of calcium-phosphate mineral phases. Although calcium phosphate is not being directly tested in this study, calcium pyrophosphate (Figure 2), an inorganic calcium-phosphate deposit is being tested. In a previous S4 Initiative study, Matney et al. (2014) were able to detect high concentration 
a)<smiles>CC(C)C[C@H](N)C(=O)O</smiles>

b)<smiles>COP(=O)([O-])OP(=O)([O-])[O-]</smiles>

c)

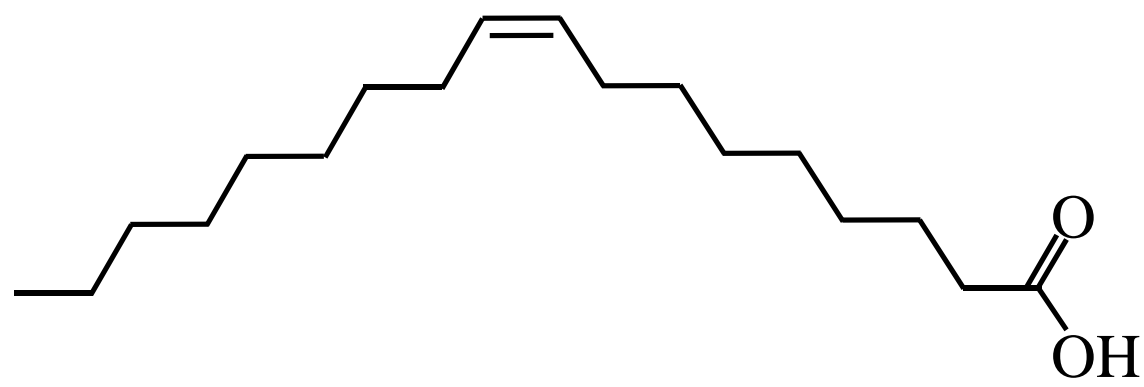

d)

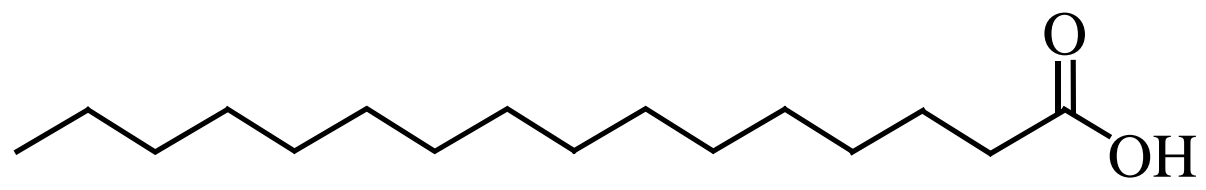

Figure 2. Chemical formulas and structures for the four decomposition products used in this study. a) Leucine: $\mathrm{C}_{6} \mathrm{H}_{13} \mathrm{NO}_{2}$ b) Calcium Pyrophosphate: $\mathrm{Ca}_{2} \mathrm{O}_{7} \mathrm{P}_{2}$ c) Oleic Acid: $\mathrm{C}_{18} \mathrm{H}_{34} \mathrm{O}_{2}$ d) Palmitic Acid: $\mathrm{C}_{16} \mathrm{H}_{32} \mathrm{O}_{2}$. 
of phosphorus in the archaeological soil of a food storage pit using diffuse reflectance spectroscopy. Stuart et al. (2000) investigated the use of diffuse reflectance infrared spectroscopy on the detection of adipocere. They stated that the method proved to be successful in detecting adipocere (fatty acids) in the exhumed remains of cemetery and clandestine graves (Stuart et al., 2000). Both oleic acid (Figure 2) and palmitic acid (Figure 2), the fatty acids used in this study, are components of adipocere (Dent et al., 2003). 


\section{CHAPTER II}

\section{METHODS}

\section{Overview}

I determined the detection limits of four human decomposition products (leucine, calcium pyrophosphate, oleic acid, and palmitic acid) under laboratory conditions by collecting ATR-FTIR spectra on soil samples to which I had added known concentrations of the four human decomposition products. Once the detection limits were determined, I used a similar process to detect the compounds in soil samples taken from two sites where pigs had been buried as human analogues. Pigs were used because pigs and humans have similar adipose tissue (Notter et al. 2009). Soil cores taken from the "pig dig” sites presented an opportunity to apply the knowledge I gained from determining detection limits on samples with known concentrations under laboratory conditions, to sample analogues of human burials under field conditions.

\section{Soil Sample Collection and Preparation}

I identified three locations to collect soil samples which differed based on soil texture; one clayey soil, one silty soil, and one sandy soil. Since the organic matter content of soil decreases as one moves down the soil profile (Schaetzl and Anderson, 2005), this allowed for the detection of the decomposition products over a range of organic matter (high to low), as well as over a range of textures (fine to coarse). All soils were described and sampled by horizon using standard procedures (Shoeneberger et al., 2012). 
The clayey soil, hereafter the Steiner Property soil (S), was collected from Bath Township in Summit County, Ohio. Three soil samples were collected from a pit located at $41^{\circ} 10^{\prime} 21.11^{\prime \prime} \mathrm{N}$ and $81^{\circ} 38^{\prime} 41.48^{\prime \prime} \mathrm{W}$ on June 13th, 2015 (Figure 3). The pit was located in a moderately-drained, forested area with a $1-2 \%$ slope. The vegetation at the site was forested, with trees, leaf litter, and rotting wood present. The parent material was glacial till.

The silty soil, hereafter the Delaney Property soil (A), was collected from Farmington Township in Clarion County, Pennsylvania. Four soil samples were collected from a pit located at $41^{\circ} 24^{\prime} 8.53^{\prime \prime} \mathrm{N}$ and $79^{\circ} 18^{\prime} 52.46^{\prime \prime} \mathrm{W}$ on June 7th, 2015 (Figure 3). The pit was located in a well-drained agricultural field with a $2 \%$ slope. The vegetation at the site was thick field grass, which had been plowed or tilled at some point before the pit was dug. The parent material was a colluvium derived from acid shale, siltstone, and sandstone.

The sandy soil, hereafter the North Kingsville soil (NK-1), was collected from the North Kingsville Sand Barrens in Ashtabula County, Ohio. Nine soil samples were collected from a pit located at $41^{\circ} 55^{\prime} 44.4^{\prime \prime} \mathrm{N}$ and $80^{\circ} 39^{\prime} 14.6^{\prime \prime} \mathrm{W}$ on November 11th, 2000 (Figure 3). The pit was located in a well-drained beach ridge with a north-facing slope. The vegetation at the site was scattered small trees, with decomposing leaf litter present. The parent material was eolian sand or beach sand.

The texture of each soil horizon was determined by the pipette method (Janitzky, 1986; Burt and Soil Survey Staff, 2014). Particle size analysis was performed twice for each sample, and the average of the two analyses is summarized in the results section.

The organic matter content of each soil horizon was determined by the loss-onignition (LOI) method (Nelson and Sommers, 1982). Loss-on-ignition analysis was performed four times for each sample, and the average of the four analyses is summarized in the results section. 


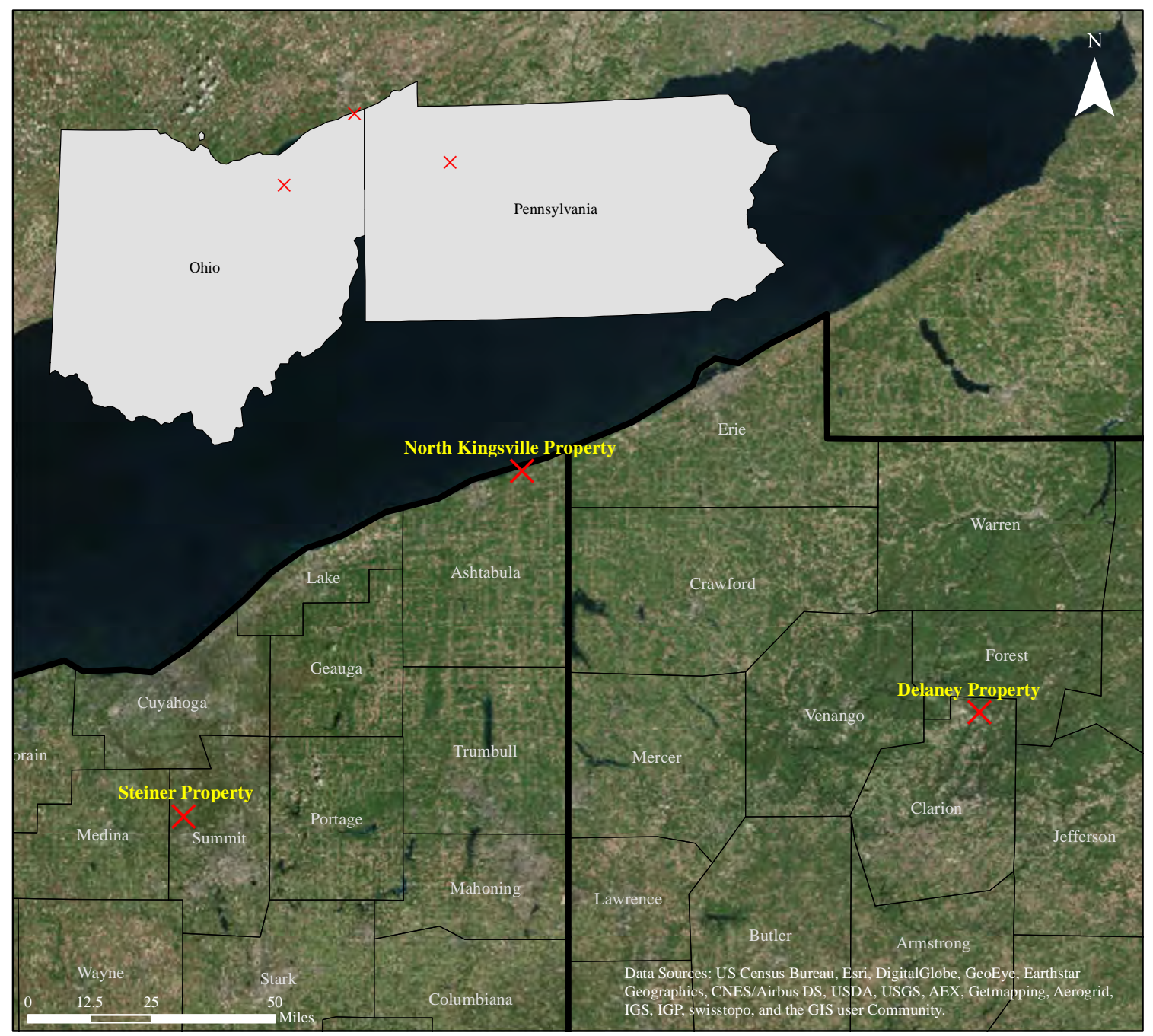

Figure 3. Location map of the three sample soils. The Steiner Property, located in Summit County, $\mathrm{OH}$ at $41^{\circ} 10^{\prime} 21.11^{\prime \prime} \mathrm{N}$ and $81^{\circ} 38^{\prime} 41.48^{\prime \prime} \mathrm{W}$; the Delaney Property, located in Clarion County, PA at $41^{\circ} 24^{\prime} 8.53^{\prime \prime} \mathrm{N}$ and $79^{\circ} 18^{\prime} 52.46^{\prime \prime} \mathrm{W}$; and the North Kingsville

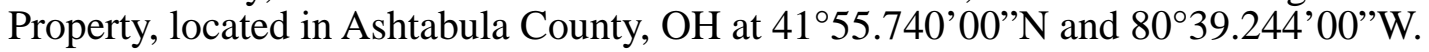


Known concentrations of the four decomposition products (leucine, calcium pyrophosphate, oleic acid, and palmitic acid) were added to subsamples of each horizon from each of the three soils with the exception of samples A1, NK1-1, NK1-2, NK1-7, NK1-8, and NK1-9 due to low sample volume. The concentrations were added in eight $\mathrm{wt} / \mathrm{wt} \%$ steps $(8 \%, 4 \%, 1 \%, 0.4 \%, 0.1 \%, 0.05 \%, 0.01 \%$, and $0.002 \%$, referred to as a-h respectively) and thoroughly mixed through the entire sample (Raubenstraw, 2014).

\section{Leucine and Calcium Pyrophosphate}

The leucine and calcium pyrophosphate were in the solid phase at room temperature $\left(20^{\circ} \mathrm{C}\right)$. The appropriate amount of a $20 \mathrm{~g} / \mathrm{L}$ leucine or $20 \mathrm{~g} / \mathrm{L}$ calcium pyrophosphate solution was added to $10 \mathrm{~g}$ of soil in a $50 \mathrm{~mL}$ glass beaker. If necessary, to ensure an even mixing of the decomposition product solution throughout each soil sample, additional milliliters of distilled water were added to the glass beaker until about $40 \mathrm{~mL}$ of liquid were in each beaker. The soil/decomposition product mixture was thoroughly mixed, transferred to a petri dish, and left at room temperature and conditions $\left(20^{\circ} \mathrm{C}\right.$ and $11 \%$ humidity) to evaporate. When the samples were air-dry, they were transferred to a mortar and pestle to break down the crystals and then stored in a labeled sample bag.

\section{Oleic Acid and Palmitic Acid}

Since neither oleic nor palmitic acid are soluble in water, these compounds were mixed with the soil samples by melting. The appropriate amount of the acid was transferred into aluminum weigh boats, then placed on a hot plate set to $100^{\circ} \mathrm{C}$, to which $10 \mathrm{~g}$ of soil that had been heated in an oven for approximately one hour was added. The acid and the soil were thoroughly mixed while still on the hot plate, then transferred to a mortar and pestle to break down the clumps before being stored in a labeled sample bag. For the smaller wt/wt\% steps, $30 \mathrm{~g}$ of soil was used instead of $10 \mathrm{~g}$. 


\section{Laboratory Spectroscopy and Analysis}

Detection limits of the four decomposition products used in this study were determined under laboratory conditions using ATR-FTIR. For each sample, 10 midinfrared spectra (with a background spectrum before each) were collected. The specific instrument used was an iD5 ATR Accessory for a Nicolet iS5 Spectrometer from Thermo Fisher Scientific Inc. The Nicolet iS5 has a $\mathrm{KBr} / \mathrm{Ge}$ mid-infrared optimized beam splitter, mid-infrared Ever-Glo and Tungsten/halogen components, and a spectral range of 400 to 7,500 wavenumbers $\left(\mathrm{cm}^{-1}\right)$, or 2,500 $\mathrm{nm}$ to $1,333 \mathrm{~nm}$ (Thermo Fisher Scientific, 2016).

The spectra were then plotted as absorbance versus wavenumber and analyzed for peak height. The height of the peak for each subsample represented the amount of decomposition product in the subsample; the higher the concentration of the decomposition product, the higher the peak. The 10 spectra for each subsample were then averaged together to create a representative spectrum for the subsample. The spectrum representative of the lowest concentration of decomposition product $(0.002 \%)$ was then subtracted from all of the other representative spectra to create a preliminary baseline. The $0.002 \%$ samples were the closest to $0.00 \%$ concentration which underwent the same sample preparation as the more concentrated samples; therefore acting as a baseline for the other samples.

The detection limit for each decomposition product was determined to be where the peak was no longer distinguishable from the background noise of the spectrum. A macro routine (Appendix I) which integrated the area under the curve (peak) of each spectrum was utilized to determine this detection limit. The Fat_abs routine operated by fitting a mask wave to the spectrum, creating a baseline from the mask wave, and then subtracting the baseline from the original spectrum. This created a flattened spectrum with a baseline and recognizable peaks from which the routine integrated the peak areas. This process was repeated for each of the averaged spectra for each subsample. When the area under 
the curve was equal to zero, indicating there was no peak present, there was determined to be no decomposition product detected.

\section{Application of Laboratory Spectra to Field Conditions}

Two pig burial sites, one in 2011 and one in 2015, were originally selected as part of a Forensic Archaeology course at The University of Akron. Both sites were located on the Steiner Property, a property owned by the university where permission was granted for use by the class. At both sites, a dead pig was buried in soil on high ground and allowed to decompose as part of a "crime scene" for the forensics class to study. Students were meant to use archaeological survey methods to locate the clandestine burials and then excavate the burial pit as if it were a real archaeological site. Before the students attempted to recover the pigs, soil cores were collected from the burial sites, five at the 2011 site and six at the 2015 site. At both sites, the core locations represent a transect of increasing distance from the burial site.

At the 2011 site, five soil cores were extracted on June 26, 2011. The pig cadaver had been buried approximately 12 months prior, in the summer of 2010, approximately $41-56 \mathrm{~cm}$ below the surface in a $2 \times 2 \mathrm{~m}$ square pit (Figure 4). The first core, MC1, was located approximately $20 \mathrm{~cm}$ north of the northern midpoint of the 2x2 m excavation square, and therefore outside the boundary of the burial pit. The next four cores were extracted at $40-50 \mathrm{~cm}$ intervals along a slightly NW transect (Figure 4).

At the 2015 site, six soil cores were extracted in May 2015 at a location southwest of the 2011 site. The pig cadaver had been buried 9 months prior, in the fall of 2014, approximately $34-40 \mathrm{~cm}$ below the surface in a $2 \times 3 \mathrm{~m}$ rectangular pit (Figure 5). The first core, C1D1 and C1D2, was as near to the buried pig as possible using the estimation of the professors who buried the pig and the distance the truck mounted probe was able to extend into the woods. The next five cores were extracted at $30-40 \mathrm{~cm}$ intervals along 
a SW transect extending from the presumed location of the pig to beyond the extent of the burial pit. In several locations the soil probe was unable to be inserted very deep into the ground, its progress hindered by a compact layer in the subsurface. Under normal circumstances, the probe could have breached the compact layer with the use of stabilizer feet, however doing so would cause a slight compaction of the soil which would have interfered with the archaeological class's results.

In the laboratory, the cores from both sites were described, photographed, and sectioned for analysis. The cores were sectioned at $10 \mathrm{~cm}$ intervals or at visible horizon breaks, when present. The texture and organic matter content of each section was determined using the same methods used for the other soil samples. Mid-infrared spectra of each sample were also determined and analyzed using the methods previously described. 


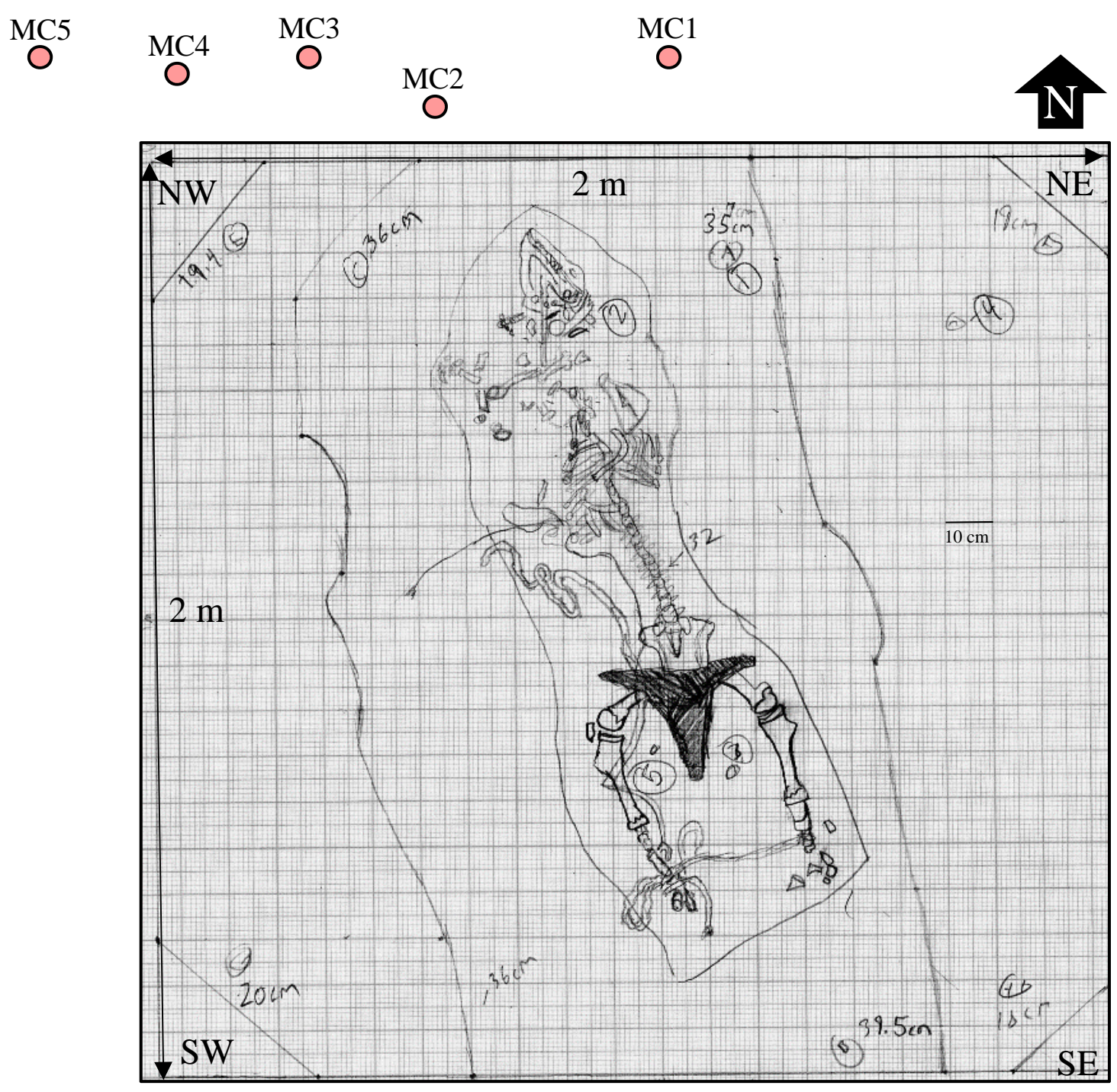

Figure 4. Site map of the $20112 x 2 \mathrm{~m}$ pig burial after excavation. Site map courtesy of Linda Whitman and the Forensic Archaeology 2011 Field Course. 


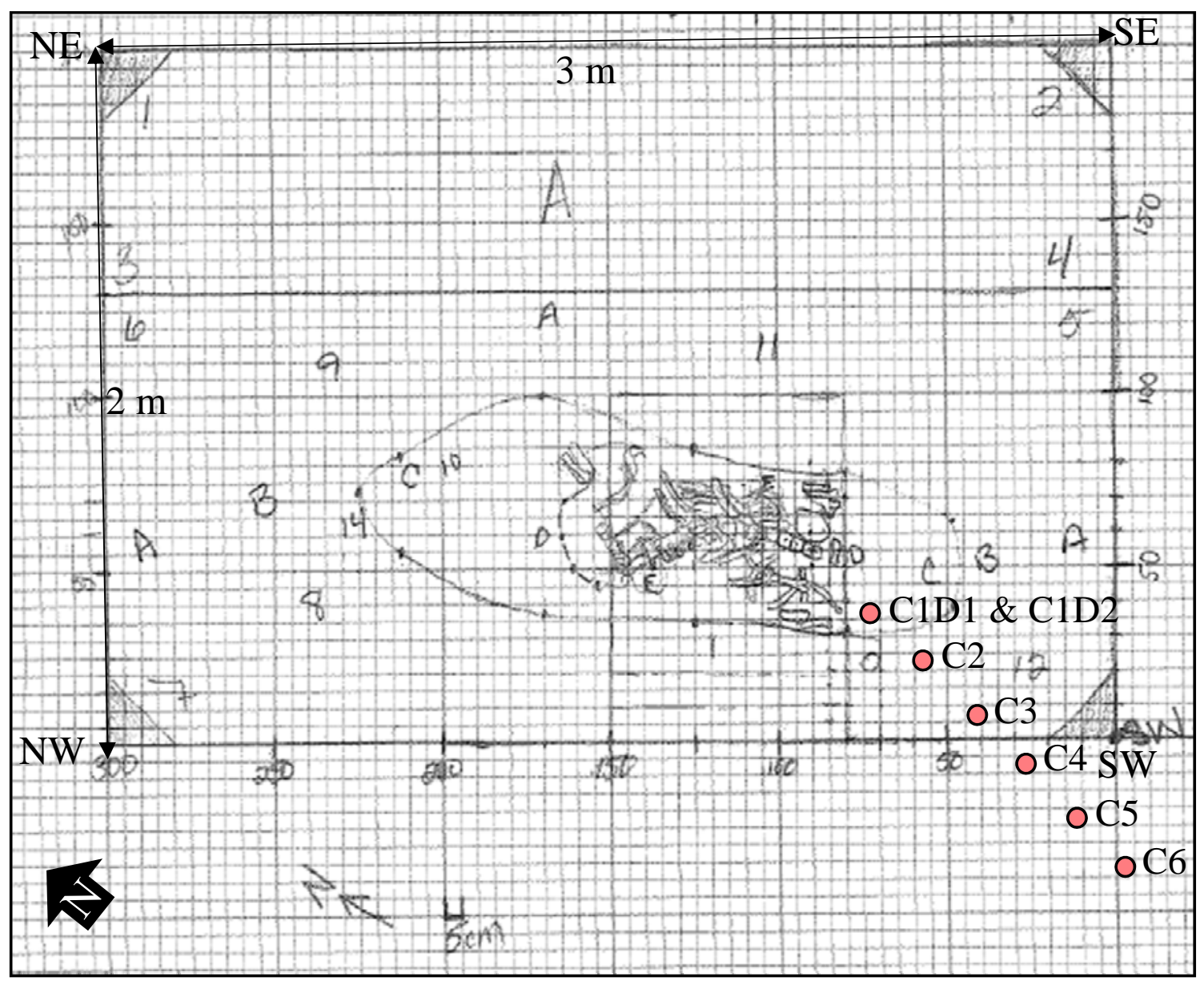

Figure 5. Site map of the 2015 2x3 m pig burial after excavation. Site map courtesy of Linda Whitman and the Forensic Archaeology 2015 Field Course. 


\title{
CHAPTER III
}

\section{RESULTS}

\begin{abstract}
Soil Results
The Steiner Property soil contained three horizons which extended from the surface to $58 \mathrm{~cm}$ below the surface (Table 1; Figure 6). It should be noted that the bottommost soil horizon extended deeper than $58 \mathrm{~cm}$ below the surface, but the soil was too firm for the available tools to continue digging. In general, the Steiner Property soil was a silt loam to a silty clay texture-wise and contained more clay overall than the Delaney Property and North Kingsville Property soils (Figure 7). As one looks down profile, the sand and silt content decreased, while the clay content increased. In the deepest horizon sampled, the clay content was more than half of the particle fraction (54.4\%). The organic matter content decreased down profile from $8.6 \%$ to $2.5 \%$ (Figure 8). The Steiner Property soil was the representative clayey soil in this study.

The Delaney Property soil contained four horizons which extended from the surface to $52 \mathrm{~cm}$ below the surface (Table 2; Figure 9). There was an abrupt sandstone contact at $52 \mathrm{~cm}$ below the surface, possibly indicative of the sandstone bedrock in the area. It should be noted that the soil horizons may have extended below the sandstone contact, but the rock was too hard for the available tools to continue digging. In general, the Delaney Property soil was a silt loam of a primarily silt-sized particle fraction (Figure 7). The sand content decreased down profile, while the clay content increased. The silt content hovered around 50\% throughout the entire profile. The organic matter content,
\end{abstract}




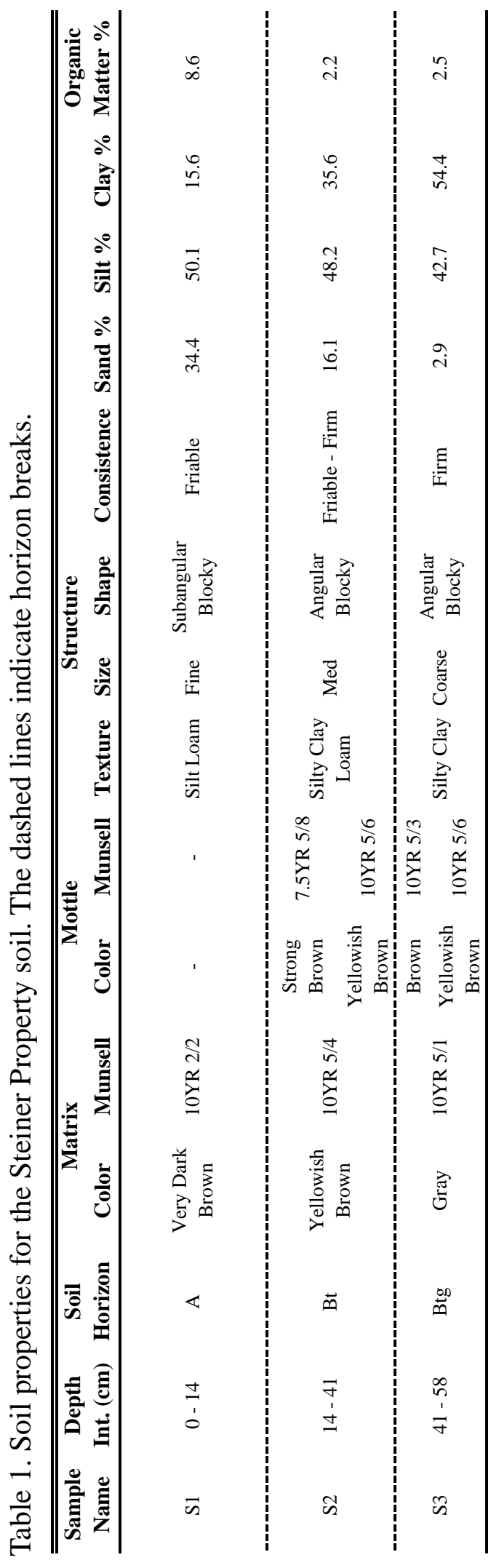




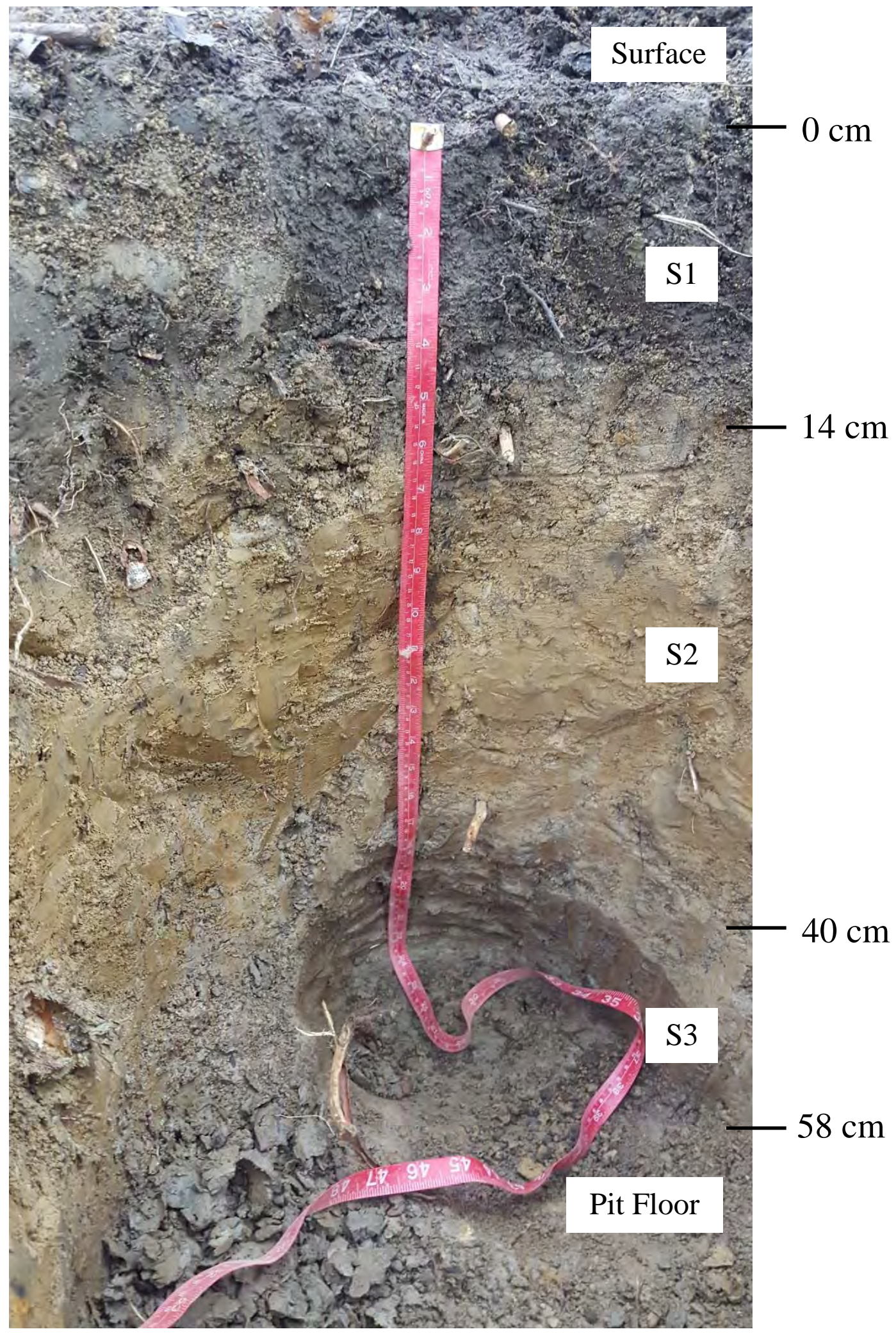

Figure 6. Photograph of the Steiner Property soil profile. 


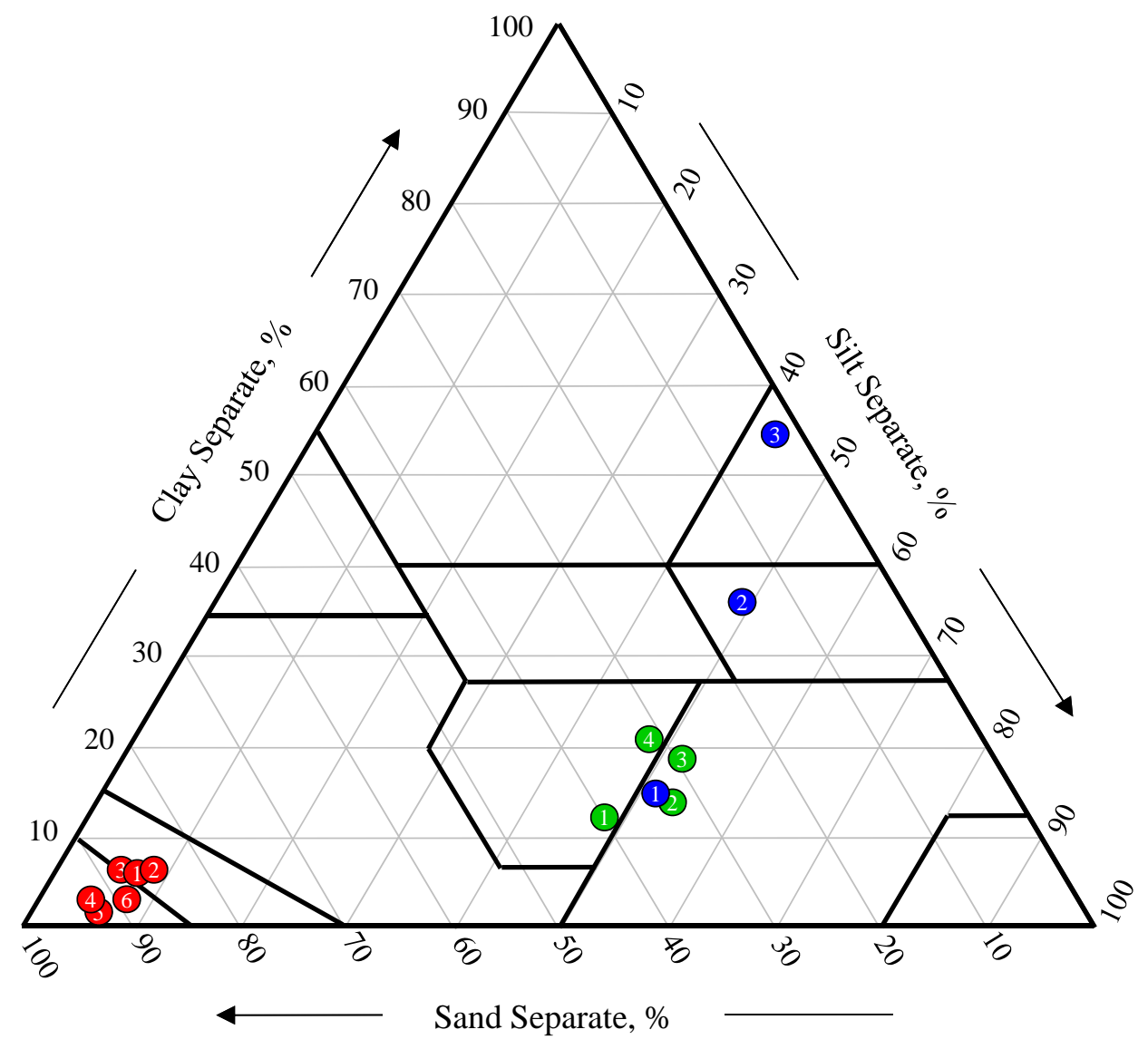

Figure 7. Texture triangle showing particle size distribution of the three soils. The Steiner Property (clayey soil) is blue, the Delaney Property (silty soil) is green, and the North Kingsville Property (sandy soil) is red. The numbers on the points represent the sample name. 


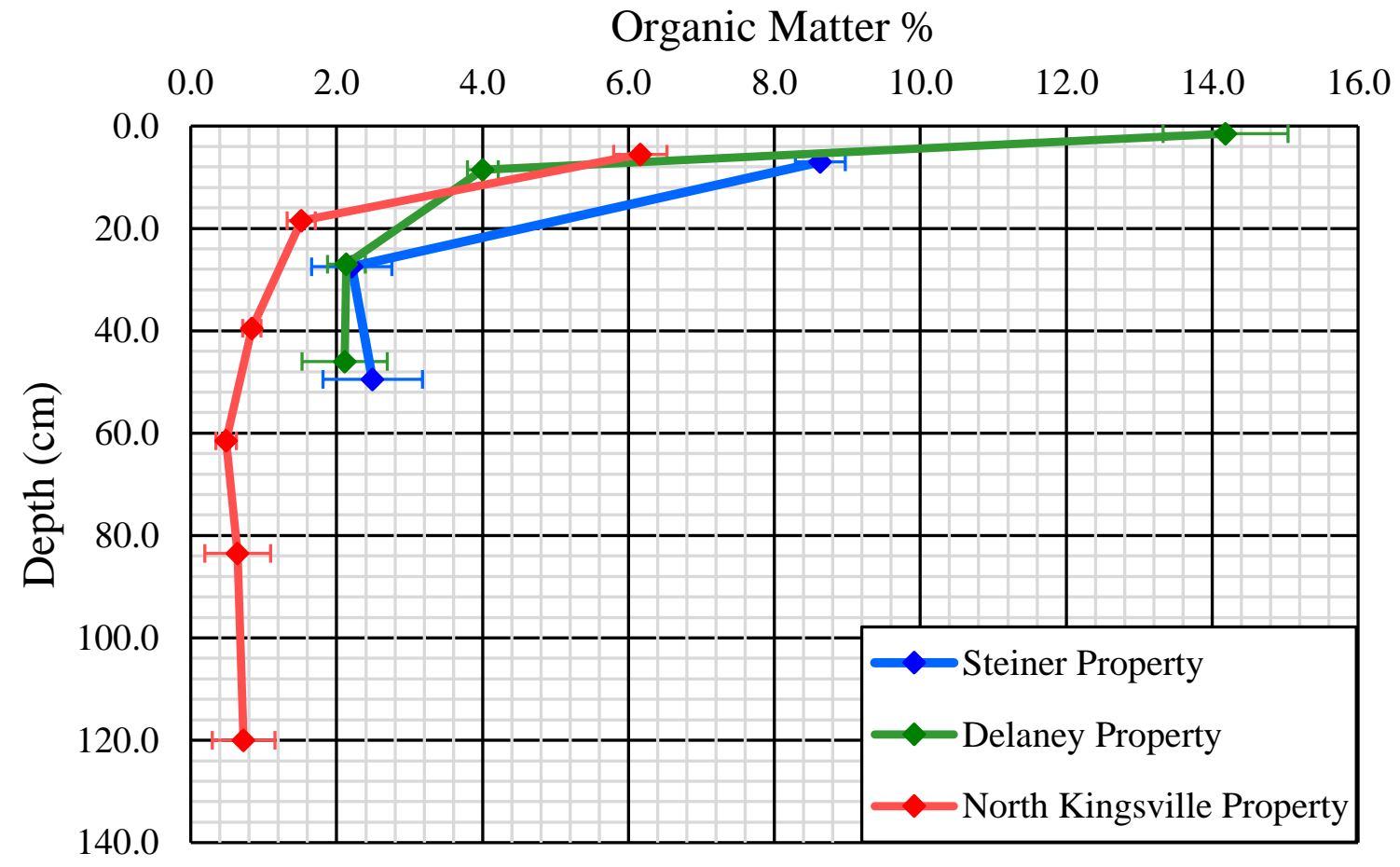

Figure 8. Organic matter versus depth for the three soil profiles. The points are plotted at the midpoints of the horizons on the vertical axis. 


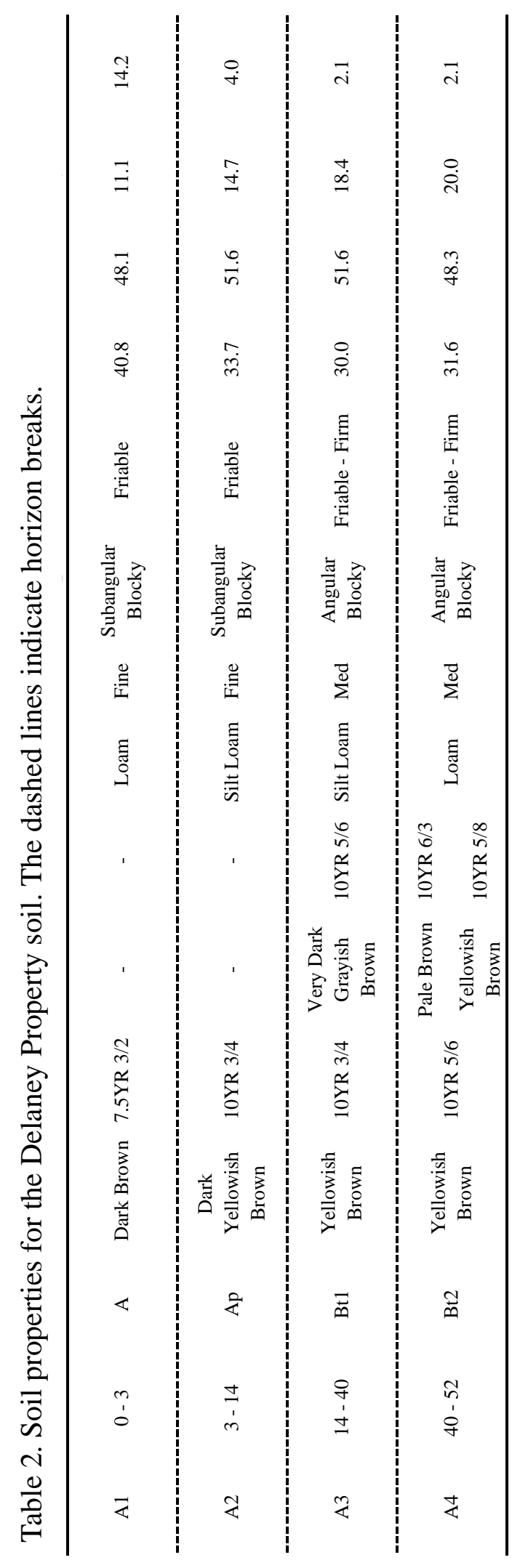




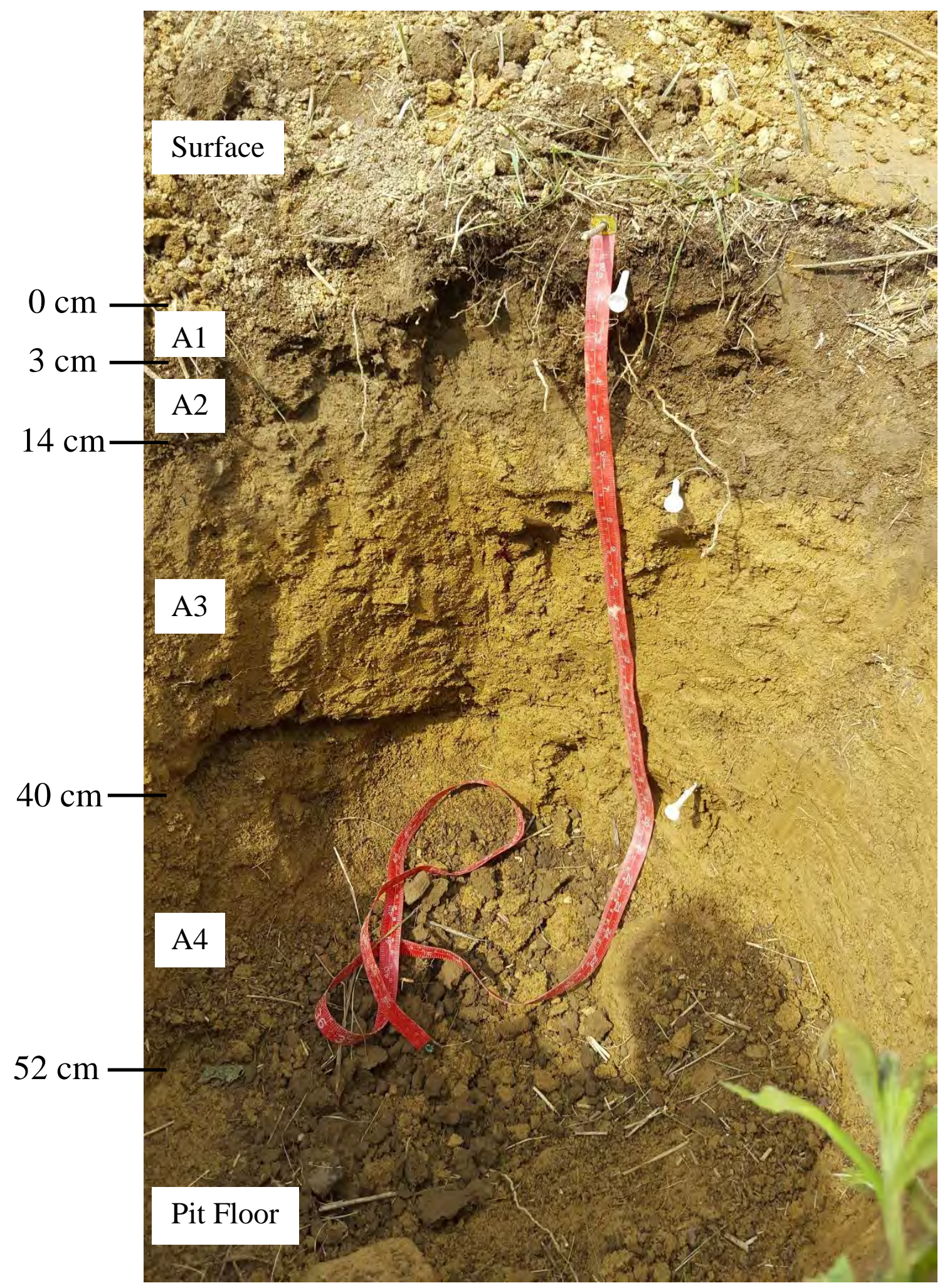

Figure 9. Photograph of the Delaney Property soil profile. 
while high in the surface horizon (14.2\%), decreased down profile to only $2.1 \%$ (Figure 8). The Delaney Property soil was the representative silty soil in this study.

The North Kingsville Property soil contained nine horizons which extended from the surface to $200 \mathrm{~cm}$ below the surface (Table 3), however the uppermost and two bottommost horizons were omitted from this study due to lack of appropriate soil quantity. In general, the North Kingsville Property soil was a loamy sand of a primarily sand-sized particle fraction (Figure 7). The soil was predominantly loose friable sand throughout the entire profile, $85 \%$ or higher in every horizon. The organic matter was low in the surface horizon (6.2\%), and continued to decrease down profile to less than $1 \%$ (Figure 8). The North Kingsville Property soil was the representative sandy soil in this study.

\section{Decomposition Product Spectra - Leucine}

The presence of leucine in the soil samples created three visible peaks between 2800 and $3200 \mathrm{~cm}^{-1}$ (Figure 10; Appendix 2). The first two peaks, between 2800 and 3000 $\mathrm{cm}^{-1}$, were prominently sharp, while the third peak, between 3000 and $3200 \mathrm{~cm}^{-1}$, was more gradual. The second peak $\left(\sim 2950 \mathrm{~cm}^{-1}\right)$ was chosen as the peak of interest because its presence was so prominent in the concentrated samples that its absence was clearly noticeable in the less concentrated samples (Tables 4a and 4b).

Leucine detection limits using the soils tested were between $1.0 \%$ and $0.04 \%$ (Table 4a). In general, detection limits were lower in samples with lower clay content, as shown by the Steiner Property and North Kingsville Property samples (Figure 11). A very slight relationship was observed between leucine detection limits and soil organic matter content (Figure 11). Low- and some moderate-organic matter samples showed detection limits of $\leq 0.1 \%$ while some moderate- and high-organic matter samples showed detection limits of $\geq 0.1 \%$. 


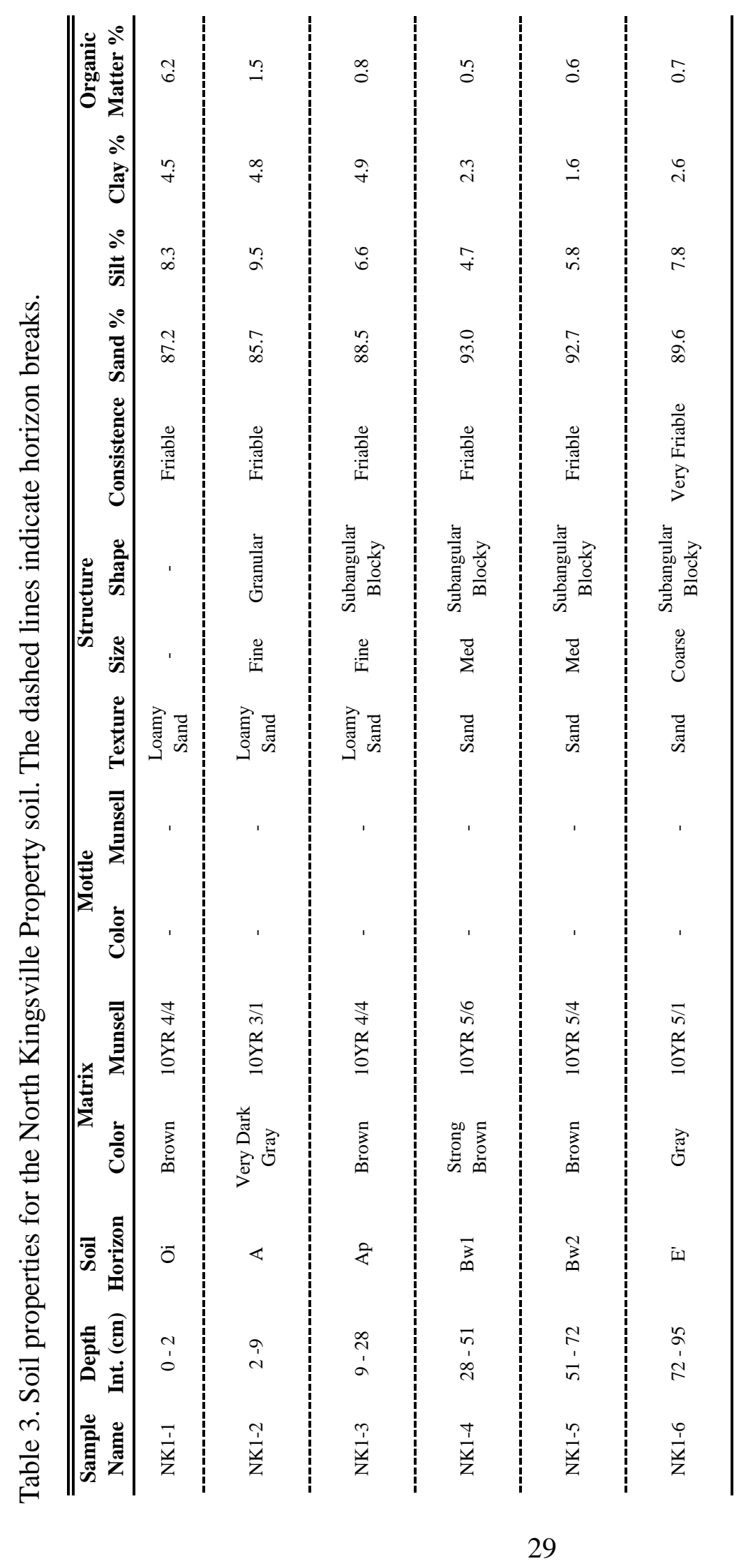




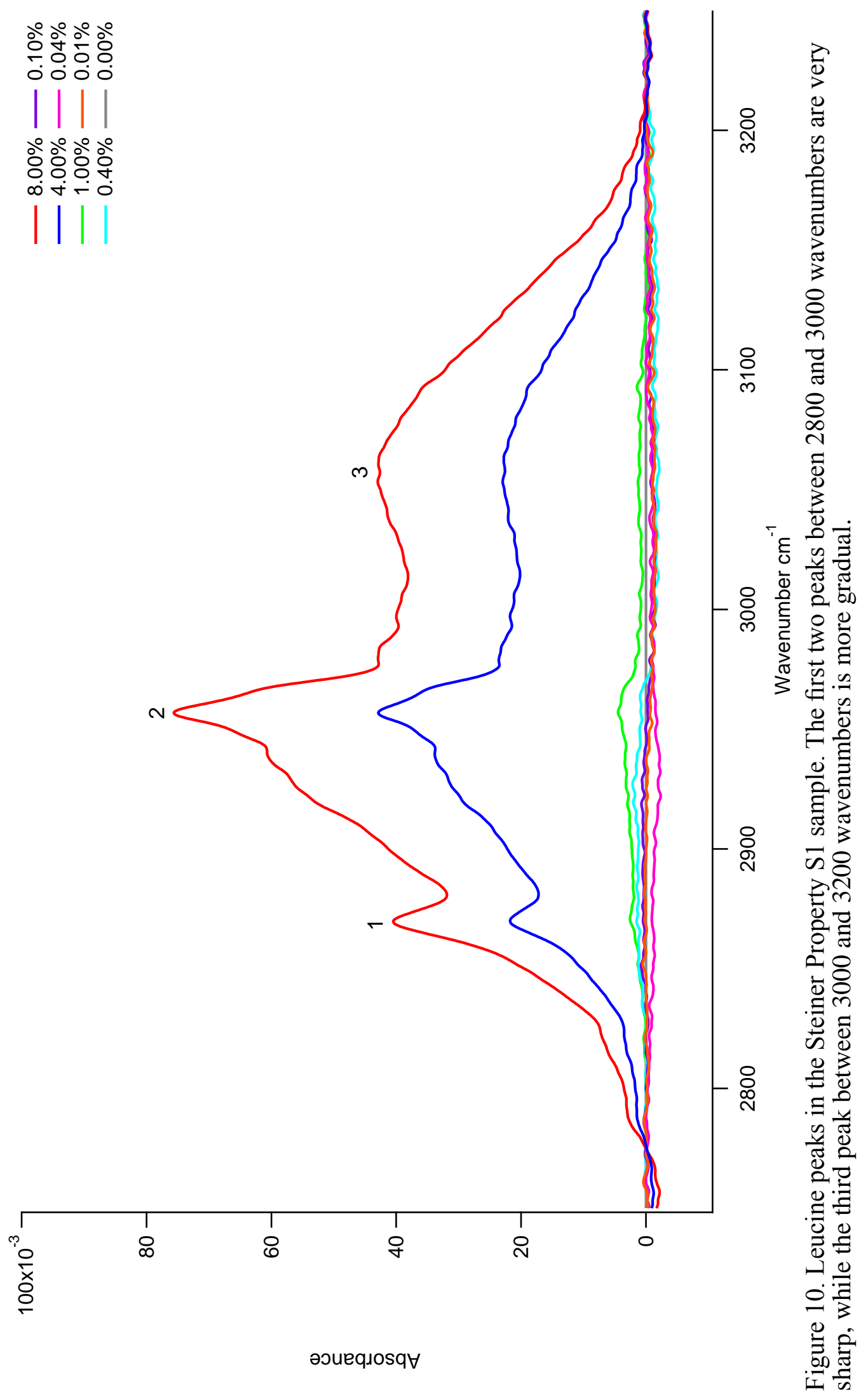




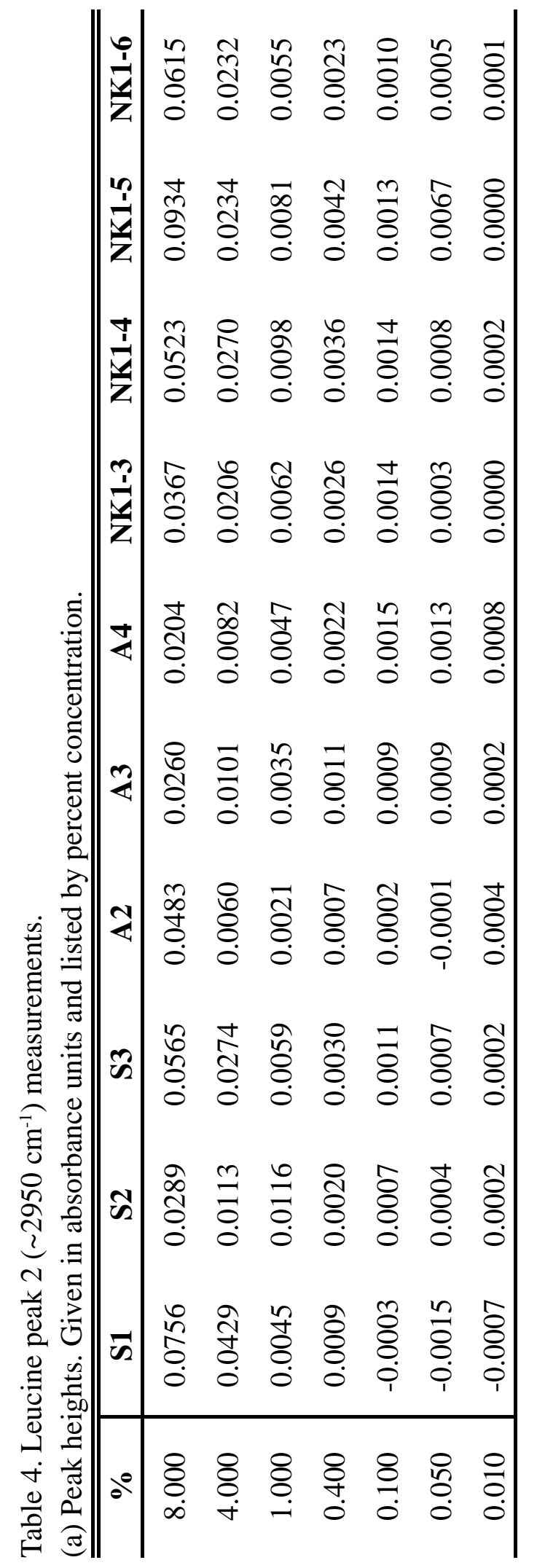

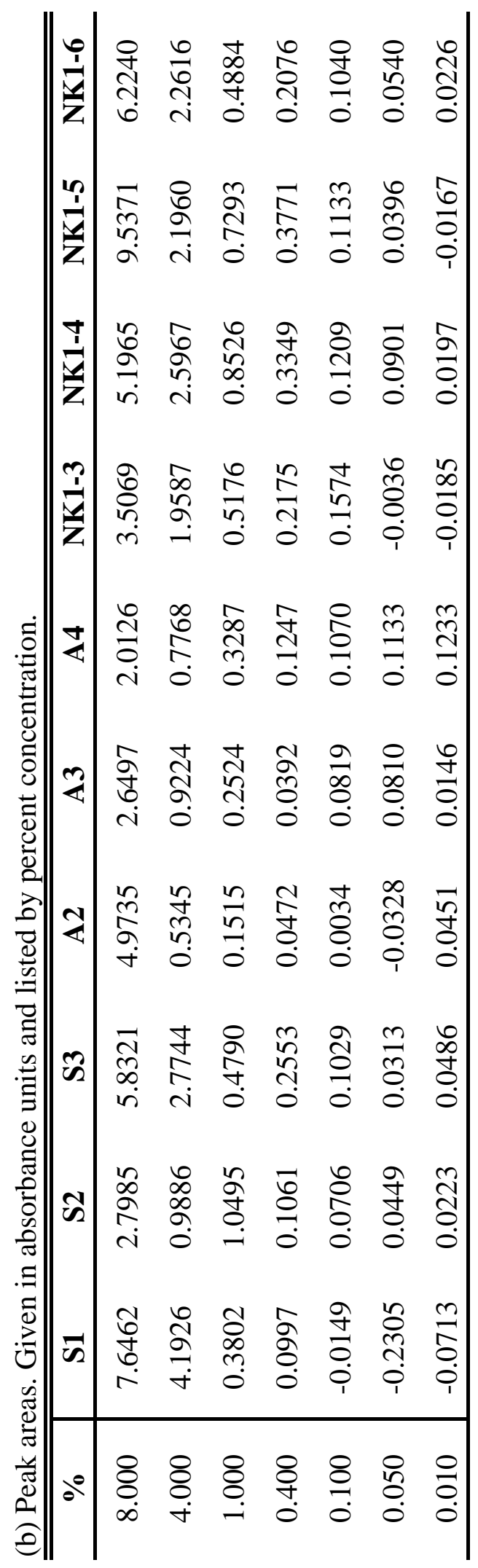



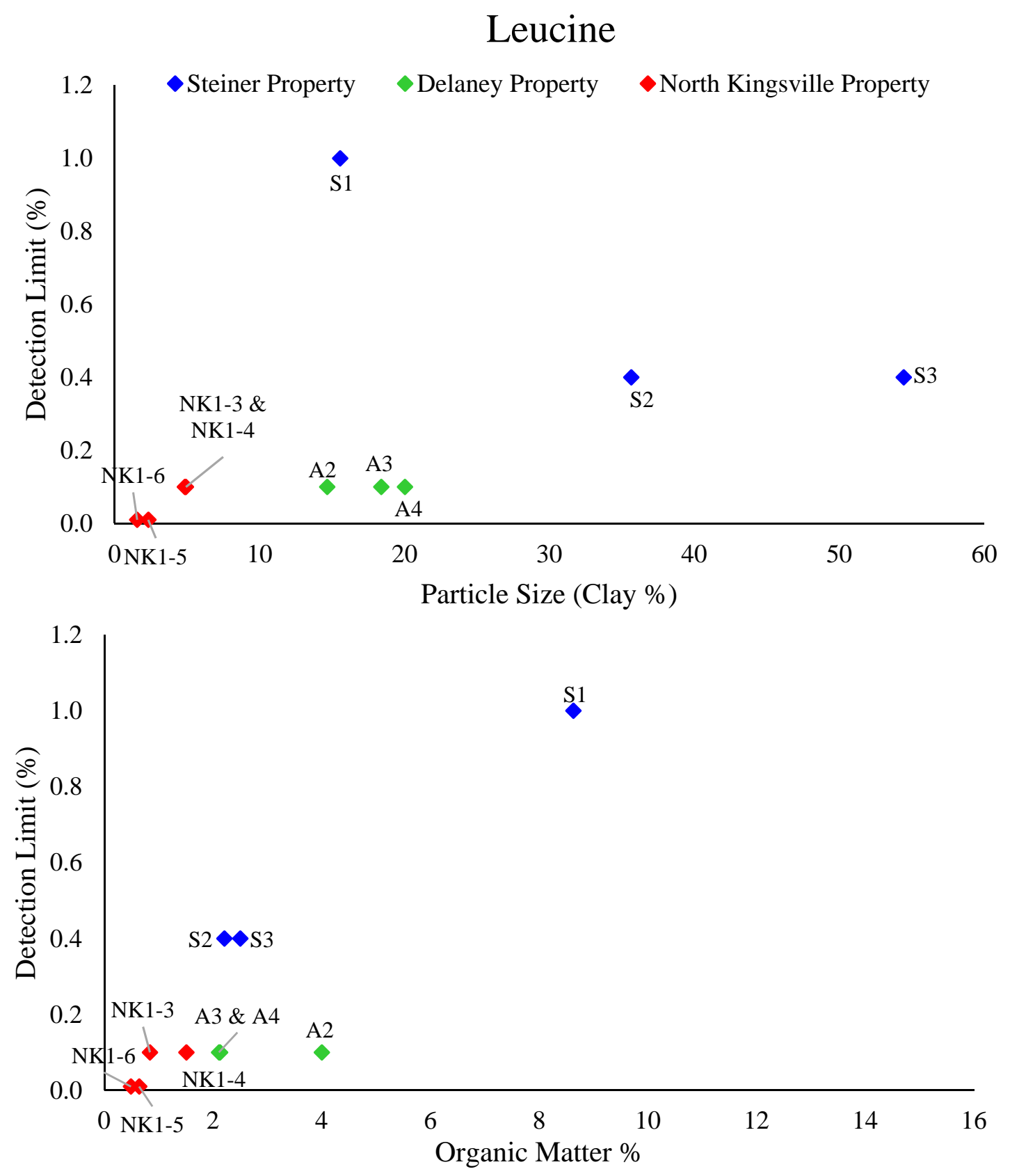

Figure 11. Leucine detection limits plotted against particle size and plotted against organic matter in the three soils. 


\section{Decomposition Product Spectra - Calcium Pyrophosphate}

Calcium pyrophosphate created three visible peaks between 900 and $1300 \mathrm{~cm}^{-1}$ in the soil samples (Figure 12; Appendix 3). The first peak was a broad shoulder between 980 and $1020 \mathrm{~cm}^{-1}$; the second peak was the most prominent, visible between 1000 and $1200 \mathrm{~cm}^{-1}$; and the third peak was the smallest, visible between 1200 and $1300 \mathrm{~cm}^{-1}$. The second peak $\left(\sim 1090 \mathrm{~cm}^{-1}\right)$ was determined the primary peak because it was the most central and largest (Tables 5a and 5b).

Calcium pyrophosphate detection limits ranged from $4.0 \%$ to $0.05 \%$ in the soils tested, although the majority were $\geq 0.4 \%$ (Table $5 \mathrm{a}$ ). There was no apparent trend observed between calcium pyrophosphate detection limits and particle size (Figure 13). Both low- and high-clay content samples showed detection limits of $4.0 \%$, while samples with moderate clay content (Delaney Property samples) had much lower detection limits. As with leucine, there was a very slight relationship observed between calcium pyrophosphate detection and organic matter content (Figure 13). Samples with low- and moderate-organic matter percentages had higher detection limits, while samples with moderate- and high-organic matter percentages had lower detection limits.

\section{Decomposition Product Spectra - Oleic Acid}

The presence of oleic acid in the soil samples created five visible peaks between 2800 and $3050 \mathrm{~cm}^{-1}$ (Figure 14; Appendix 4). The first and third peaks were very prominent and each was followed by a much smaller peak. The fifth peak was much lower and broader than the other four, and was located between 3000 and $3050 \mathrm{~cm}^{-1}$. The third peak $\left(2925 \mathrm{~cm}^{-1}\right)$ was chosen as the peak of interest because, similar to leucine, its presence was very prominent in the concentrated samples (Tables 6a and 6b).

In general, the detection limits for oleic acid were much lower than those observed for leucine and calcium pyrophosphate, ranging from $0.1 \%$ to $0.01 \%$ (Table $6 a$ ). There 


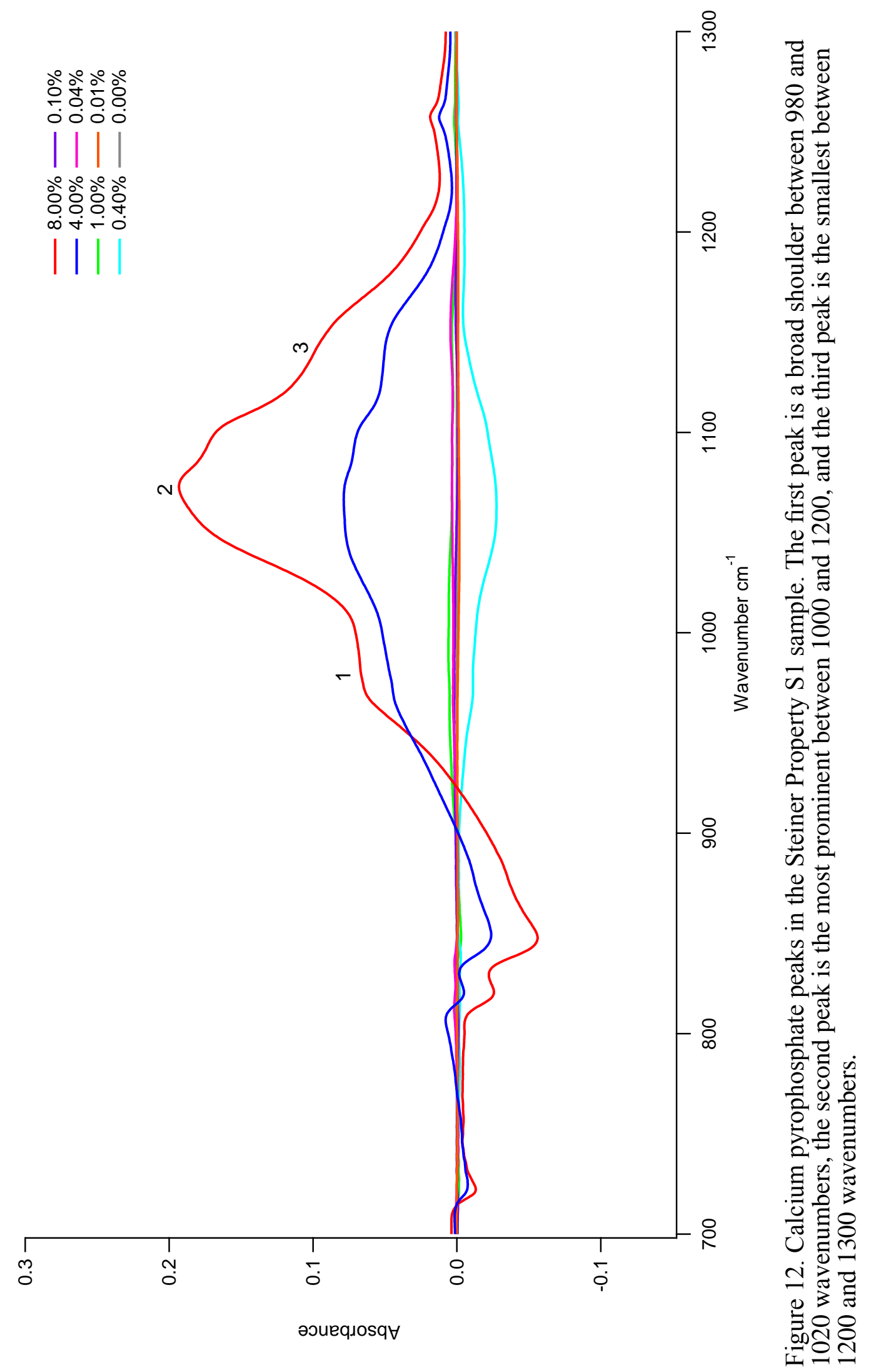




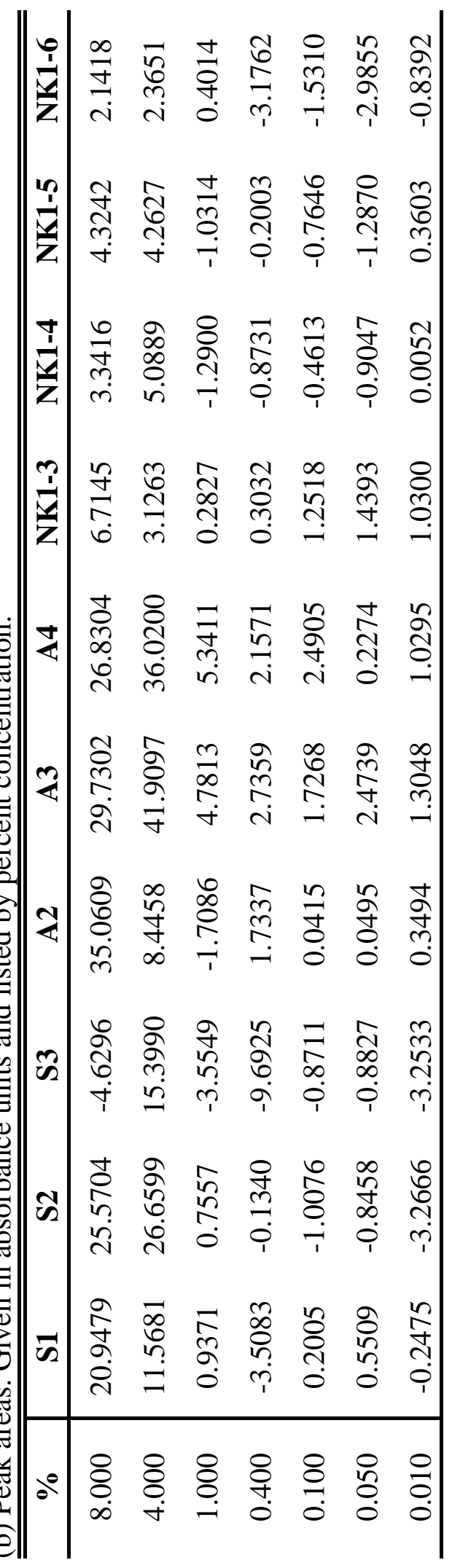



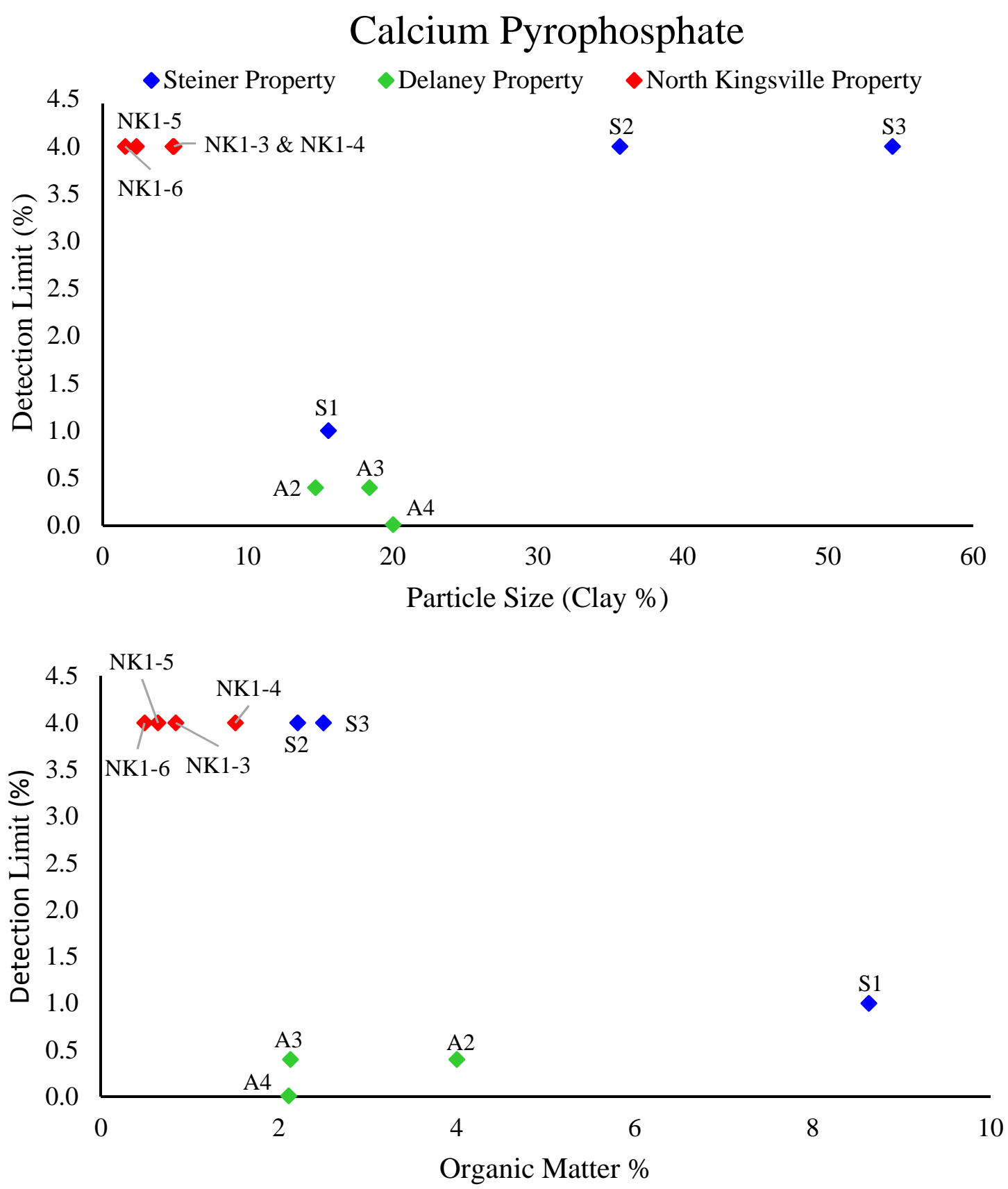

Figure 13. Calcium pyrophosphate detection limits plotted against particle size and plotted against organic matter in the three soils. 

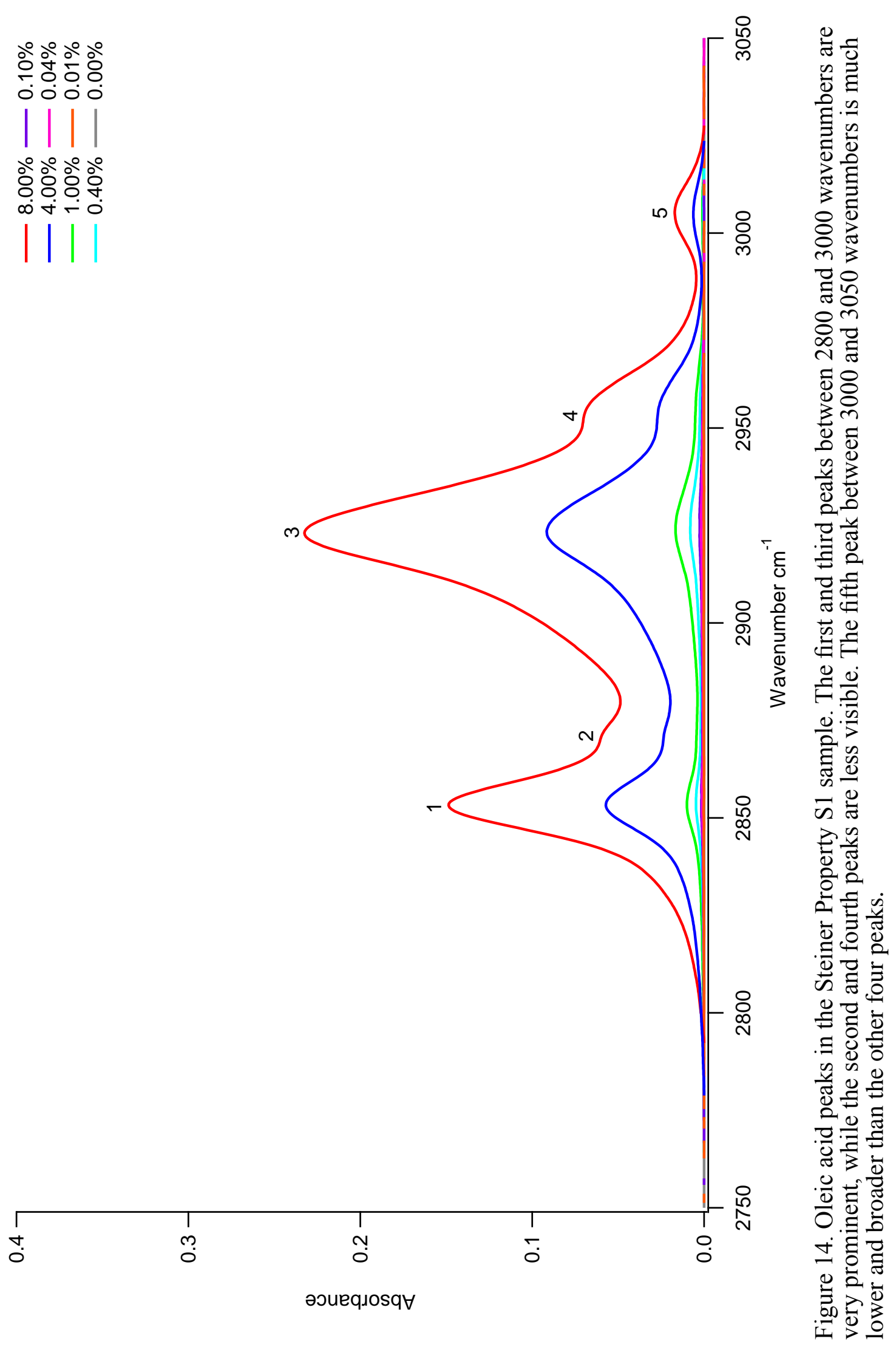
was no observable trend in detection limits with particle size; at least two samples from each location displayed detection limits of $0.04 \%$ (Figure 15 ). There was also no apparent relationship between detection limits with organic matter content (Figure 15). Most of the samples displayed a detection limit of $0.04 \%$; however, one low- and one high-organic matter content sample each had a detection limit of $0.01 \%$.

\section{Decomposition Product Spectra - Palmitic Acid}

Palmitic acid created four visible peaks in a similar location to oleic acid, between 2800 and $3000 \mathrm{~cm}^{-1}$, in all of the sampled soils (Figure 16; Appendix 5). The first and third peaks were very prominent and each was followed by a much smaller peak, the fourth being somewhat of a double peak. As with oleic acid, the third peak $\left(\sim 2915 \mathrm{~cm}^{-1}\right)$ was designated as the primary peak because of its prominence (Tables $7 \mathrm{a}$ and $7 \mathrm{~b}$ ).

Palmitic acid detection limits were close in range with oleic acid detection limits, observed between $1.0 \%$ and $0.01 \%$ (Table $7 \mathrm{a}$ ). There was no observable relationship between detection limits and particle size (Figure 17). Samples with lower clay content and samples with higher clay content displayed similar detection limits, near $0.1 \%$. Also similar to oleic acid, there was no apparent trend in detection limits with organic matter content (Figure 17). Samples of low- and high-organic matter content each had detection limits of $0.01 \%$, while samples of moderate-organic matter content had detection limits of $0.04 \%$.

\section{Human Burial Analogue 2011 - Soil Results}

The five cores extracted from the 2011 pig burial ranged in length from approximately half a meter to just over a meter, the shortest being $59 \mathrm{~cm}$, while the longest was $109 \mathrm{~cm}$ (Figures 18 and 19; Tables 8 - 12). The first two cores, MC1 and MC2, ranged in texture from silty clay loam to silty clay and consisted of four horizons. The organic matter 

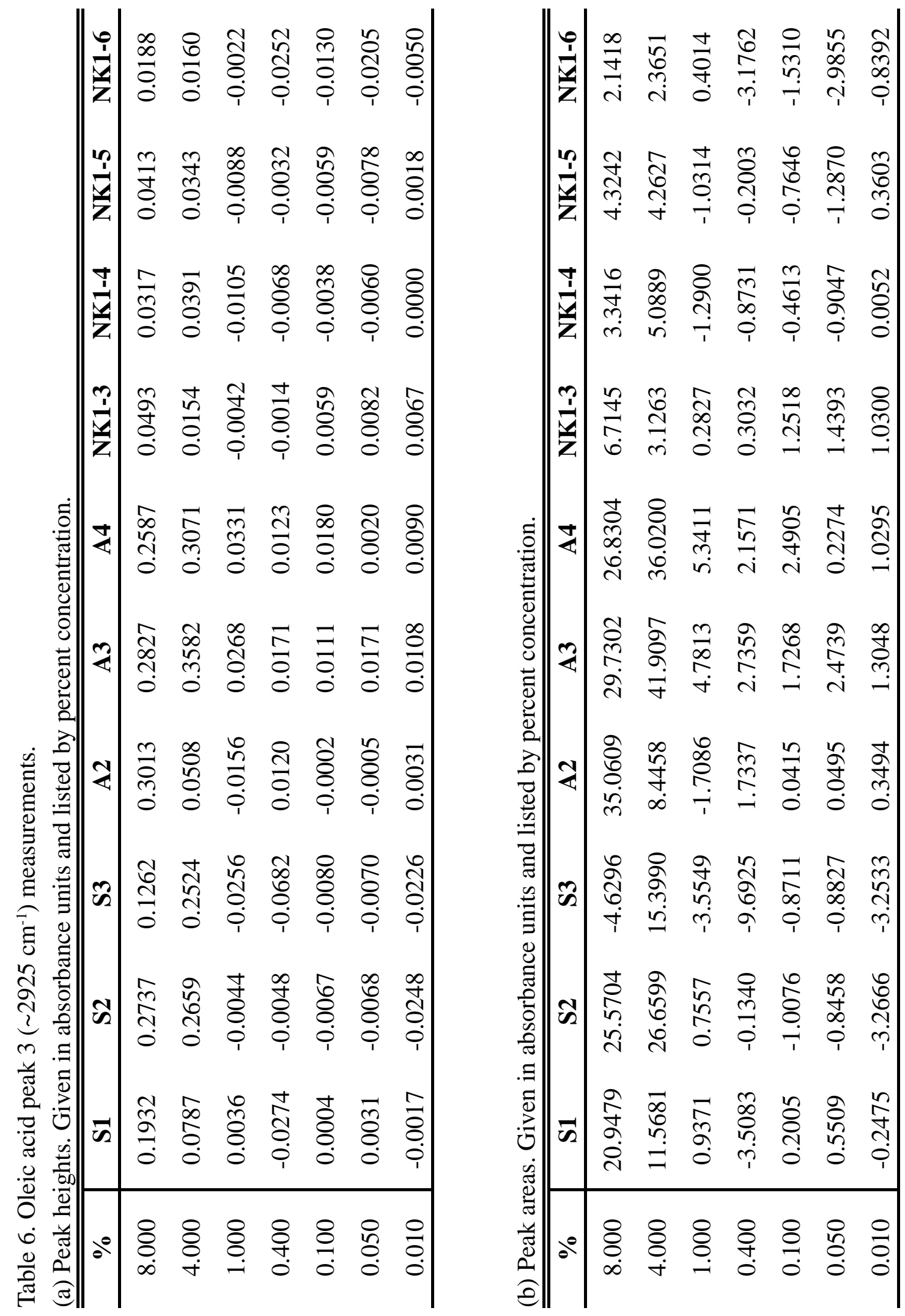

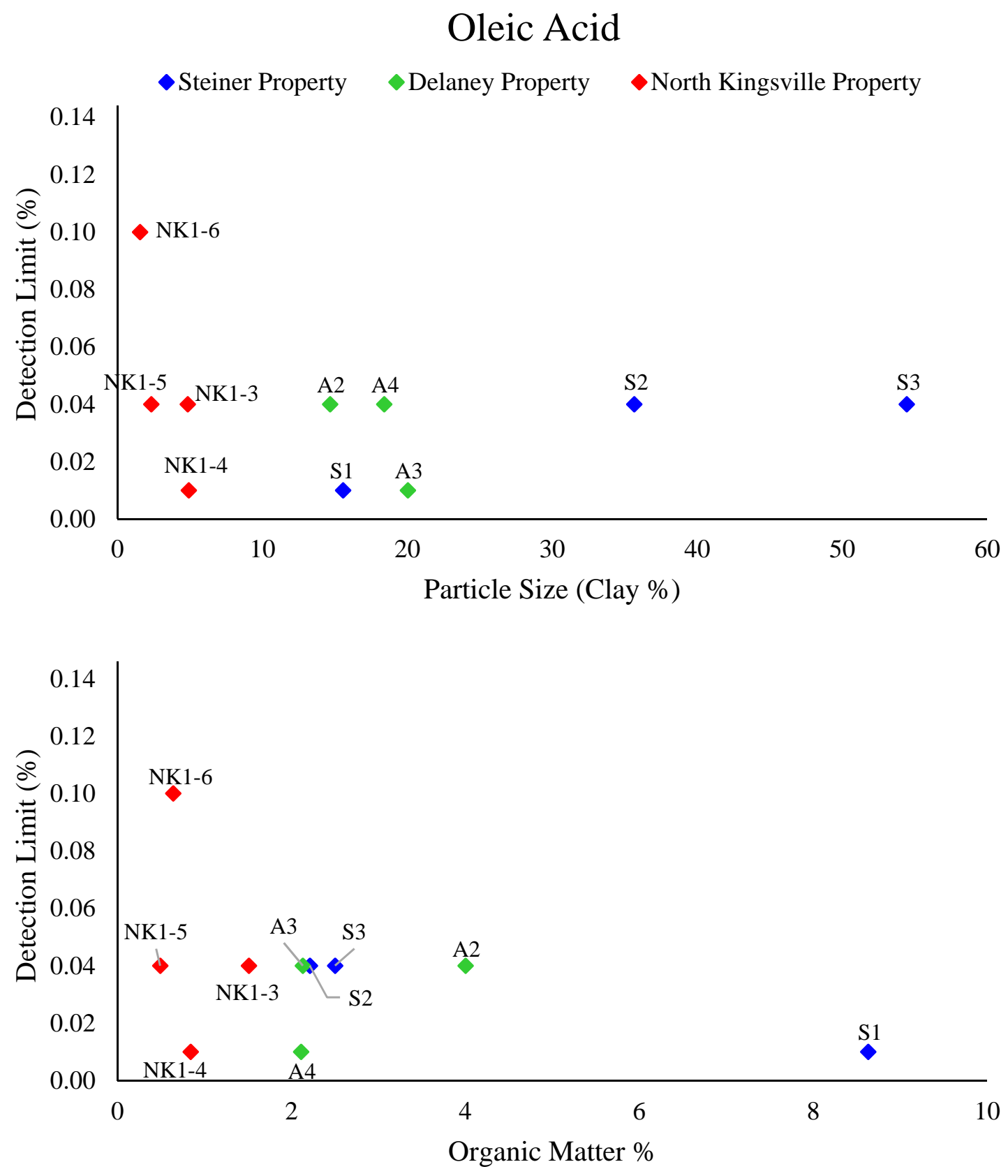

Figure 15. Oleic acid detection limits plotted against particle size and plotted against organic matter in the three soils. 


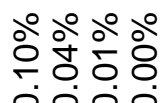

ำo

|| | |

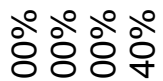

๓ิเ

|l||

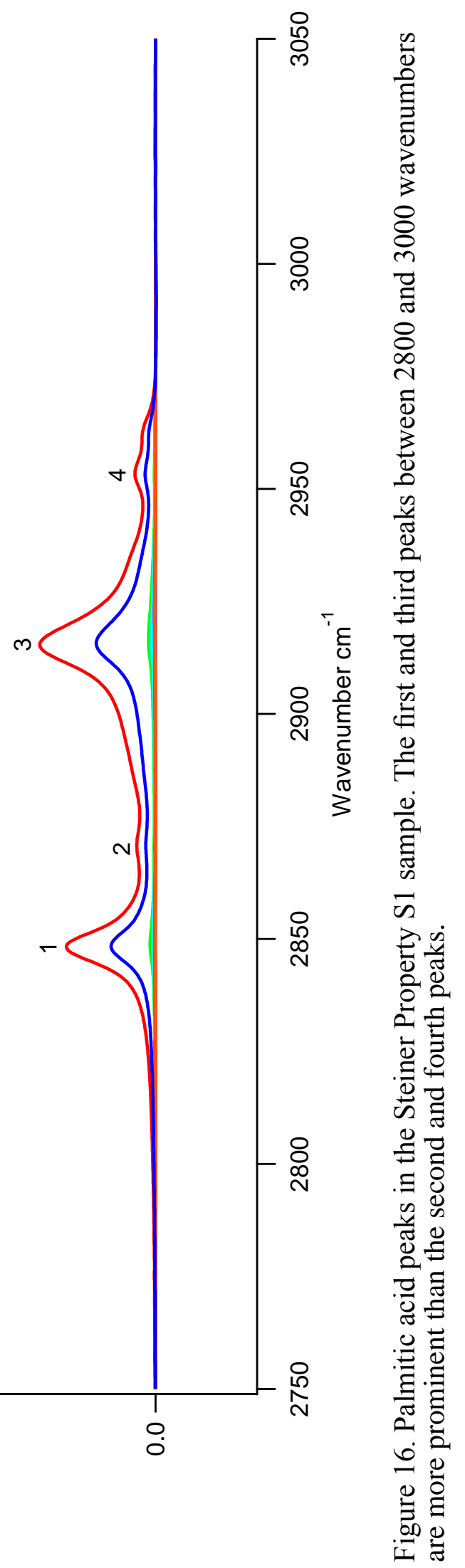




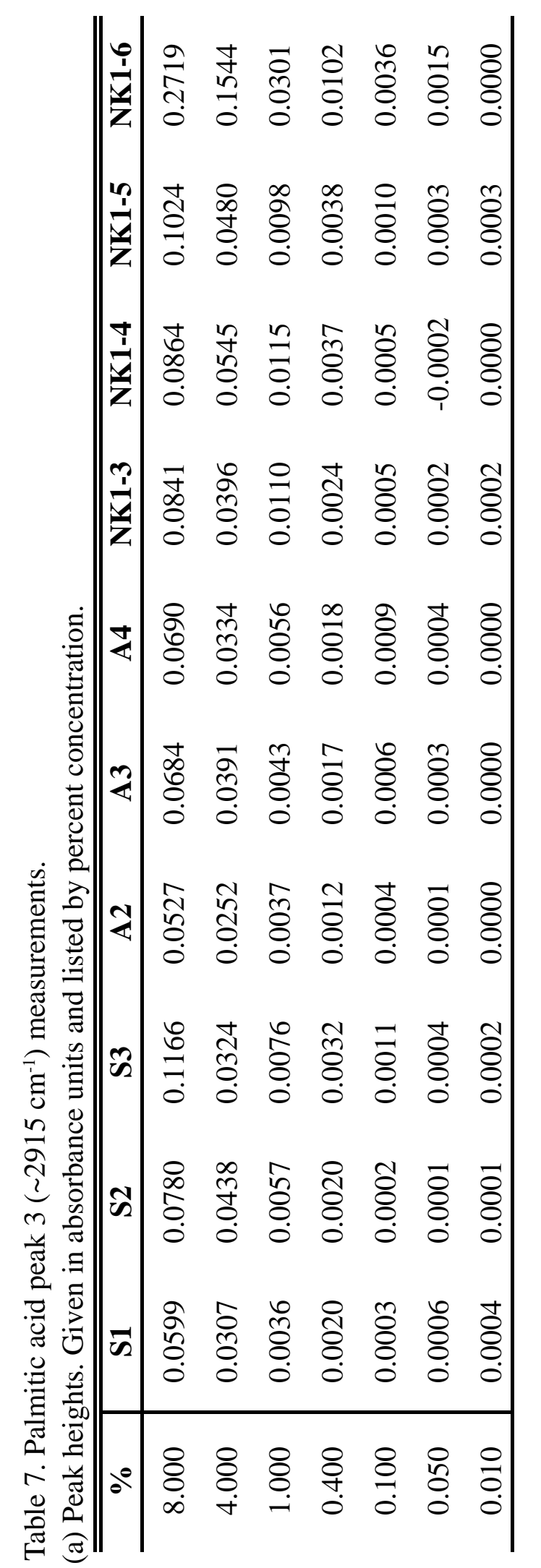

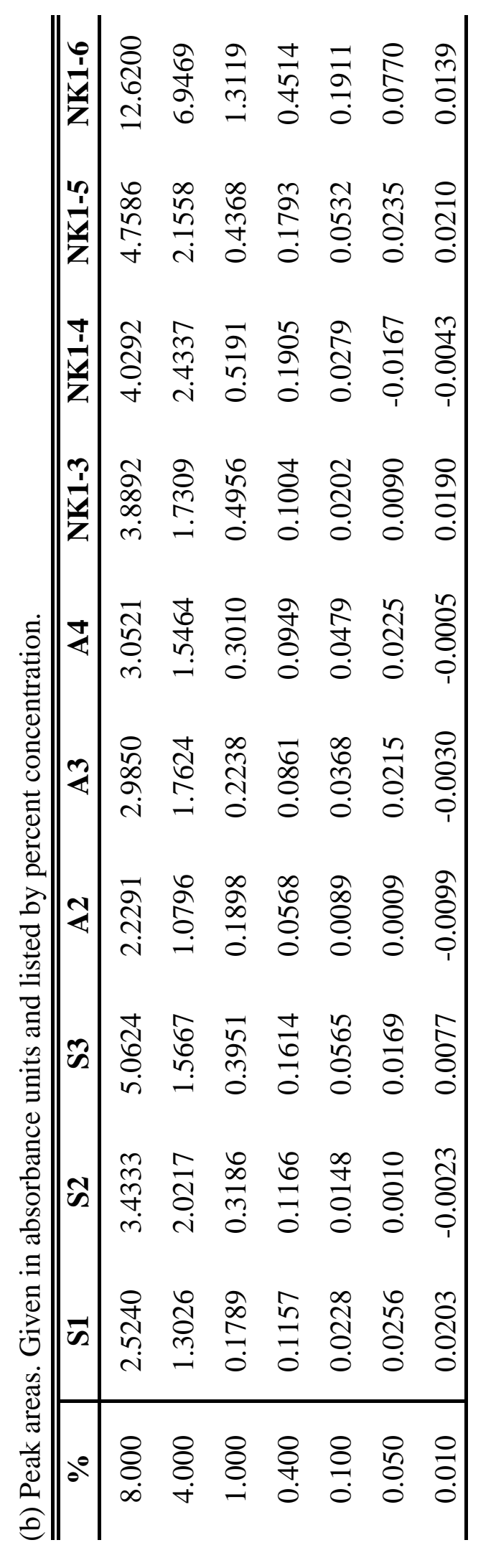



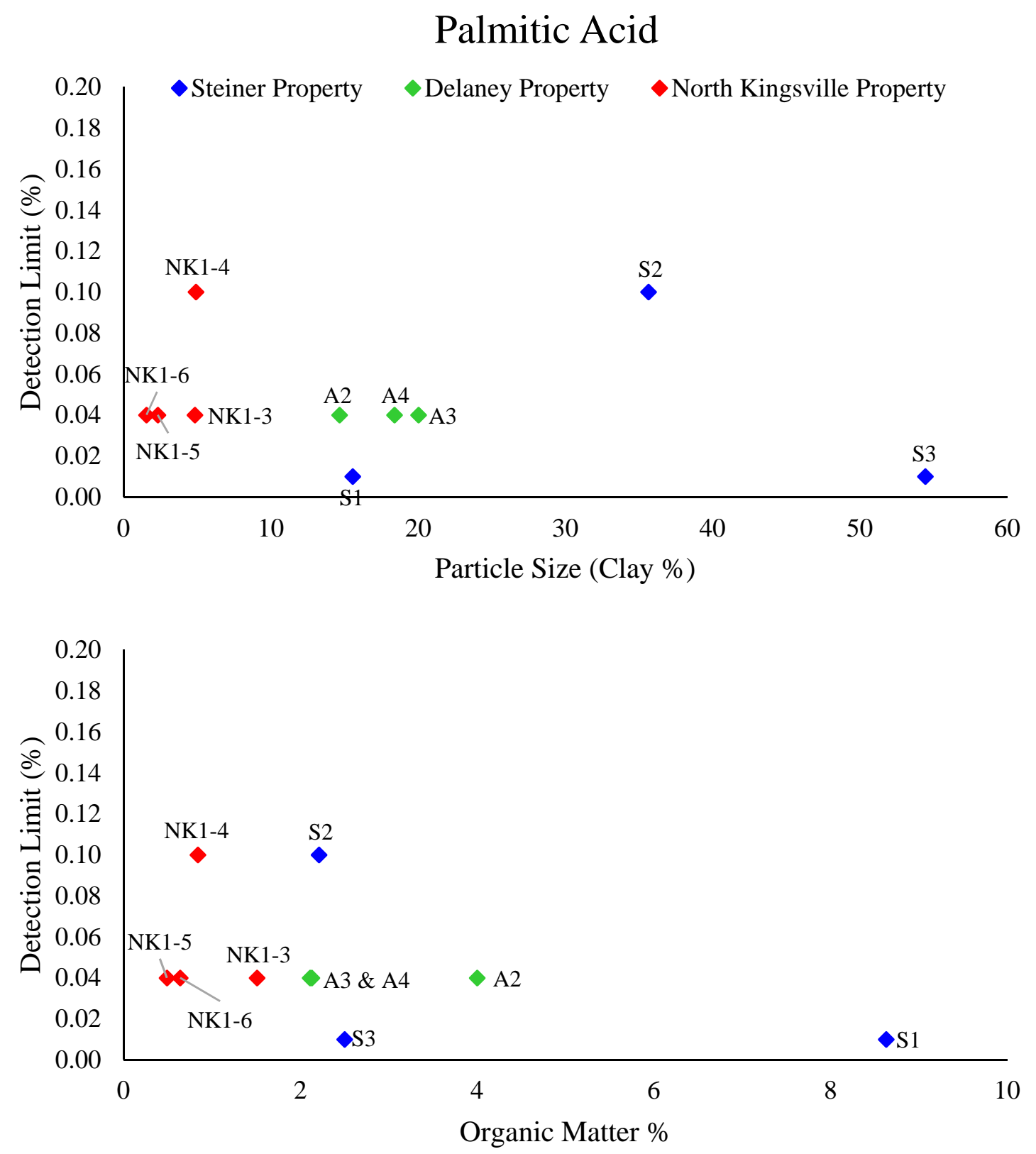

Figure 17. Palmitic acid detection limits plotted against particle size and plotted against organic matter in the three soils. 
decreased down core from $\sim 10 \%$ to $\sim 3 \%$. MC3 had similar textures of silty clay loam to silty clay, but consisted of only three horizons. Organic matter decreased down core from $\sim 15 \%$ to $\sim 2 \%$. Like the first two cores, MC4 also ranged in texture from a silty clay loam to a clay to a silty clay and consisted of four horizons. However, there was less overall organic matter, decreasing down core from $\sim 7 \%$ to $\sim 1 \%$. The final core, MC5, ranged in texture from a clay to a silty clay and consisted of four horizons. The organic matter decreased down core from $\sim 13 \%$ to $\sim 2 \%$.

\section{Human Burial Analogue 2011 - Spectra Results}

There were two visible peaks between 2800 and $3100 \mathrm{~cm}^{-1}$ present in all five of the 2011 cores, but there were no peaks representative of leucine or calcium pyrophosphate present (Figure 20; Tables 13a and 13b). The shape and location of the peaks suggest they are indicative of a fatty acid, potentially oleic or palmitic acid. The two fatty acid peaks were present from the surface to a depth of $50 \mathrm{~cm}$ in all cores except for MC5, where they were only visible from the surface to a depth of $40 \mathrm{~cm}$. The highest peaks were present in each core at a depth of $20-30 \mathrm{~cm}$, except for MC2, where the peaks are highest at a depth of $10-20 \mathrm{~cm}$. At these respective depth intervals, cores MC1 and MC2 had average clay percentages of around 30\%; they were compared with the oleic acid and palmitic acid spectra from S2 which contained 35\% clay. Cores MC3 - MC5 on average contained more clay, so they were compared with the oleic acid and palmitic acid spectra from S3 which contained 55\% clay.

Cores MC1, MC3, MC4, and MC5 were very similar; the highest peaks in the cores were in samples from 20 - $30 \mathrm{~cm}$ below the surface (Table 13a). These peaks were between those which represented $0.04 \%$ and $1.0 \%$ oleic acid and between those which represented $1.0 \%$ and $4.0 \%$ palmitic acid (Figure 21). This suggests that the highest concentrations of fatty acid in these cores were between $0.04 \%-1.0 \%$ oleic acid and/or 


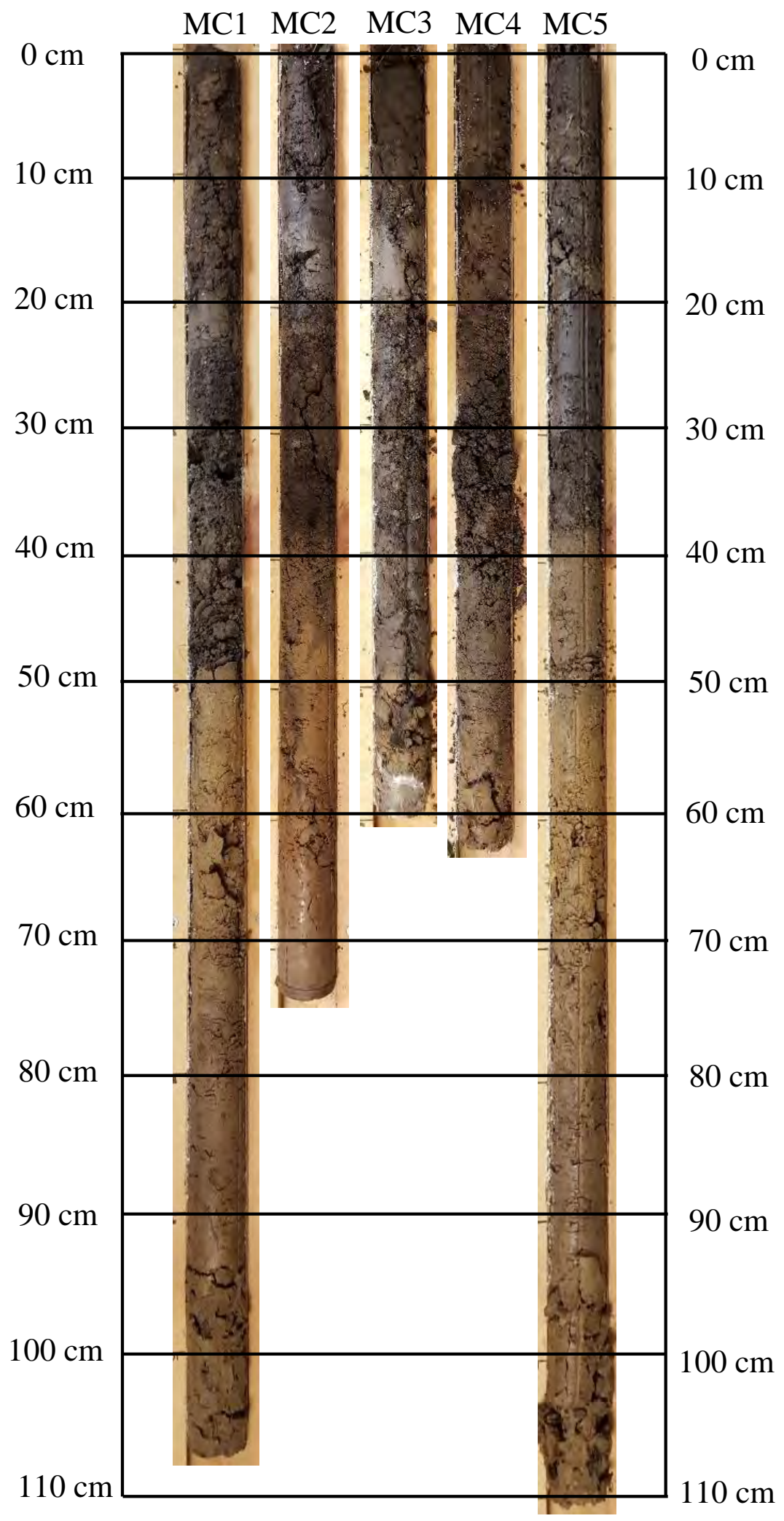

Figure 18. Photographs of the 2011 cores. The surface is indicated at $0 \mathrm{~cm}$. 


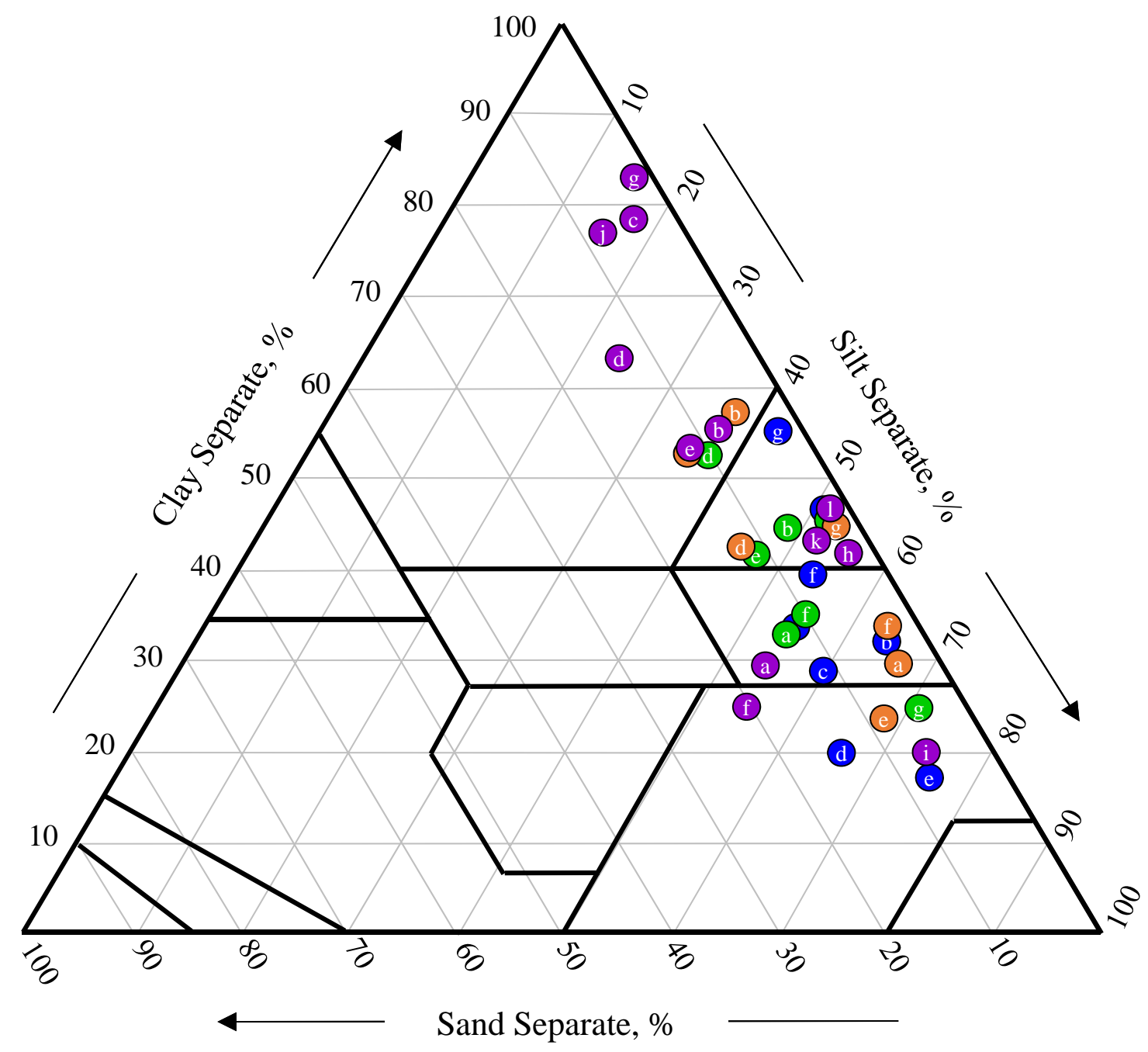

Figure 19. Texture triangle showing the particle size distribution of the 2011 cores. MC1 is red, MC2 is blue, MC3 is green, MC4 is orange, and MC5 is purple. The letters on the points represent the core section. 


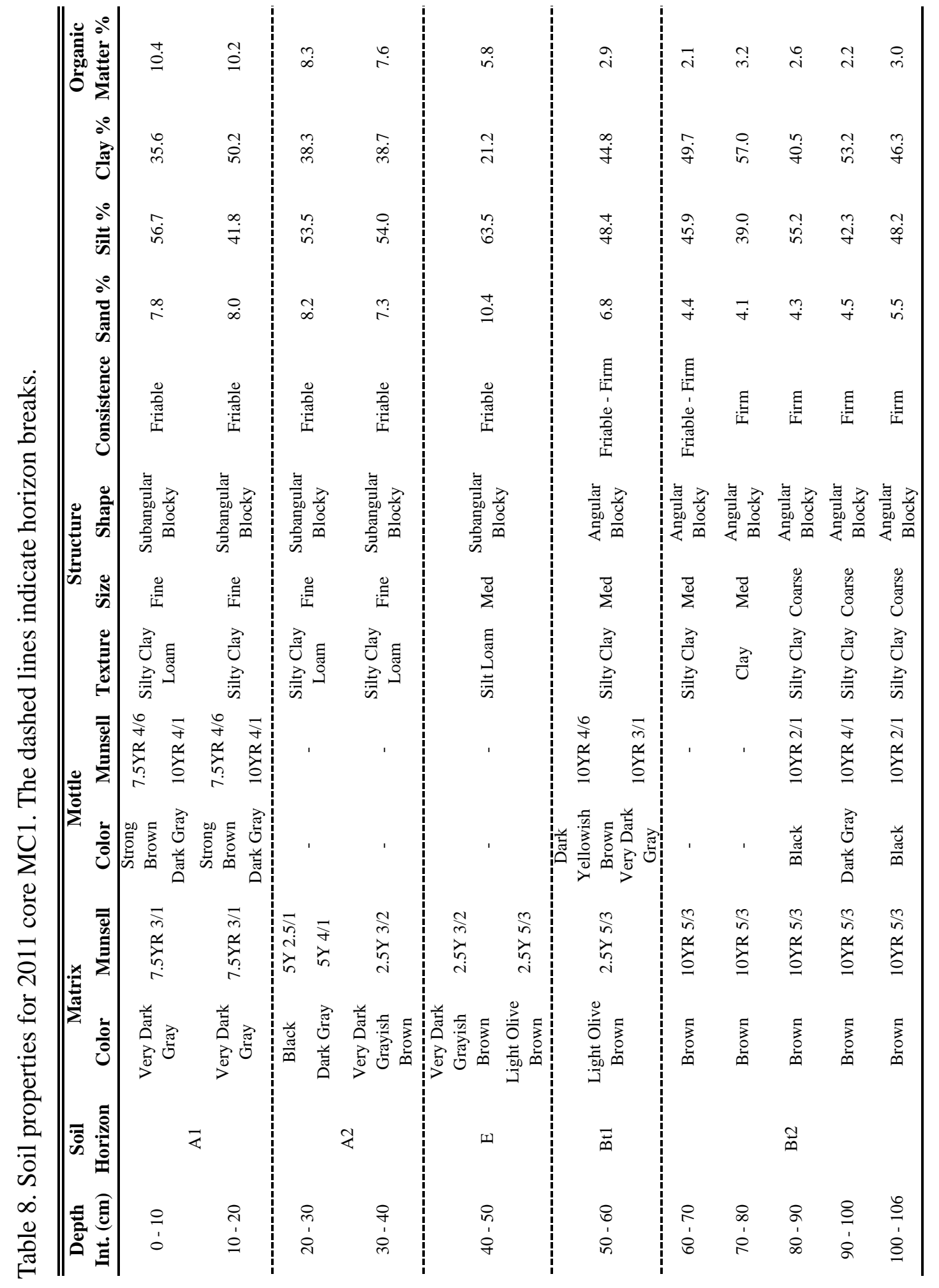




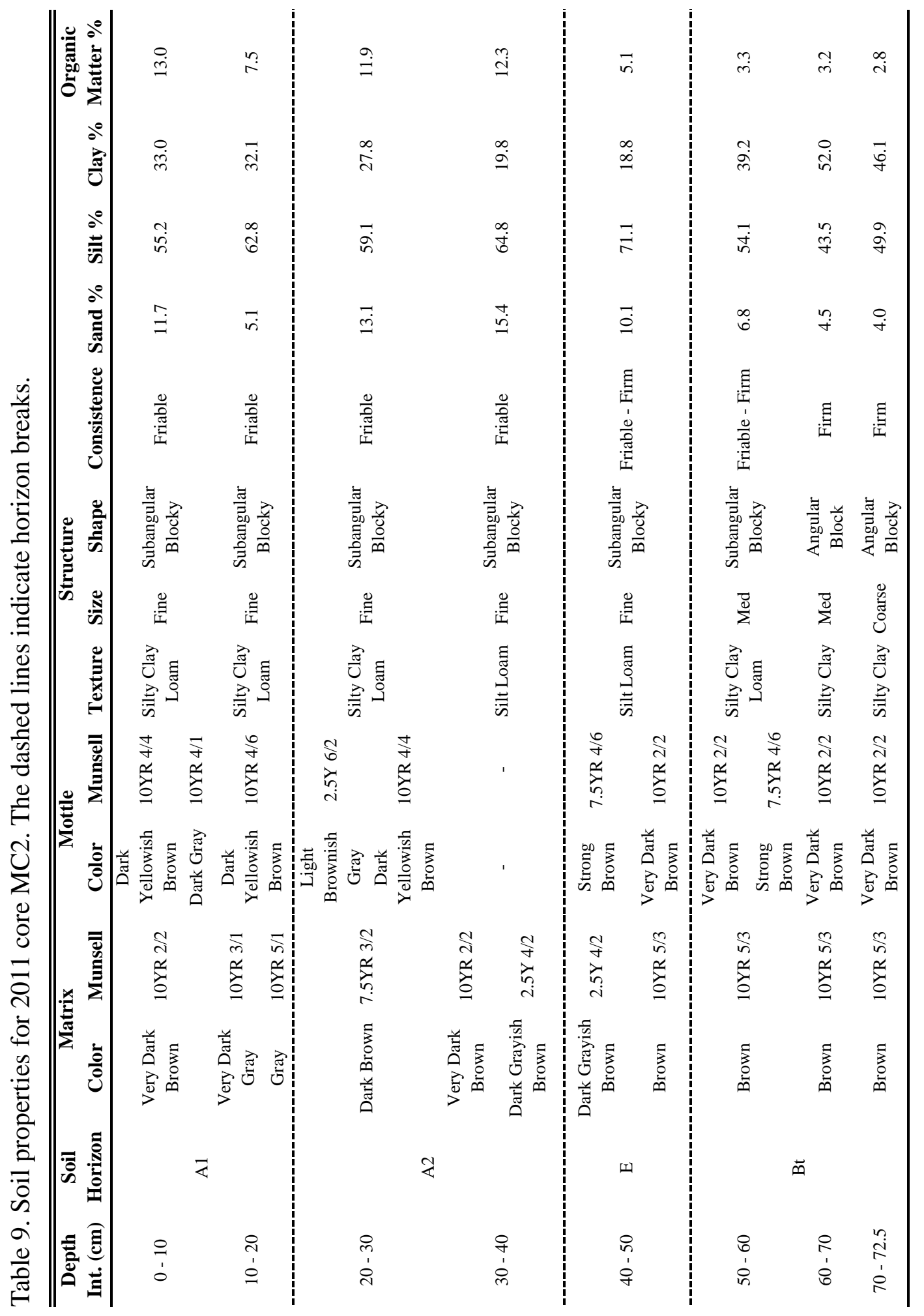




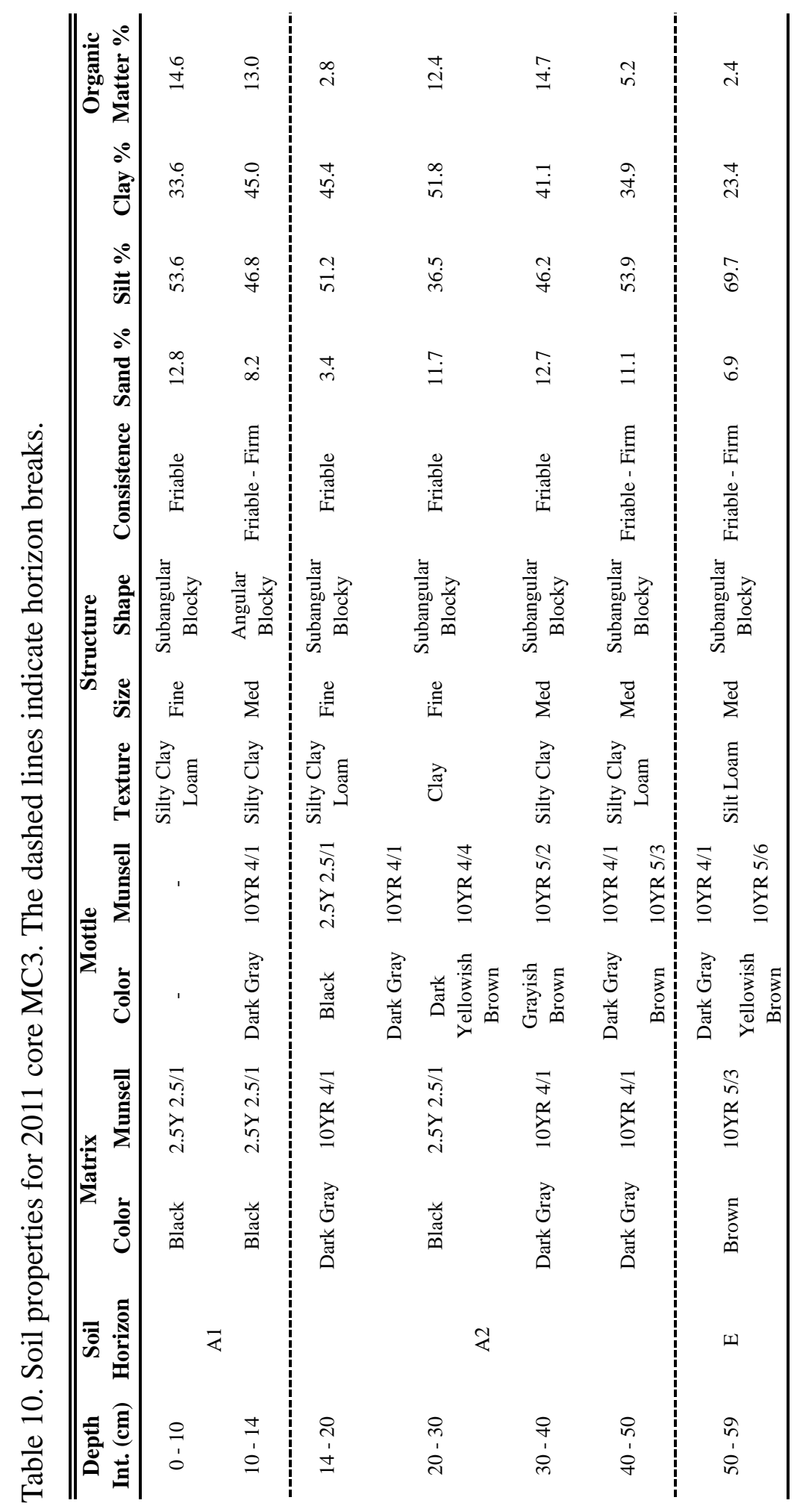




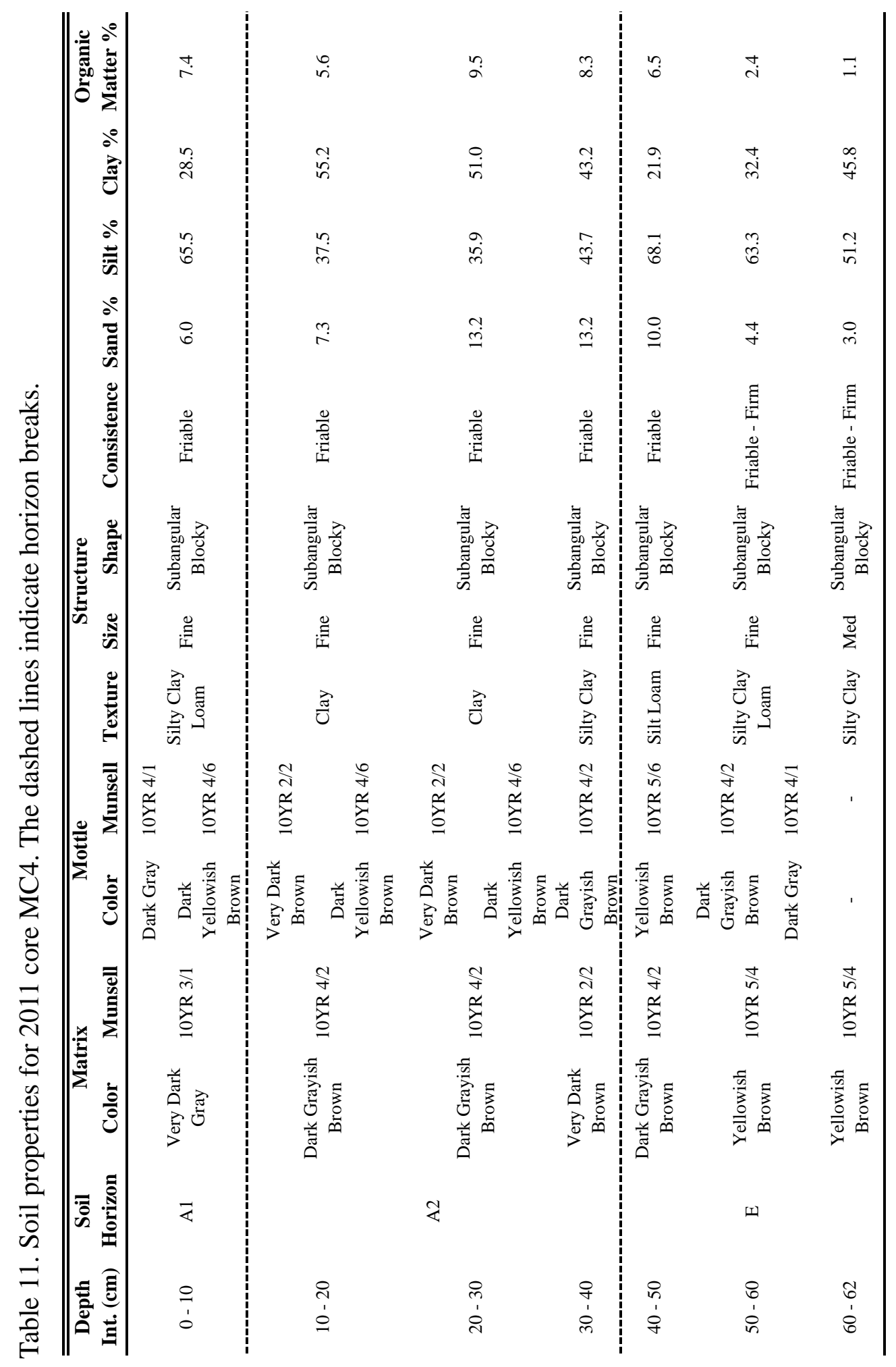




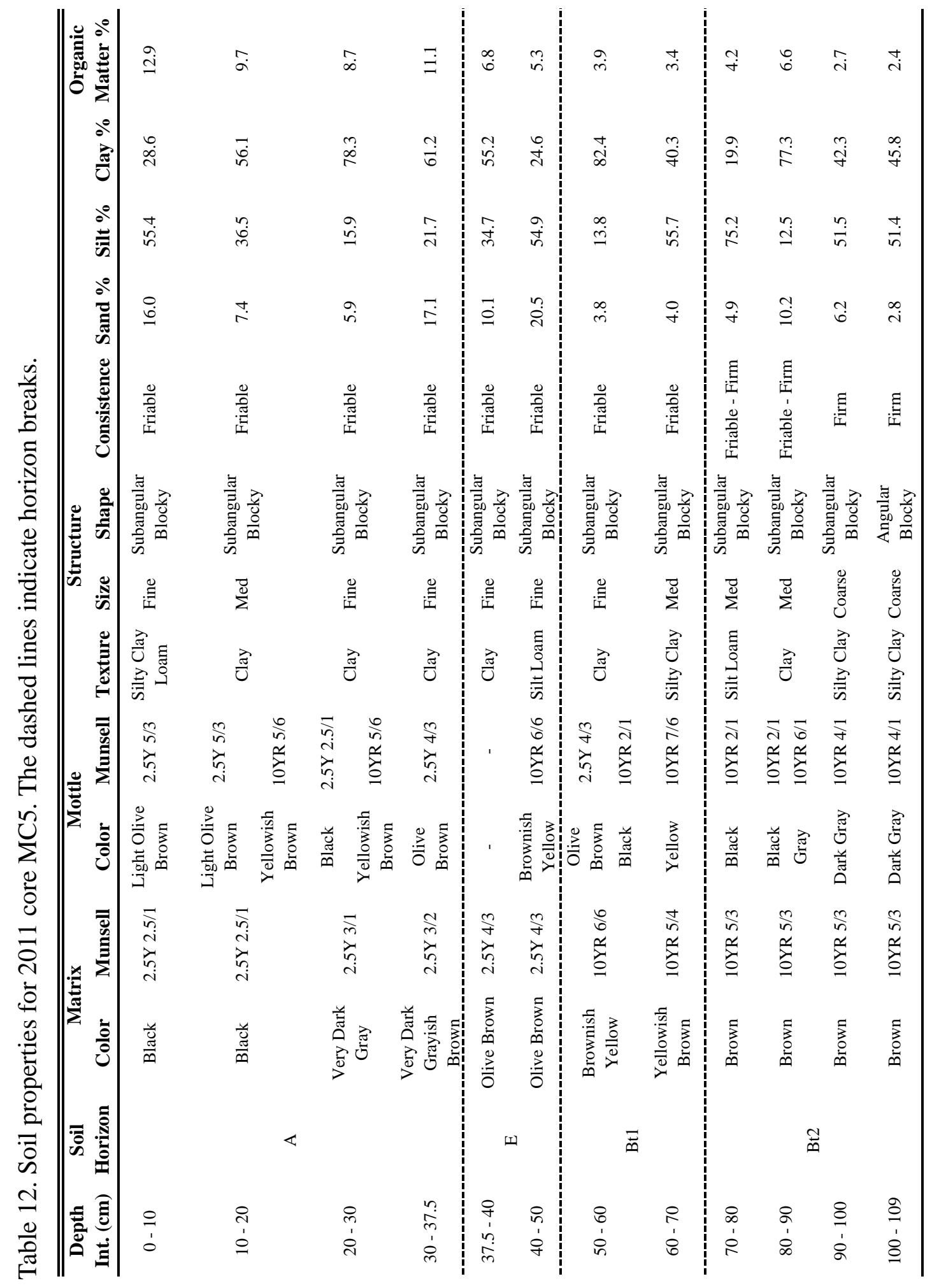



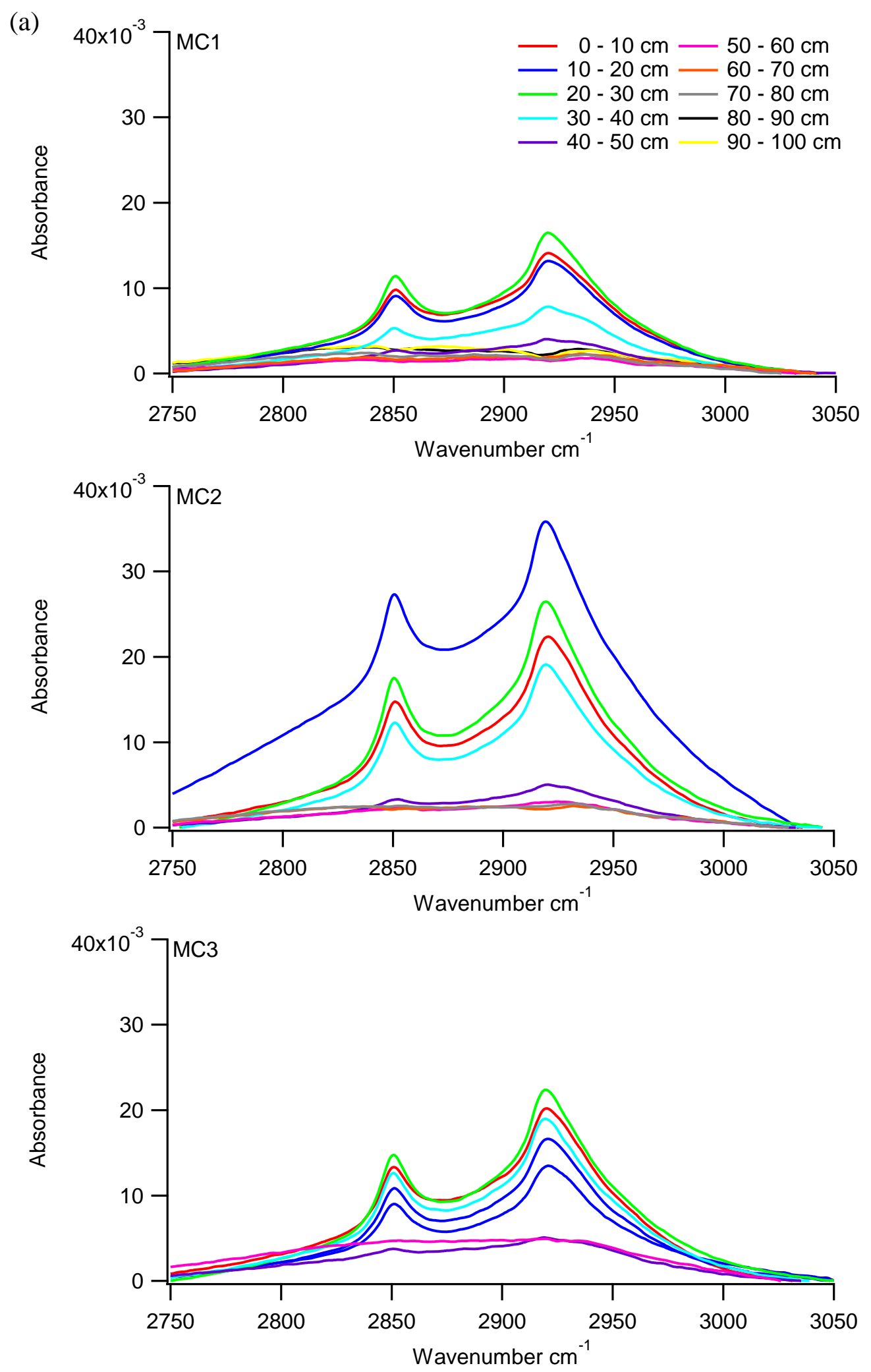

Figure 20. Spectra results of the 2011 cores. There are visible peaks between 2800 and 3050 wavenumbers. 

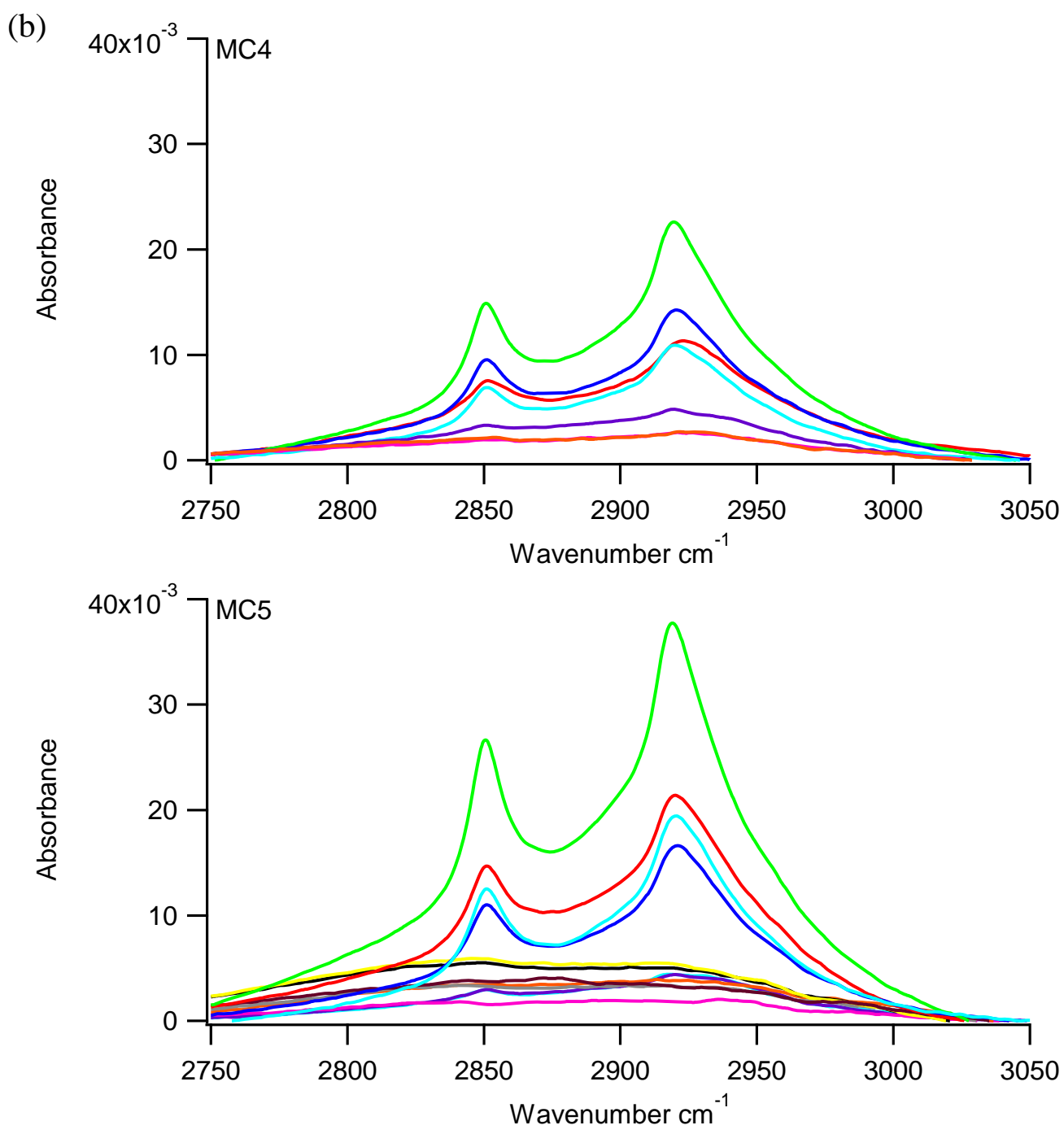

Figure 20. Spectra results of the 2011 cores. There are visible peaks between 2800 and 3050 wavenumbers. 
Table 13. 2011 cores peak $2\left(\sim 2915 \mathrm{~cm}^{-1}\right)$ measurements.

(a) Peak heights. Given in absorbance units and listed by depth interval. The highest peaks in each core are bolded.

\begin{tabular}{c|ccccc}
\hline \hline Depth Int (cm) & MC1 & MC2 & MC3 & MC4 & MC5 \\
\hline $0-10$ & 0.0141 & 0.0224 & 0.0202 & 0.0113 & 0.0214 \\
$10-20$ & 0.0132 & $\mathbf{0 . 0 3 5 8}$ & 0.0151 & 0.0143 & 0.0166 \\
$20-30$ & $\mathbf{0 . 0 1 6 8}$ & 0.0265 & $\mathbf{0 . 0 2 2 4}$ & $\mathbf{0 . 0 2 2 6}$ & $\mathbf{0 . 0 3 7 7}$ \\
$30-40$ & 0.0078 & 0.0191 & 0.0190 & 0.0109 & 0.0194 \\
$40-50$ & 0.0040 & 0.0051 & 0.0050 & 0.0048 & 0.0044 \\
$50-60$ & 0.0015 & 0.0030 & 0.0049 & 0.0026 & 0.0018 \\
$60-70$ & 0.0019 & 0.0022 & & 0.0027 & 0.0038 \\
$70-80$ & 0.0017 & 0.0025 & & & 0.0033 \\
$80-90$ & 0.0022 & & & & 0.0050 \\
$90-100$ & 0.0018 & & & & 0.0054 \\
$100-110$ & & & & & 0.0032 \\
\hline
\end{tabular}

(b) Peak areas. Given in absorbance units and listed by depth interval.

\begin{tabular}{c|ccccc}
\hline \hline Depth Int (cm) & MC1 & MC2 & MC3 & MC4 & MC5 \\
\hline $0-10$ & 1.2932 & 1.8671 & 1.7609 & 1.0911 & 1.9148 \\
$10-20$ & 1.1833 & 3.6248 & 2.5622 & 1.2248 & 1.4003 \\
$20-30$ & 1.4063 & 2.1371 & 1.8501 & 1.8455 & 3.1183 \\
$30-40$ & 0.7456 & 1.5506 & 1.6009 & 0.9332 & 1.9849 \\
$40-50$ & 0.4239 & 0.5043 & 0.5830 & 0.5270 & 0.4670 \\
$50-60$ & 0.2487 & 0.3627 & 0.7133 & 0.3198 & 0.2791 \\
$60-70$ & 0.2990 & 0.3642 & & 0.3302 & 0.5502 \\
$70-80$ & 0.3249 & 0.3804 & & & 0.5013 \\
$80-90$ & 0.4287 & & & & 0.7677 \\
$90-100$ & 0.4383 & & & & 0.8169 \\
$100-110$ & -0.1919 & & & & 0.5424 \\
\hline
\end{tabular}


$1.0 \%-4.0 \%$ palmitic acid. The exact concentration of each fatty acid contribution could not be determined using this method because naturally decomposing fats are not pure oleic or palmitic acids, but some mixture of these and other fatty acids.; this is reflected in the spectra. In MC2, the highest peaks were at a depth of $10-20 \mathrm{~cm}$ and intermediate in height between peaks indicative of $1.0 \%$ oleic acid and $4.0 \%$ palmitic acid in a comparable soil (Figure 21). This suggests that MC2 contained higher amounts of fatty acids than the other 2011 cores, and perhaps a more localized pulse of decomposing material. The spatial differences in the amounts of fatty acid present in the cores can be seen in Figure 22.

\section{Human Burial Analogue 2015 - Soil Results}

The six cores extracted from the 2015 pig burial ranged in length from approximately $25 \mathrm{~cm}$ to $80 \mathrm{~cm}$, the shortest of which was only $14 \mathrm{~cm}$ (Figures 23 and 24; Tables 14 - 19). Cores C1 - C3 were extracted from locations inside the burial pit, and therefore from a disturbed soil profile, while cores $\mathrm{C} 4$ - C6 were extracted from locations outside of the burial pit from an undisturbed profile (Figure 4). The first core was composed of two samples (C1D1 and C1D2). A compact layer in the subsurface prevented the probe from penetrating deeper than $23 \mathrm{~cm}$ below the surface, so a second sample was collected adjacent to the first probe hole. For all cores, the texture was primarily a loam with a maximum clay content in the subsurface. Organic matter content in the undisturbed cores was highest at the surface and generally decreased with depth.

\section{Human Burial Analogue 2015 - Spectra Results}

There were two visible peaks indicative of a fatty acid, visible between 2800 and $3100 \mathrm{~cm}^{-1}$, present in four of the 2015 cores, however there were no peaks indicative of leucine or calcium pyrophosphate (Figure 25; Tables 20a and 20b). Unlike the 2011 

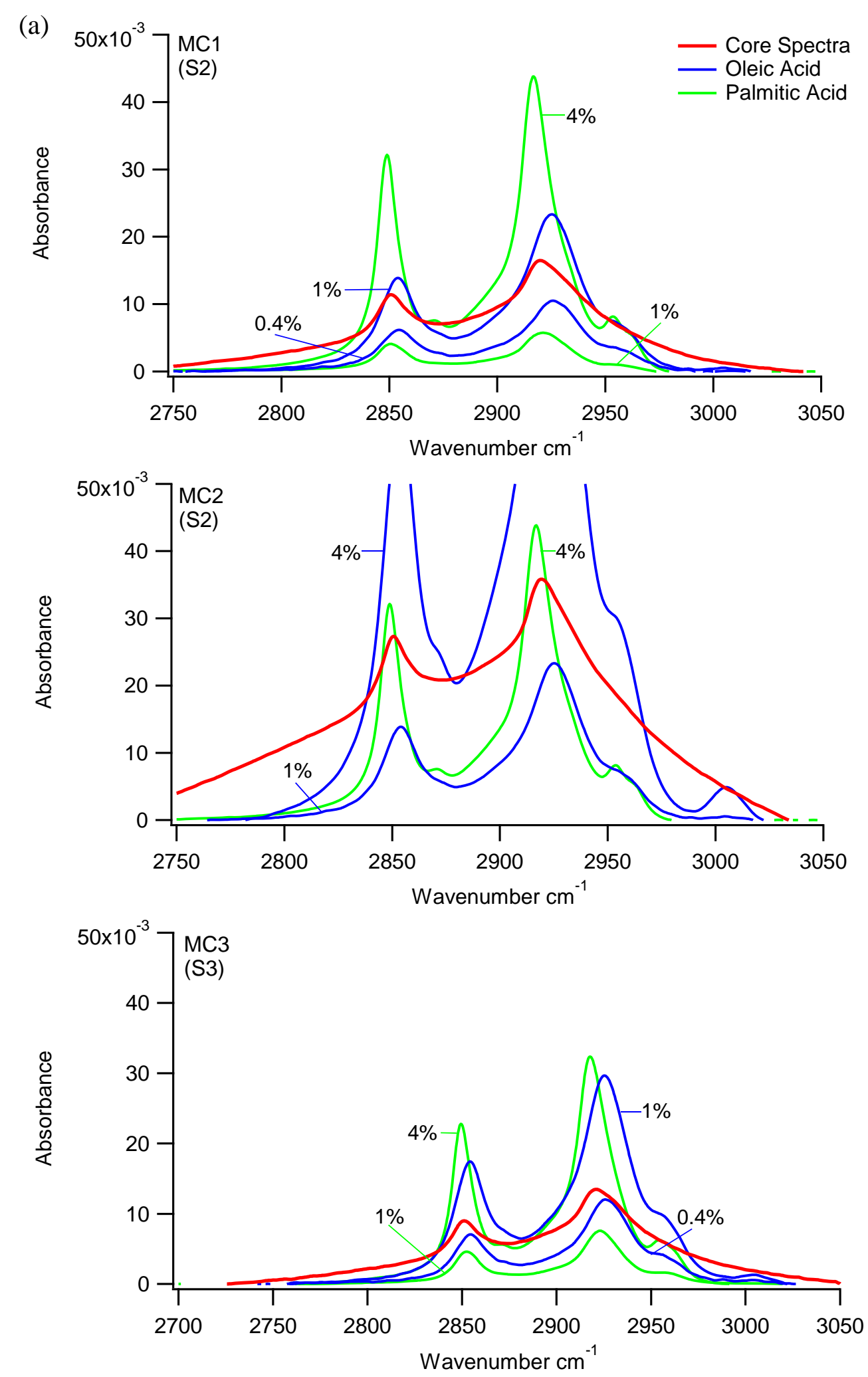

Figure 21. Spectra results of the 2011 cores compared to the Steiner Property palmitic acid spectra and oleic acid spectra. 

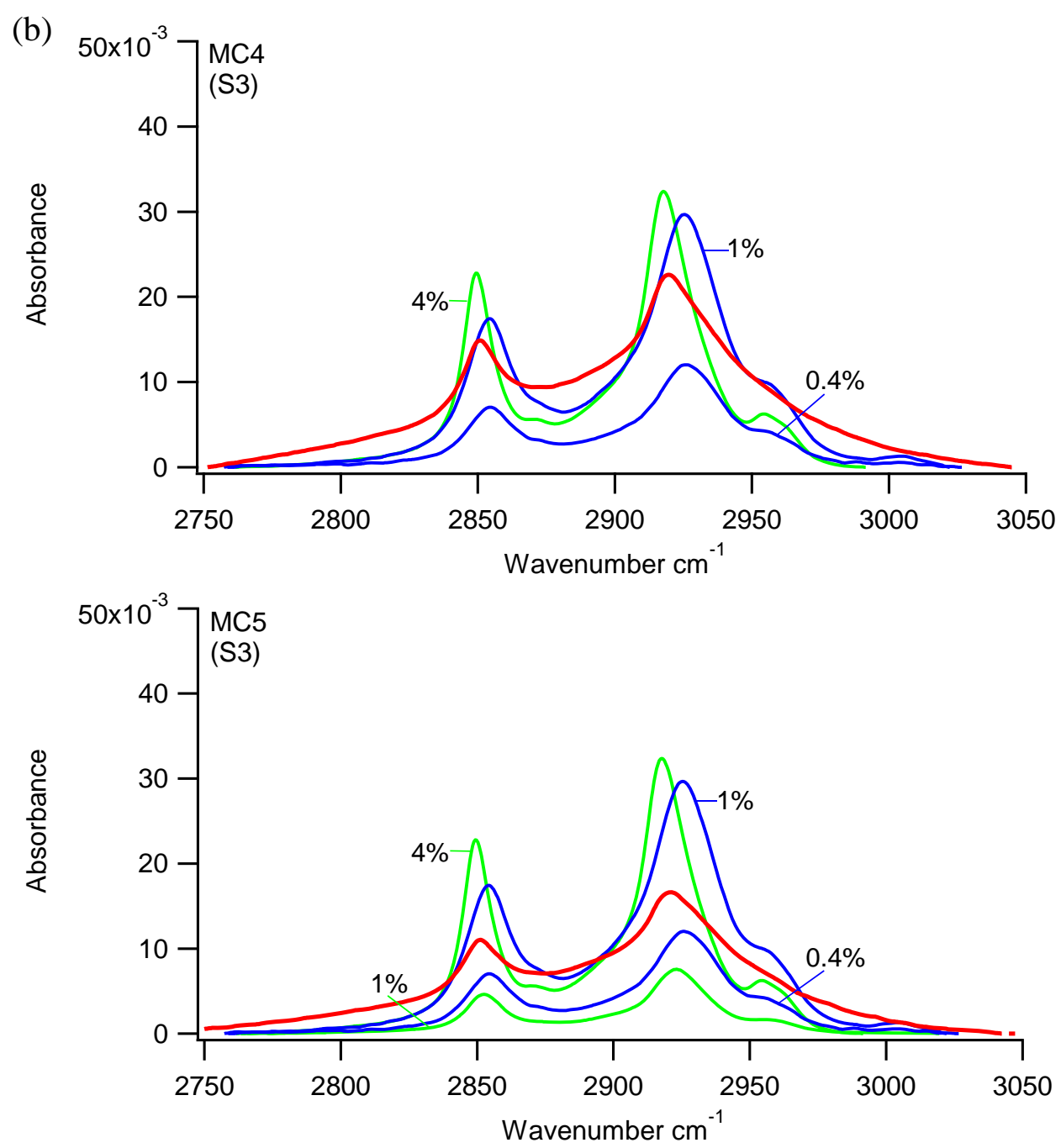

Figure 21. Spectra results of the 2011 cores compared to the Steiner Property palmitic acid spectra and oleic acid spectra. 


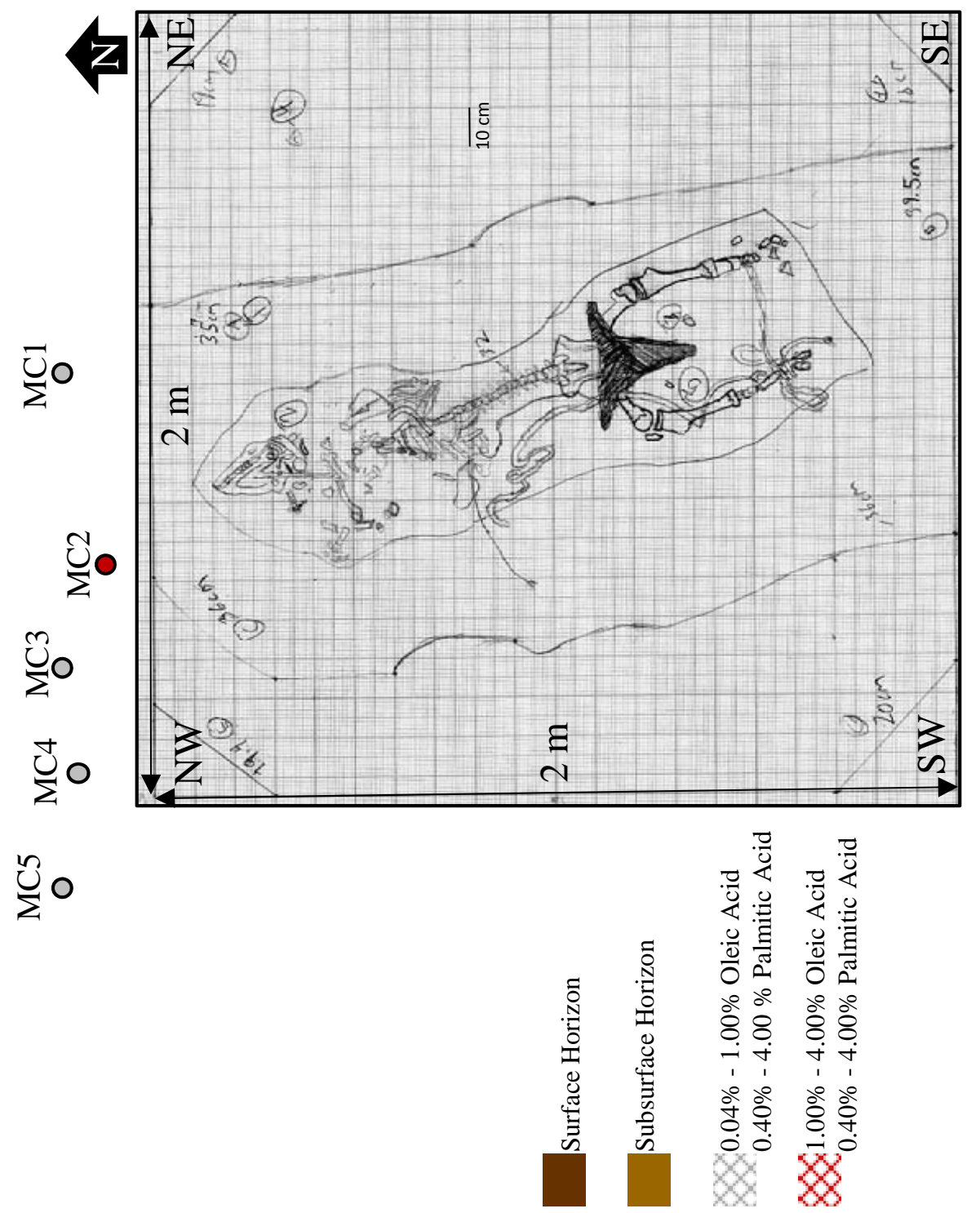

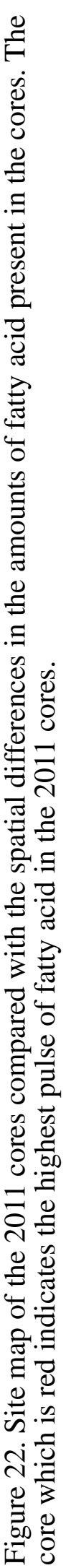




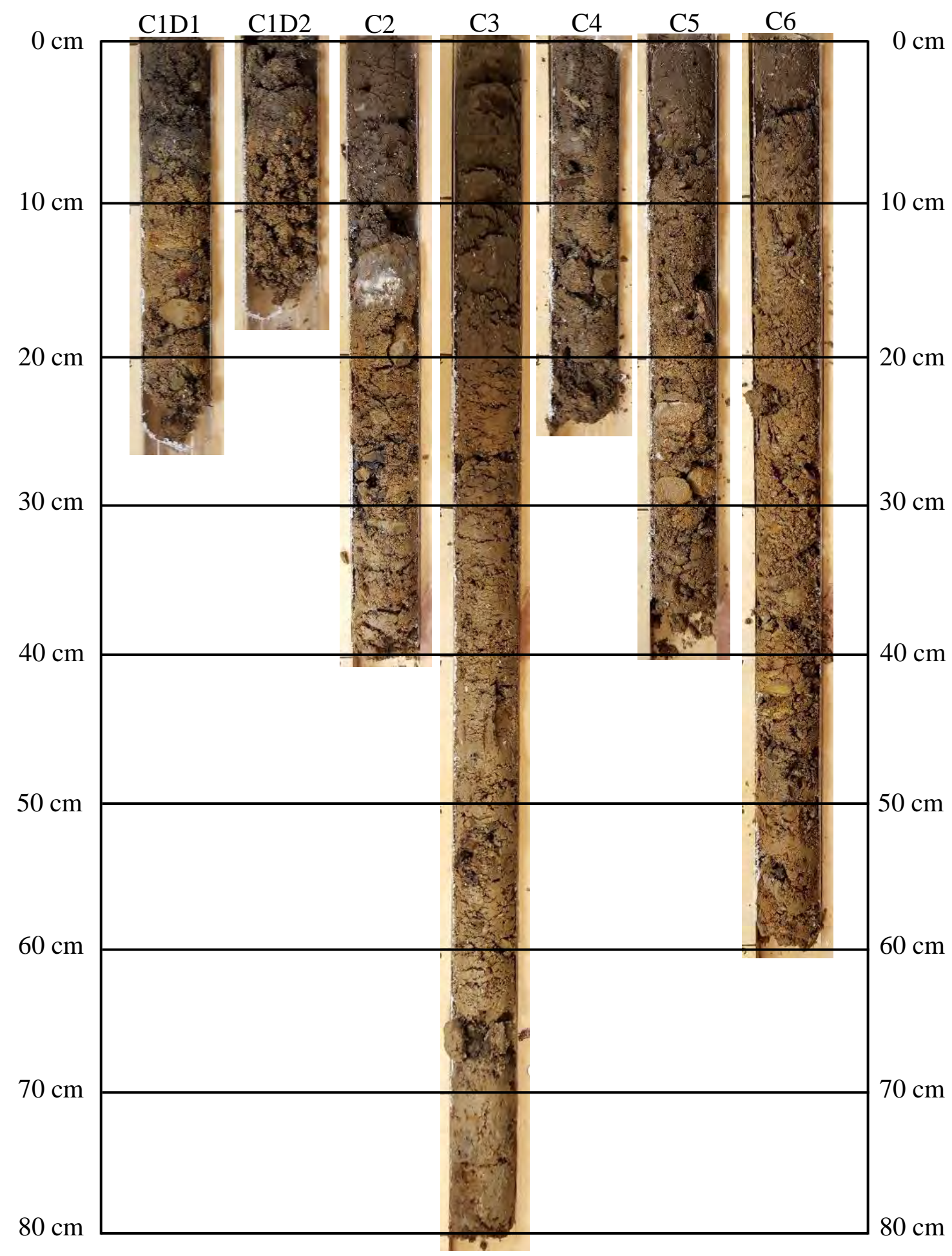

Figure 23. Photographs of the 2015 cores. The surface is indicated at $0 \mathrm{~cm}$. 


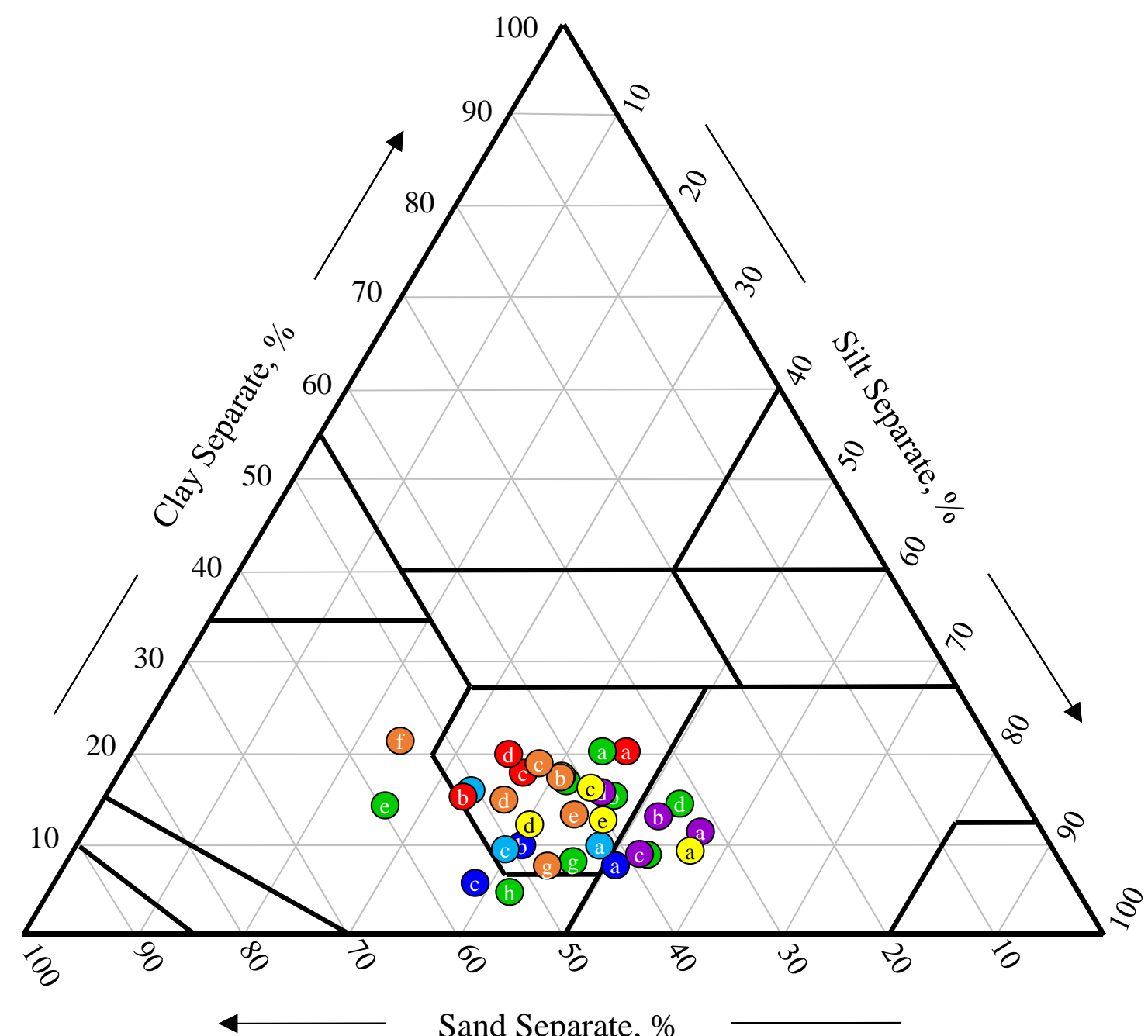

Figure 24. Texture triangle showing the particle size distribution of the 2015 cores. C1D1 is dark blue, C1D2 is light blue, C2 is red, C3 is green, C4 is purple, C5 is yellow, and C6 is orange. The letters on the points represent the core section. 


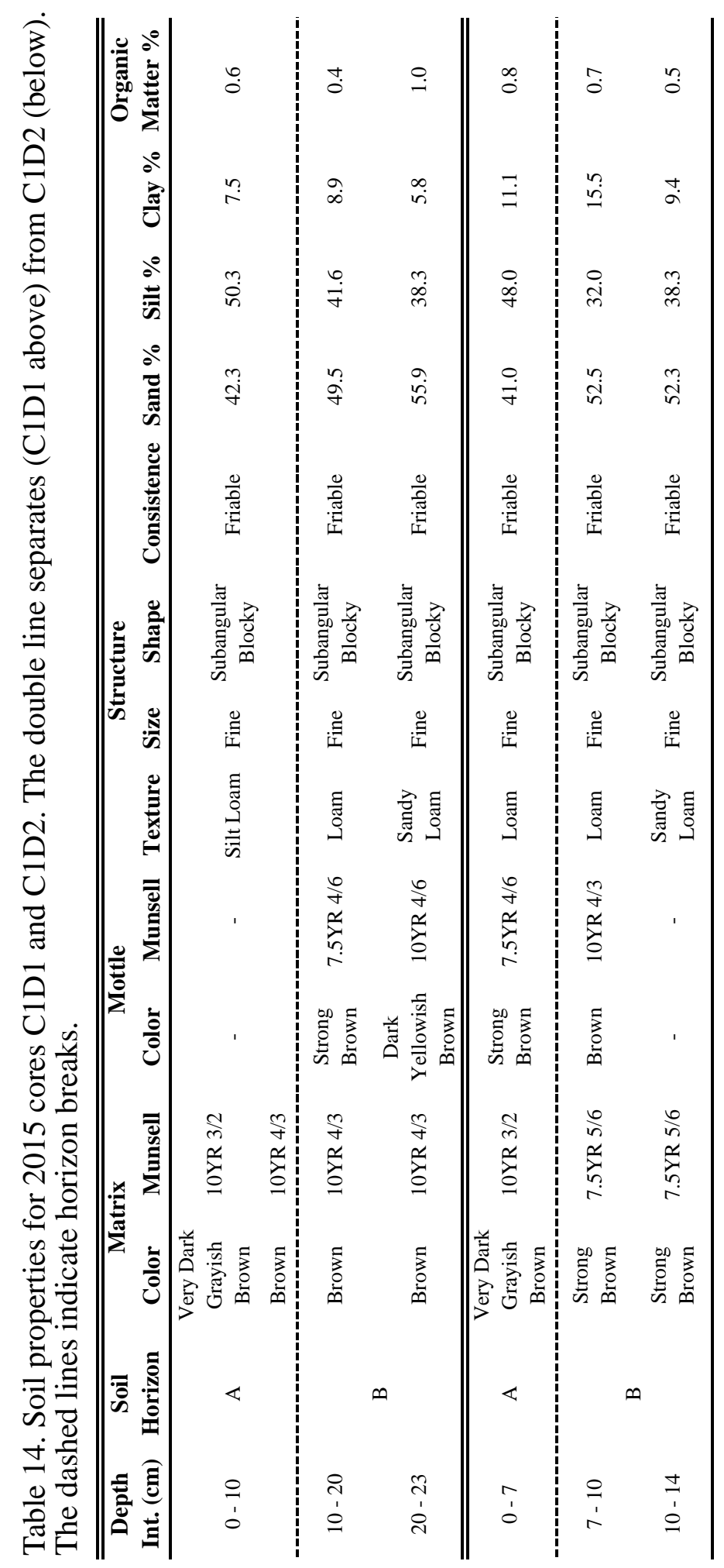




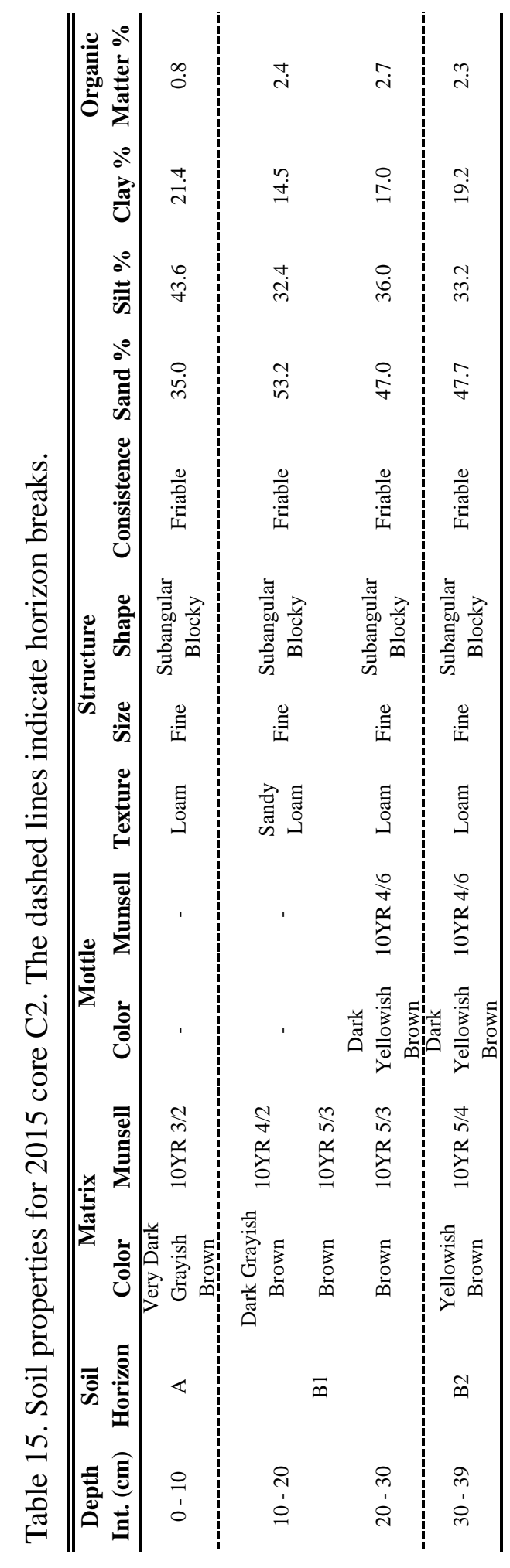




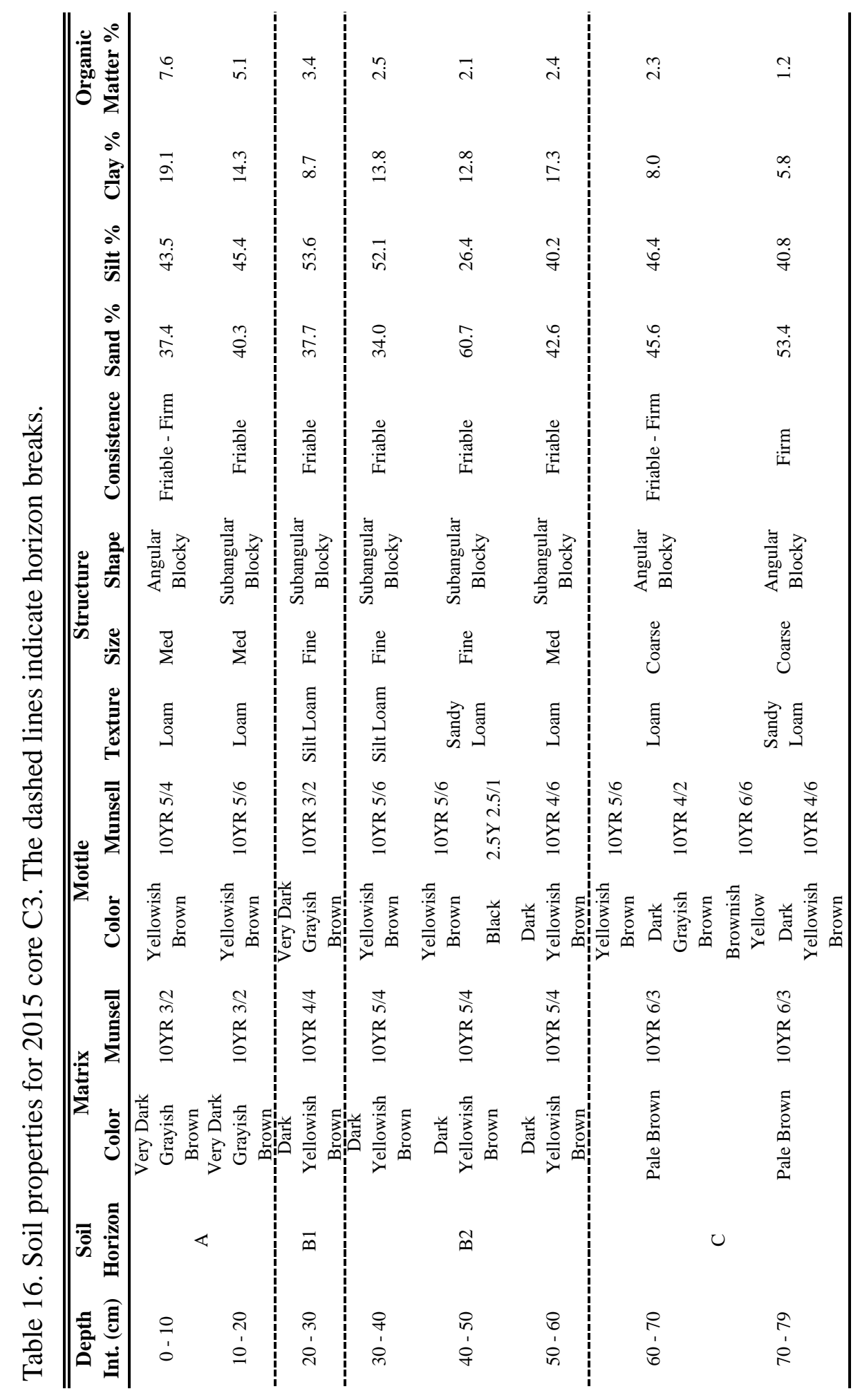




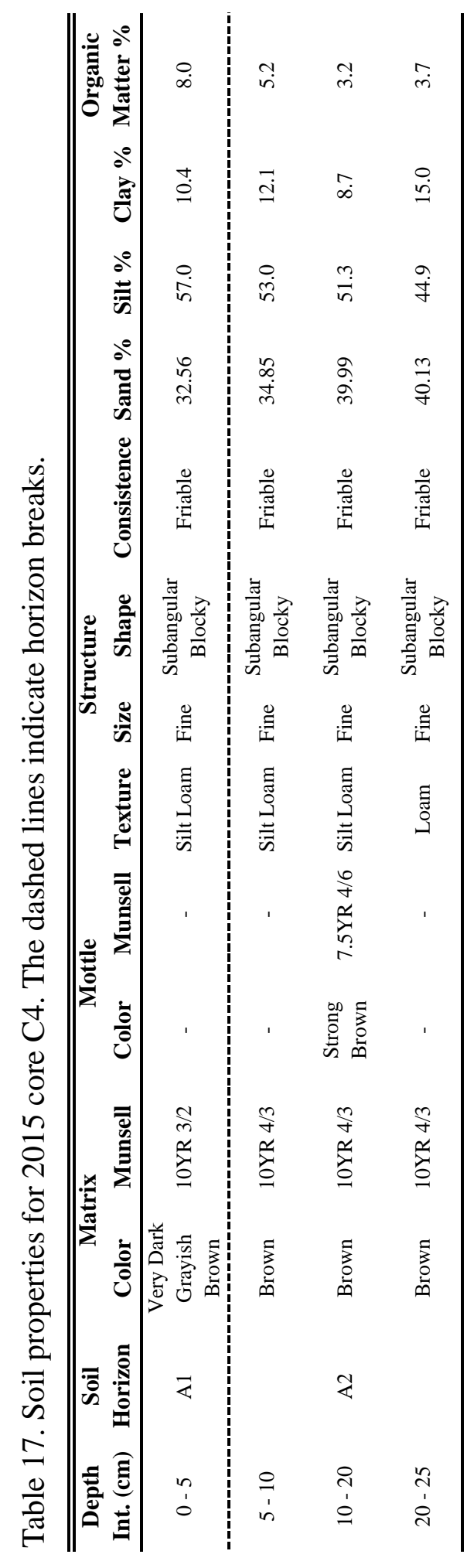




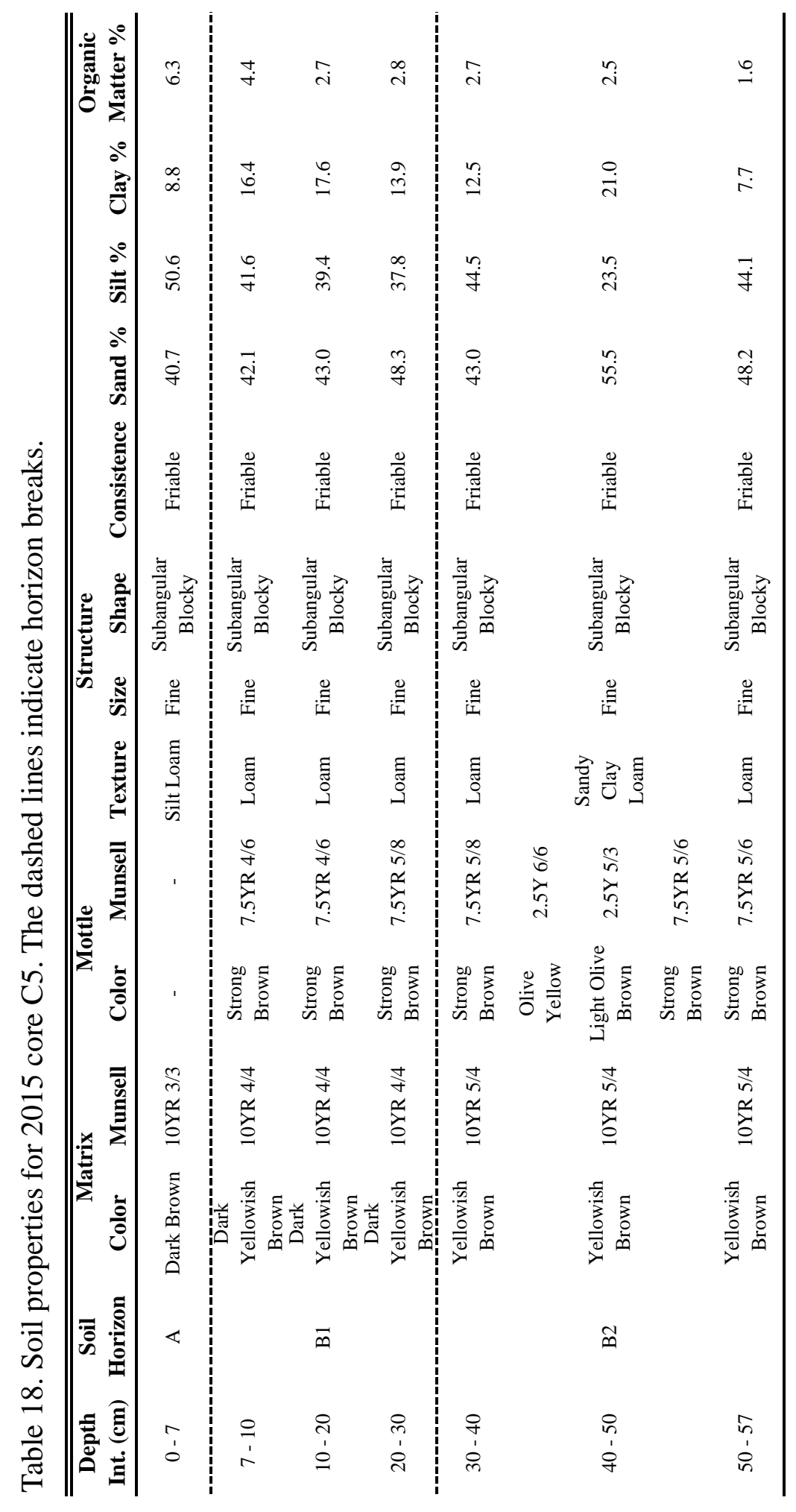




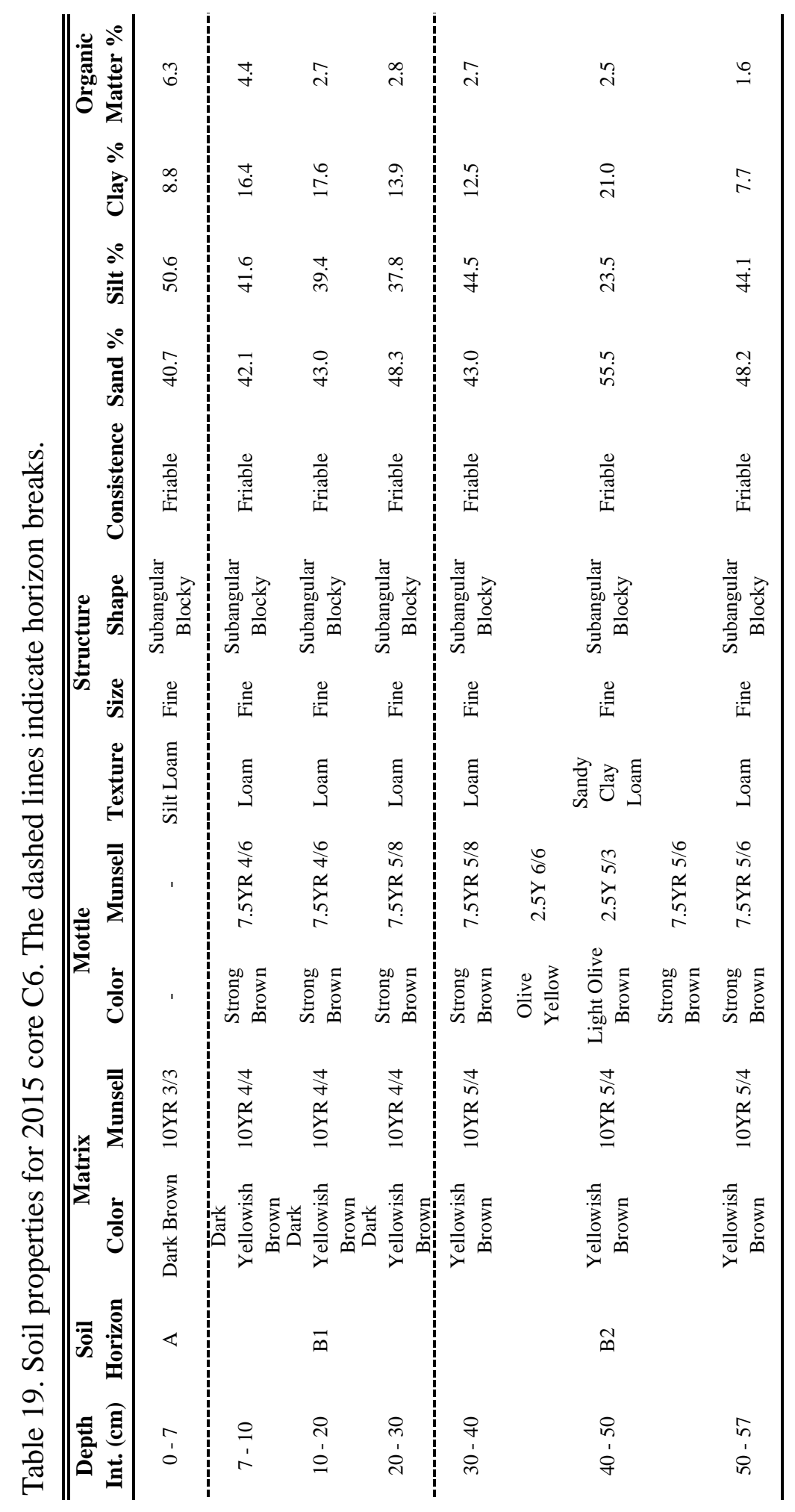


cores, the two representative peaks in the 2015 cores were present only in samples from the surface to a depth of $30 \mathrm{~cm}$ maximum. Clay contents in samples from this depth interval were most similar to that of sample S1, so they were compared with the oleic acid and palmitic acid spectra of that sample. The representative peaks in C3, C5, and C6 were indicative of $0.04 \%$ - $0.1 \%$ oleic acid and $\sim 0.4 \%$ palmitic acid, the lowest concentrations of fatty acid in the 2015 cores (Figure 26). The next highest concentrations of fatty acid were in cores C1D1 and C4; the peaks were indicative of $0.01 \%-0.4 \%$ oleic acid and $0.1 \%$ - 1.0\% palmitic acid. Core C2, which had visible adipocere at a depth of 10 - $20 \mathrm{~cm}$ (Figure 27), presented the highest peaks in all of the core samples from 2015, suggesting the presence of 1.0\% oleic acid and/or 1.0\% - 4.0\% palmitic acid (Figure 26). The spatial differences in the amounts of fatty acid present in the cores can be seen in Figure 28. 

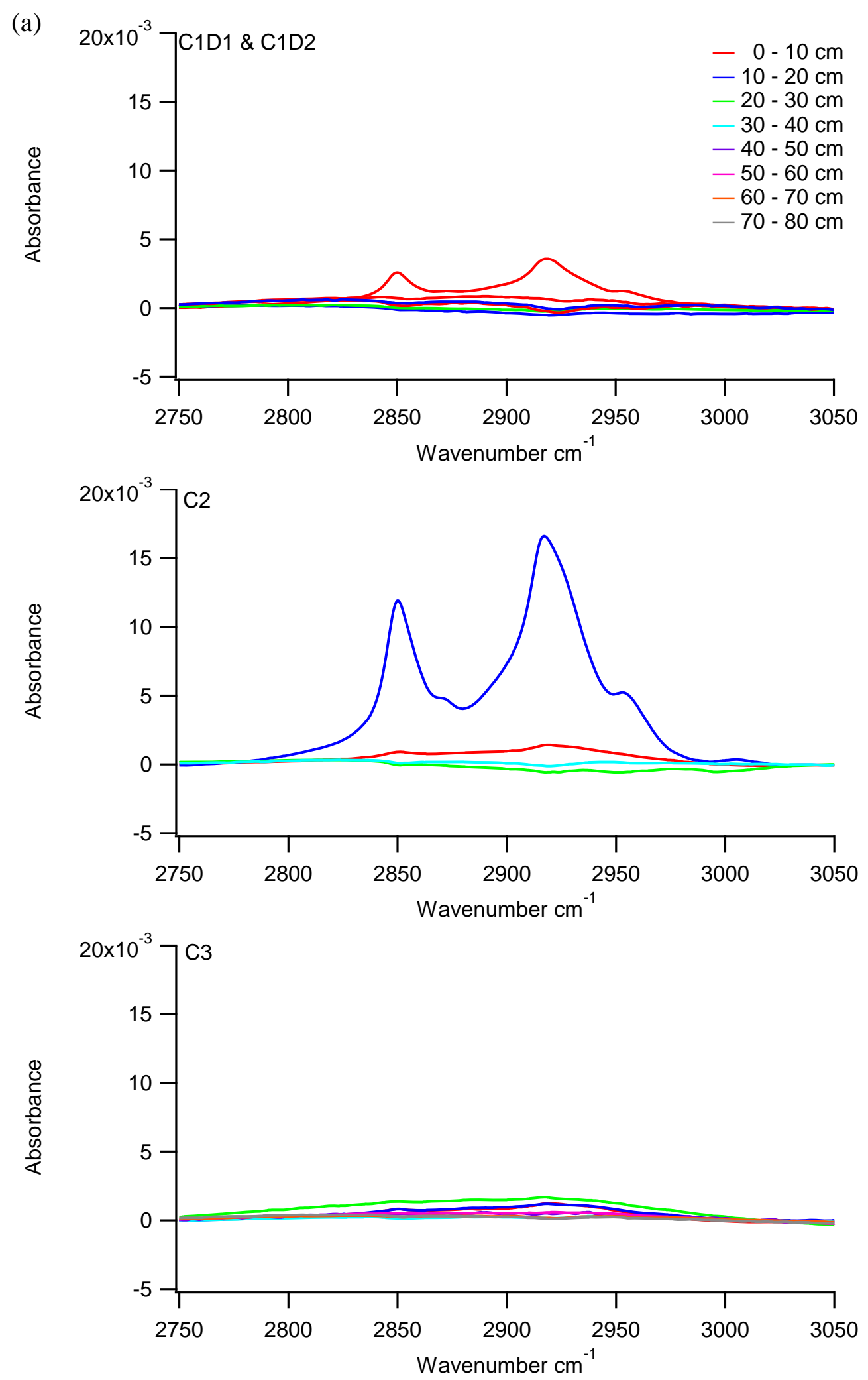

Figure 25. Spectra results of the 2015 cores. There are visible peaks between 2800 and 3050 wavenumbers. 

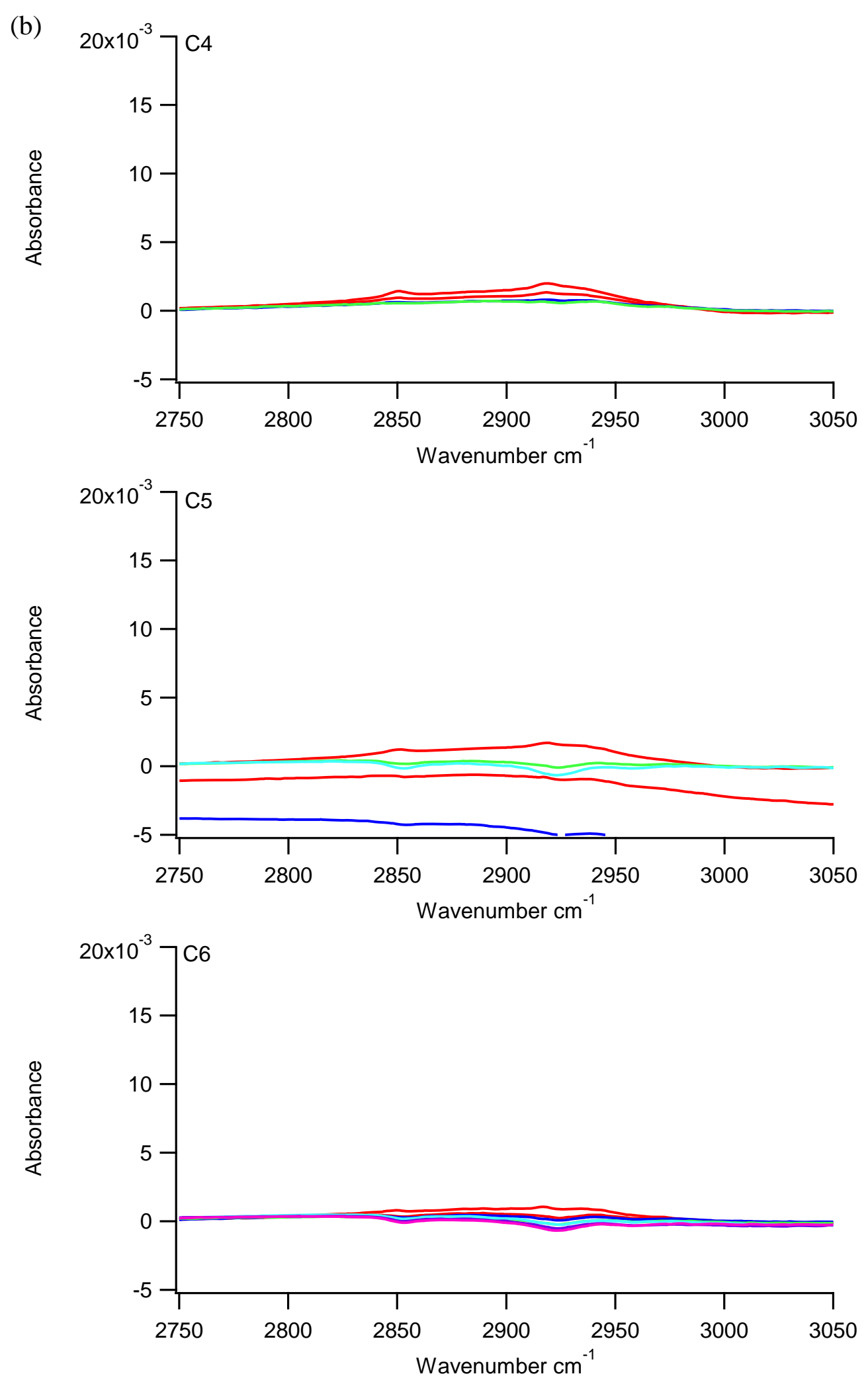

Figure 25. Spectra results of the 2015 cores. There are visible peaks between 2800 and 3050 wavenumbers. 
Table 20. 2015 cores peak $2\left(\sim 2915 \mathrm{~cm}^{-1}\right)$ measurements.

(a) Peak heights. Given in absorbance units and listed by depth interval. The highest peaks in each core are bolded.

\begin{tabular}{c|ccccccc}
\hline \hline Depth Int (cm) & C1D1 & C1D2 & C2 & C3 & C4 & C5 & C6 \\
\hline $0-10$ & $\mathbf{0 . 0 0 3 6}$ & $\mathbf{0 . 0 0 0 2}$ & 0.0014 & 0.0012 & 0.0017 & $\mathbf{0 . 0 0 0 5}$ & $\mathbf{0 . 0 0 0 7}$ \\
$10-20$ & -0.0005 & 0.0000 & $\mathbf{0 . 0 1 6 6}$ & 0.0012 & $\mathbf{0 . 0 0 0 8}$ & -0.0048 & 0.0002 \\
$20-30$ & -0.0002 & & -0.0006 & $\mathbf{0 . 0 0 1 7}$ & 0.0006 & 0.0000 & -0.0001 \\
$30-40$ & & & -0.0001 & 0.0002 & & -0.0006 & -0.0001 \\
$40-50$ & & & & 0.0005 & & & -0.0003 \\
$50-60$ & & & & 0.0006 & & & -0.0005 \\
$60-70$ & & & & 0.0002 & & & \\
$70-80$ & & & & 0.0001 & & & \\
\hline
\end{tabular}

(b) Peak areas. Given in absorbance units and listed by depth interval.

\begin{tabular}{c|ccccccc}
\hline \hline Depth Int (cm) & C1D1 & C1D2 & C2 & C3 & C4 & C5 & C6 \\
\hline $0-10$ & 0.2539 & 0.1415 & 0.1340 & 0.1222 & 0.1735 & 0.0179 & 0.0946 \\
$10-20$ & -0.0385 & 0.0528 & 1.0712 & 0.1300 & 0.0986 & -0.7535 & 0.0500 \\
$20-30$ & -0.0034 & & -0.0309 & 0.2169 & 0.0912 & 0.0392 & 0.0209 \\
$30-40$ & & & 0.0243 & 0.0355 & & -0.0017 & 0.0302 \\
$40-50$ & & & & 0.0748 & & & -0.0017 \\
$50-60$ & & & & 0.0795 & & & -0.0137 \\
$60-70$ & & & & 0.0454 & & & \\
$70-80$ & & & & 0.0433 & & & \\
\hline
\end{tabular}



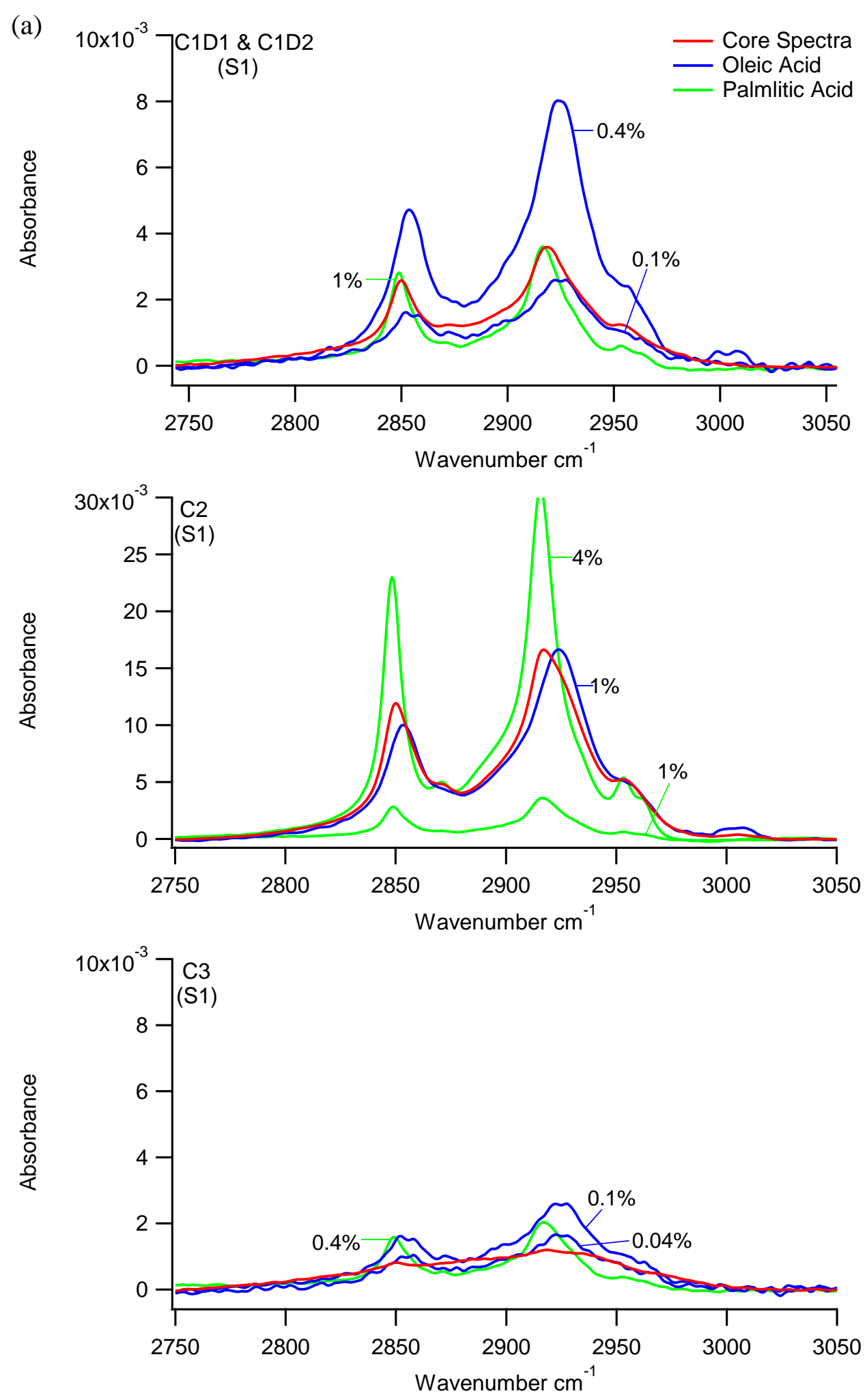

Figure 26. Spectra results of the 2015 cores compared to the Steiner Property palmitic acid spectra and oleic acid spectra. Note that C2 is at a different scale than the other cores. 

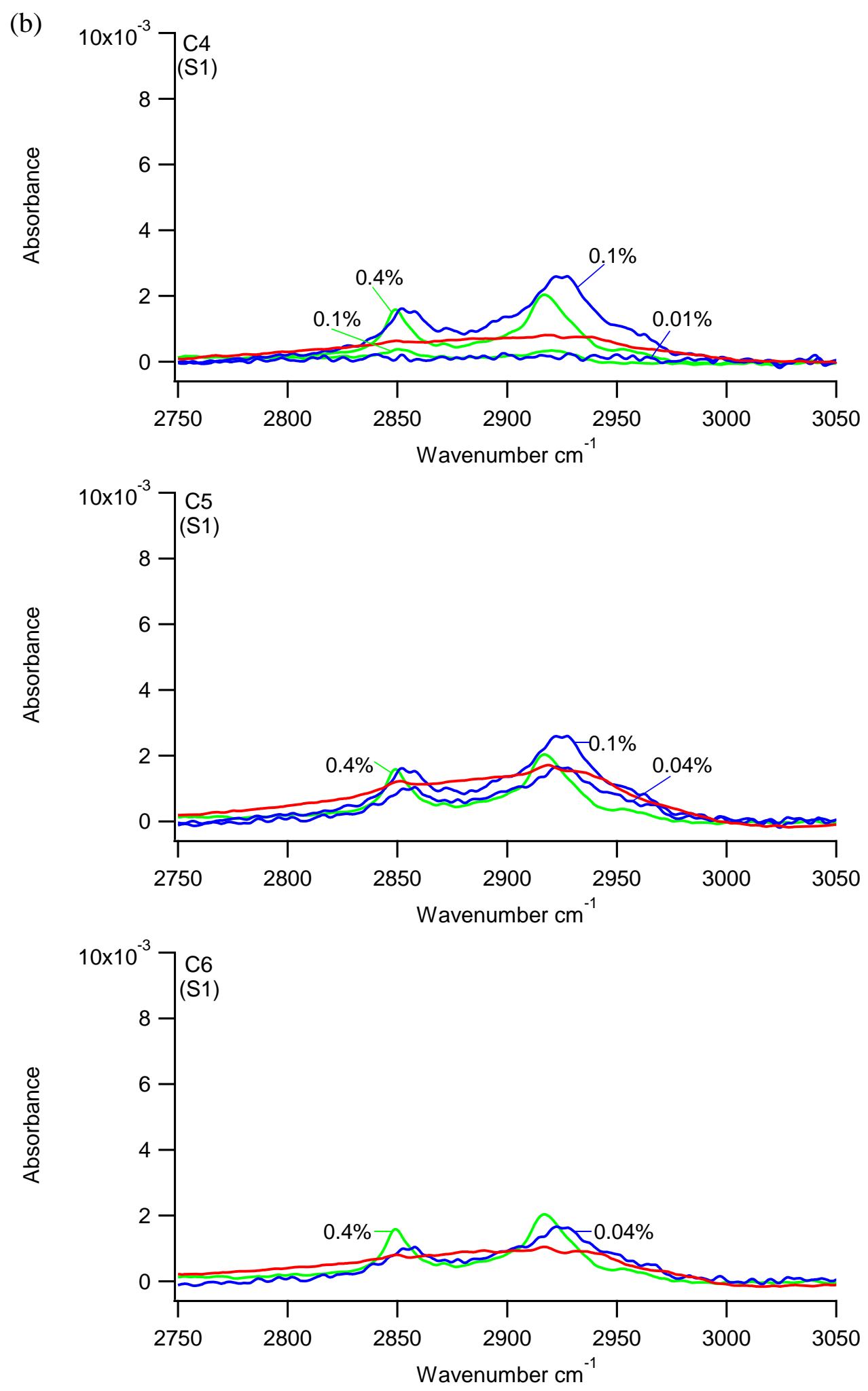

Figure 26. Spectra results of the 2015 cores compared to the Steiner Property palmitic acid spectra and oleic acid spectra. Note that C2 is at a different scale than the other cores. 


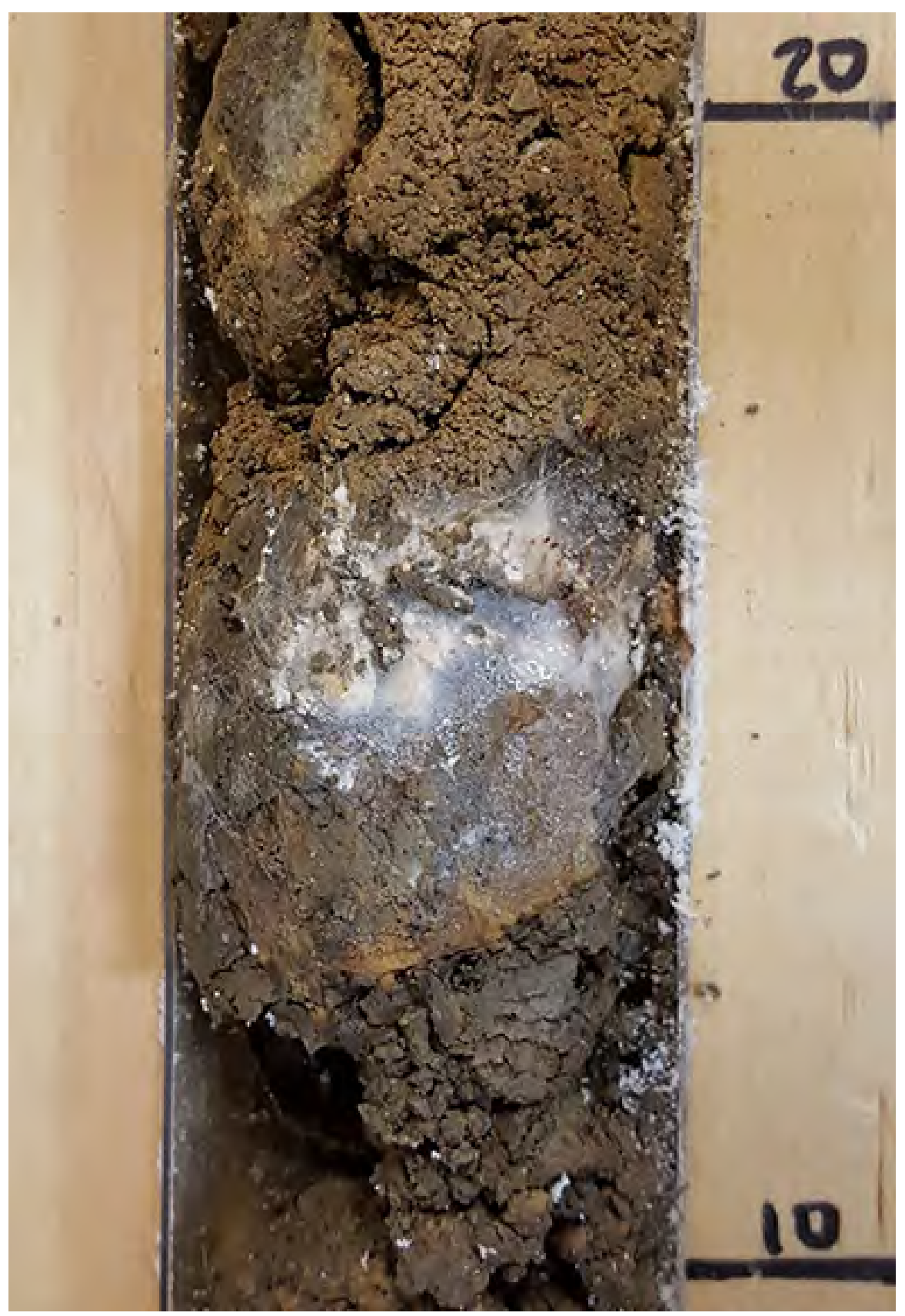

Figure 27. Photograph of the adipocere present in C2 at a depth of $10-20 \mathrm{~cm}$. 


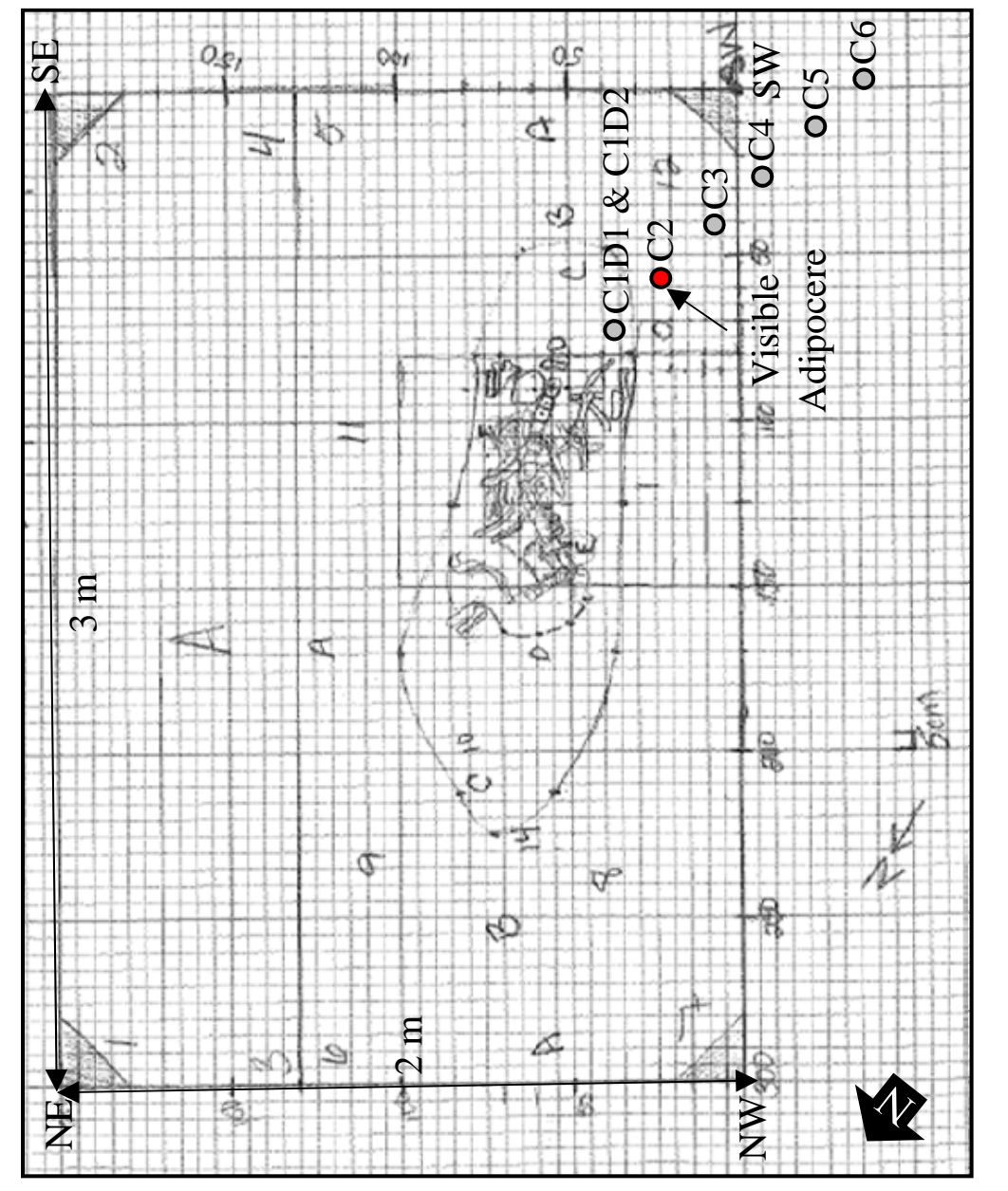

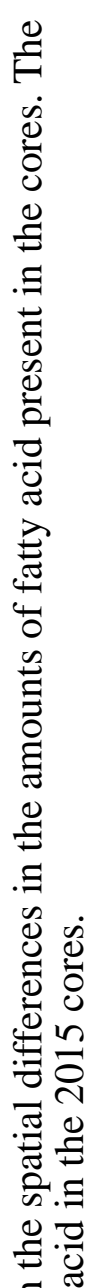

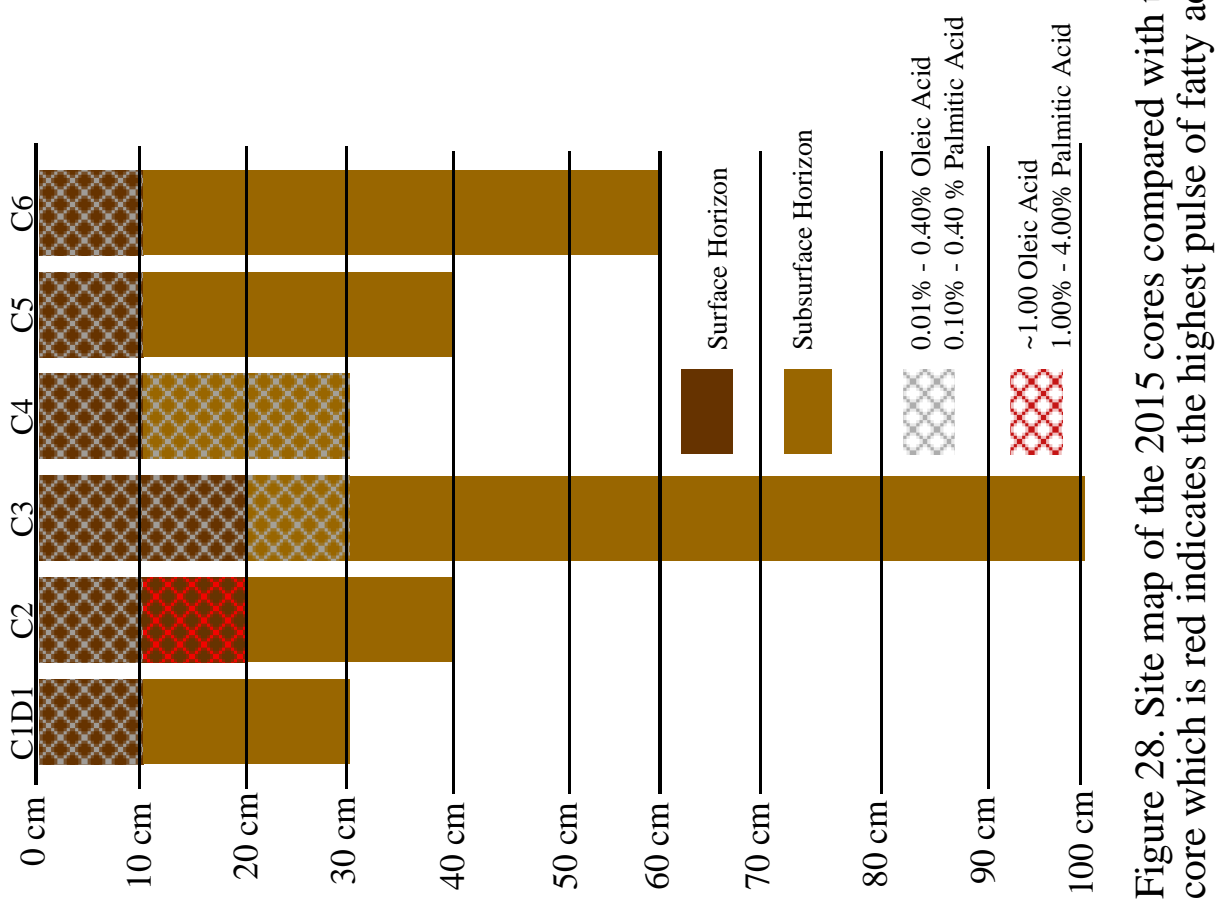




\section{CHAPTER IV}

\section{DISCUSSION}

\section{Human Burial Analogues}

At the time the cores were extracted (in 2011 and in 2015), the respective pig carcasses were in the liquefaction and disintegration phase of decomposition (Figure 29). Liquefaction and disintegration occurs after later stage decomposition when the putrescent mass left behind by the breakdown of carbohydrates, fats, and proteins becomes separated from the skeleton and the bones begin to disarticulate (Dent et al., 2003). In Figure 29, some of the bones of the 2015 pig carcass may be seen poking through the putrescent mass, however there is still enough of the mass left to infer that the carcass is not yet in the skeletonisation phase. Peaks representative of one or more fatty acids, presumably oleic and palmitic at the least, were present in some of the cores in both of the human burial analogues, however peaks representative of leucine and calcium pyrophosphate were not present in any of the cores from either human burial analogue.

\section{Leucine}

Leucine may not have been detected in any of the core samples because it is water soluble (Chumanov et al., 2005), which suggests a short residence within a soil column, especially in that of a well-drained, permeable soil. As leucine is an amino acid, it would have been released from the carcass during the deamination of amino acids which takes place during the putrefaction stage of decomposition, before liquefaction and disintegration occur (Figure 1) (Dent et al., 2003). If the leucine had already begun to 


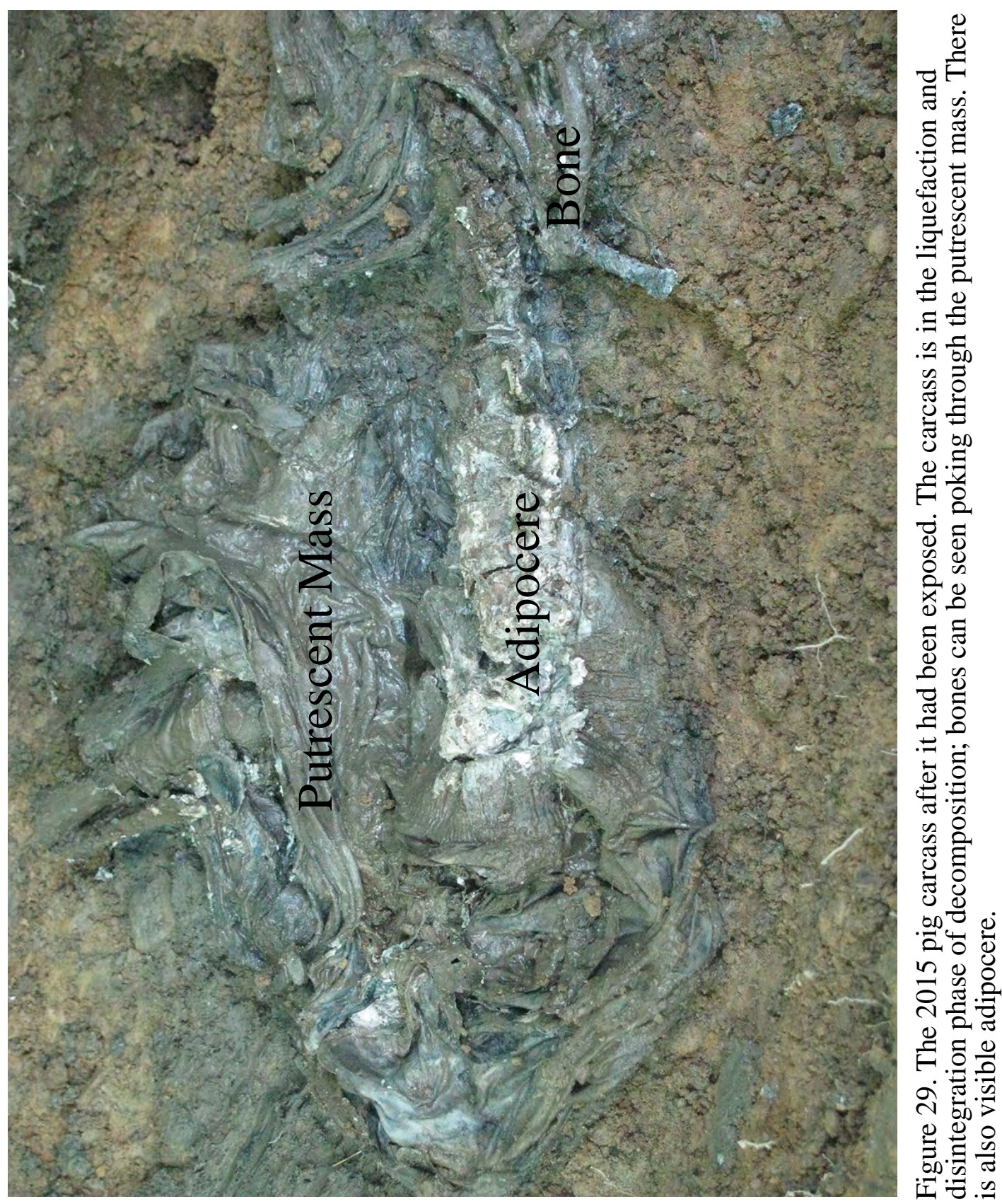


leach out through the soil column before the cores were taken, only trace amounts of leucine would have been left in the soil surrounding the carcass. In the Steiner Property, which is also the site of both pig burials, the leucine detection limit was $1.0 \%$ from the surface to $14 \mathrm{~cm}$ below the surface and $0.4 \%$ from $14-58 \mathrm{~cm}$. The pigs were buried at a depth of 41 - $56 \mathrm{~cm}$ (2011) and 34 - $40 \mathrm{~cm}$ (2015); if there was less than 0.4\% leucine in the subsurface core sections or less than $1.0 \%$ leucine in the surface core sections taken from either burial, it would not be detected by these methods.

\section{Calcium Pyrophosphate}

In the human (and pig) body, calcium pyrophosphate is most often adsorbed to bone mineral (Caswell et al., 1983). Bones, teeth, and cartilage do not begin to decompose until the process of skeletonisation occurs, after liquefaction and disintegration is complete. In the liquefaction and disintegration phase, the calcium pyrophosphate would still be adsorbed to bone mineral which had not yet begun to decompose via chemical weathering. The weathering of bone includes several chemical reactions which are controlled by water, acid, oxygen, and calcium contents in the bone and in the soil (White and Hannus, 1983). These reactions are initiated by organic and carbonic acids in the soil formed by the microbial decomposition of collagen (White and Hannus, 1983), which Dent et al. (2003) state is the "supportive scaffold” of the bone. The rate of skeletonisation depends on the characteristics of the burial, as well as the nature of the soil (Dent et al., 2003). In general, bone preservation is best in dry soils with a neutral pH; these soils incur less bacterial growth (Dent et al., 2003). In addition, it is likely that the trace amounts of calcium pyrophosphate, with low solubility in water, had not yet moved far from their source and thus had not yet reached the cores, which were taken at some distance from the decomposing carcasses. If the trace amounts of calcium pyrophosphate had reached the cores, they would be present in much less than the 3.0\% 
Steiner Property detection limit, and therefore would not be distinguished by these methods.

In the calcium pyrophosphate data, the high detection limits and lack of relationship to soil properties may have been caused by the physical nature of the compound. Calcium pyrophosphate is a hydrophilic compound (Guo et al., 2010); its chemical structure attracts and holds on to water molecules. The attracted water in the sample creates surplus peaks, not indicative of calcium pyrophosphate, which may appear larger and more eye-catching than the actual calcium pyrophosphate peaks. This makes the spectra more visibly similar to water and draws away from the calcium pyrophosphate peaks, making the spectra more difficult to interpret overall (Figure 30). The additional water also rounds the peaks, making them less distinct, and possibly moved to the left or right of where the true peaks of a pure sample would normally occur. In their study of the infrared spectra of the phosphate ions in various apatites, Klee and Engel (1970) presented a strontium phosphate spectrum with three distinct peaks between 900 and $1100 \mathrm{~cm}^{-1}$. I saw peaks similar to these in my calcium pyrophosphate spectra, however the peaks in my samples were more rounded and less distinct, with one large central peak and two shoulders instead of three distinct peaks (Figure 31). The difference in the peak shape was likely due to the presence of water in my samples, which were scanned in an air-dry state, and the absence of it in Klee's and Engel's (1970) samples, which had been ovendried. Although thoroughly desiccated samples seem advantageous in that they offer truer spectra, soil is not inherently dry; it would not be practical for an in situ instrument to utilize detection limits based upon dehydrated samples.

\section{Fatty Acids}

Oleic and palmitic acid were able to be detected in samples from both of the human burial analogues because they are present in fatty tissue, which begins to 


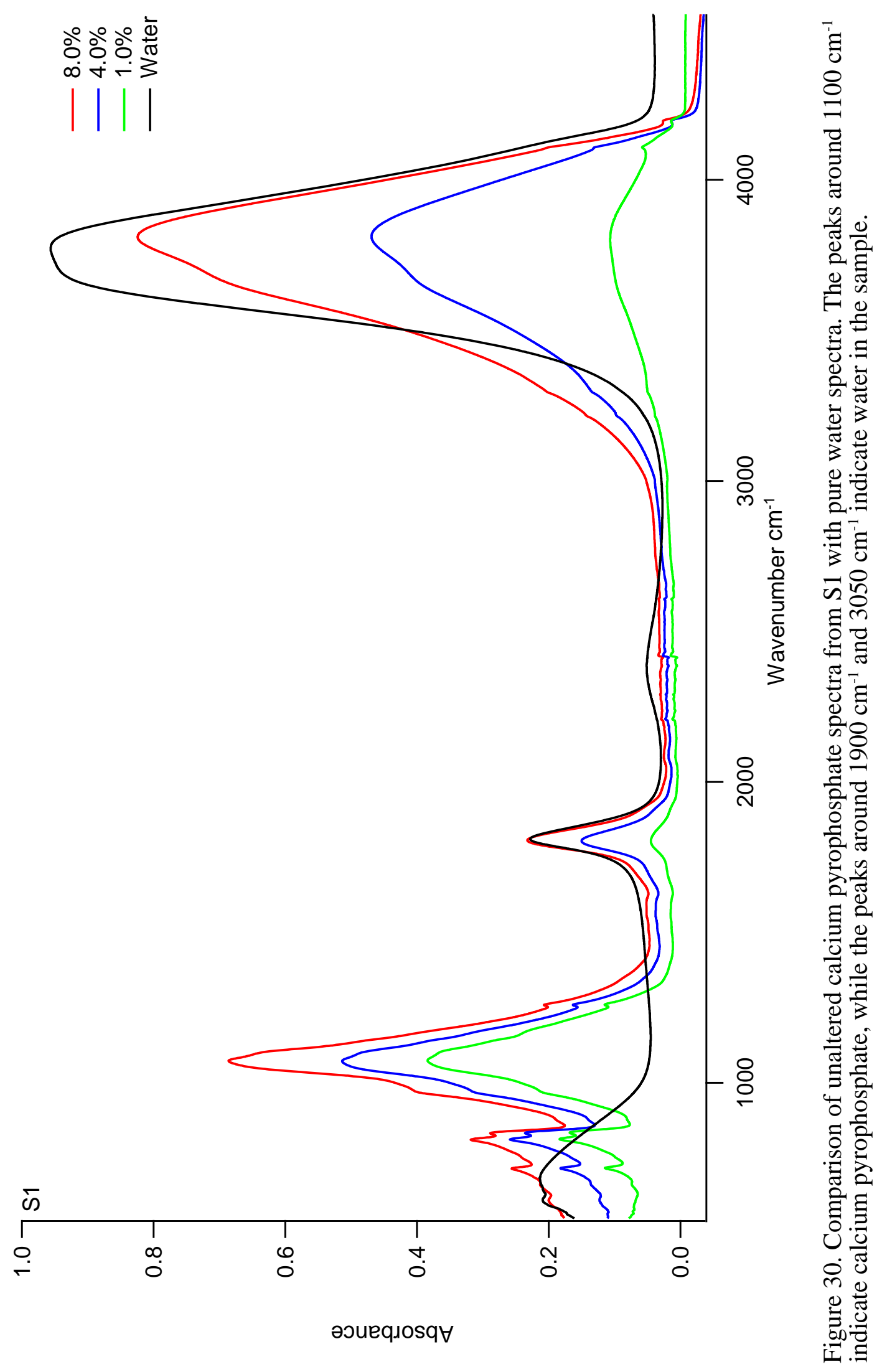




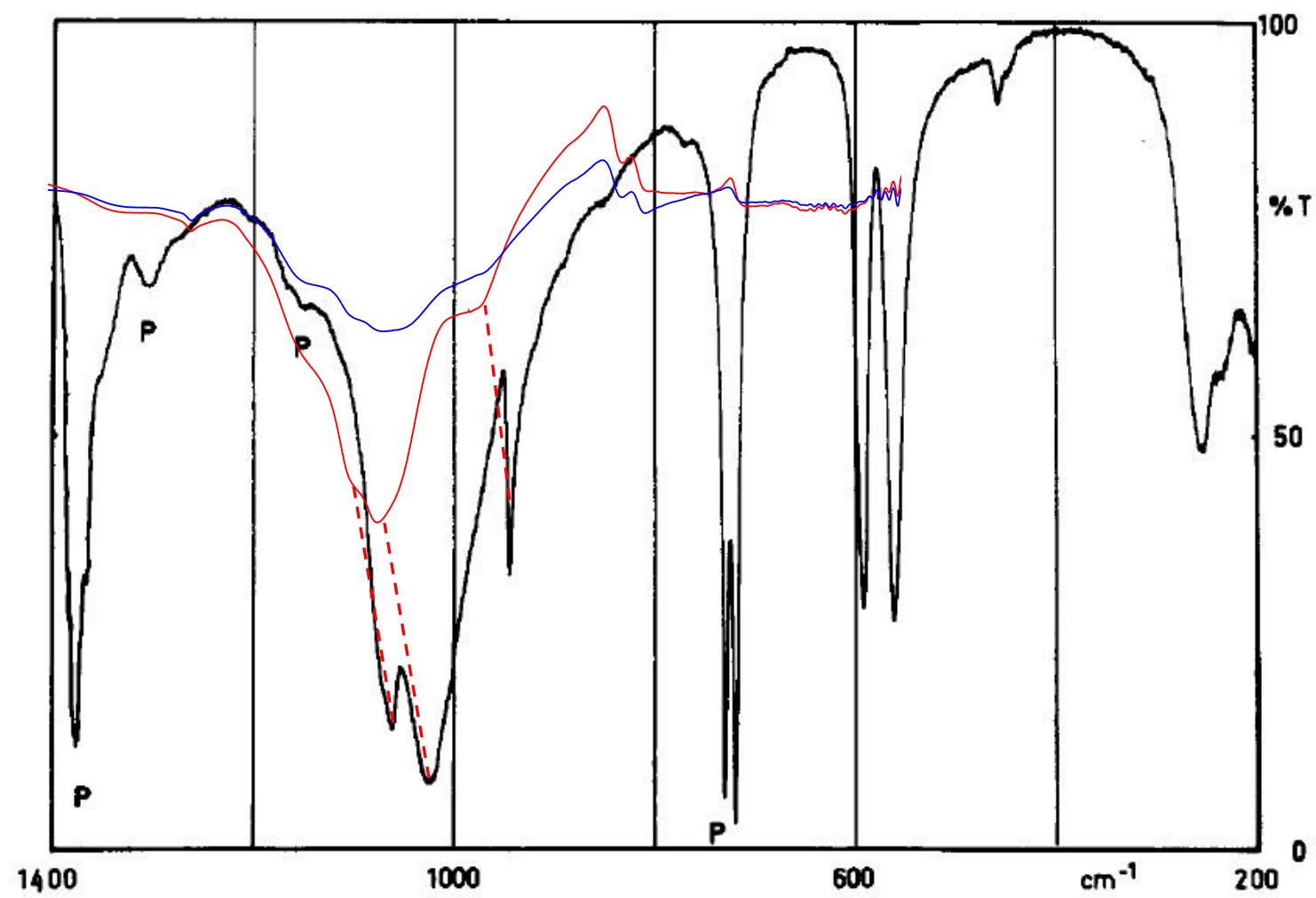

Figure 31. S1 calcium pyrophosphate peaks transposed over Klee's and Engel's (1970) Figure 1. "I.R. spectrum of Sr5(PO4)Br in Nujol-Polyethylene (bands marked with a "P" are polyethylene bands)". It should be noted that peaks have been inverted to show reflectance instead of absorbance, as that is the way they were portrayed by Klee and Engel (1970). The red dashed lines show the comparison between the desiccated samples (Klee and Engel, 1970) and the wet samples (S1 8\% (red) and S1 4\% (blue)). 
decompose during the autolysis stage of decomposition and continues until soft tissues are completely removed from the body during skeletonisation (Dent et al., 2003). The decomposition of fatty tissues may allow for the formation of adipocere in certain environments, such as those of mildly alkaline $\mathrm{pH}$, warm temperatures, and anaerobic conditions (Forbes et al., 2005a,b). Adipocere is primarily hydrogenated saturated and unsaturated fatty acids; it is plausible that oleic and palmitic acid, along with other fatty acids, would be present in both of the human burial analogues in the liquefaction and disintegration stage of decomposition. Even if they began to decompose shortly after death, fatty acids are not water soluble, so they would have a longer residence time in the soil column than other decomposition products. This would allow them to remain detectable by infrared spectroscopy for longer than other decomposition products. The shape of the peaks in the core samples suggest they represent a combination of the two fatty acids tested for, however it is possible that other fatty acids not tested for in this study could have combined with them to distort the peaks. Forbes et al. (2005b) state that adipocere formation creates "a mixture” of saturated (predominately myristic, palmitic, and stearic) and unsaturated (oleic and palmitoleic) fatty acids. It is plausible that any of these fatty acids may be contributing to the composite shape of the core spectra. Core C2 had visible adipocere present at a depth of $10-20 \mathrm{~cm}$ below the surface (Figure 27). In the spectra from $C 2$, the highest peaks are visible at this depth interval and better comparisons can be made between the "adipocere spectra" and the pamitic acid and oleic acid spectra from the Steiner Property samples (Figure 32). The apexes of the C2 peaks are in better alignment with palmitic acid peaks one and three, however the general shape of the limbs are better aligned with the oleic acid spectra. The presence of palmitic acid peaks two and four is not as distinct in the C2 spectra, but there are shoulders in the locations where peaks two and four should be. This evidence suggests that the C2 spectra, 

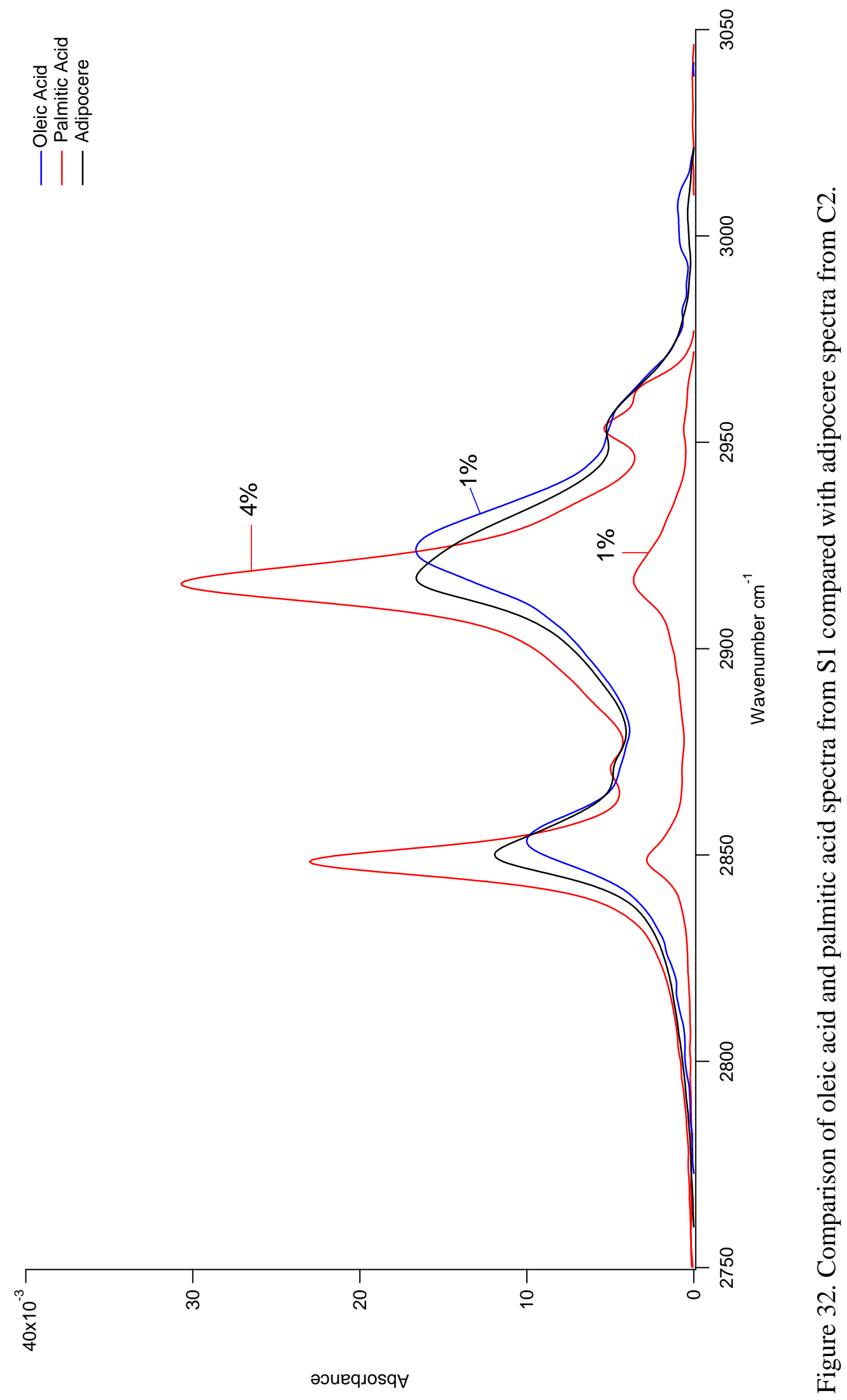
as well as the other core spectra from 2011 and 2015, are combinations of multiple types of fatty acids displayed simultaneously as one composite spectrum.

Additionally, in their study of the effect of soil type on adipocere formation, Forbes et al. (2005b) found that adipocere formed in a primarily clayey soil, like that of the Steiner Property, consisted of $53.3 \%$ palmitic acid and of only $7.8 \%$ oleic acid. This may indicate why the composite peaks in the core spectra more closely resembled the palmitic acid spectra than the oleic acid spectra. However, the adipocere in the clayey soil in Forbes et al. (2005b) study also contained $27.9 \%$ stearic acid; it is also possible that the presence of stearic acid in the core samples could have had more effect in changing the peak shape than the oleic acid did.

The similarity of the fatty acid organic matter results to the fatty acid particle size results may be attributed more to particle size differences than to organic matter differences because of the way in which ATR-FTIR collects data. FTIR results are highly dependent on the quality of the surface of the sample; information will only be collected on the portion of the sample which is in direct optical contact with the crystal window (PerkinElmer, 2005). With soil being a “complex matrix" (Stenberg et al., 2010) this is especially important. Clay particles are very small $(<0.002 \mathrm{~mm})$, and are basically entirely surface area. Conversely, sand particles are much larger $(0.05-2.00 \mathrm{~mm})$ and have much less surface area relative to the size of the particle. If a sample of a clayey soil was put over the window of a spectrometer, the portion of the sample in contact with the window would be virtually all surface; leading to a more accurate reading of the heterogeneity of the soil. But if a sample of a sandy soil was put over the window of a spectrometer, only the portion of the sand grains making contact with the window would interact with the machine; leading to a much less accurate reading of the heterogeneity of the soil, considering the void space between the grains. 
Additionally, a minor component in the soil (i.e. organic matter) could coat the large grains and become pressed between the grains and the collection window, skewing the sample toward a value less representative of the entire sample (Stenberg et al., 2010). Therefore, it may not be the percentage of organic matter which is affecting the differences in detection limits, but the influence of particle size on the organic matter or the size of the organic matter particles themselves. This characteristic may have influenced the $\mathrm{C} 2$ spectral results or may influence the results of the proposed in situ instrument. The adipocere present in core C2 was approximately 2x3 cm in size. When that portion of the soil was pulverized and mixed, the waxy chunk of adipocere prevented the sample from becoming completely homogenous. The adipocere clumped into a mass and some portion may have coated the larger soil granules, allowing them to press more of the adipocere onto the spectral window than was actually representative of the sample. This suggests that when using this method to detect the presence of human remains, fatty acids (and other insoluble products such as calcium pyrophosphate) may only be advantageous if the probe (and therefore spectral window) makes direct contact with a “chunk” of adipocere or other decomposition product; if it does not make direct contact, the instrument may not "see” the adipocere at all. 


\section{CHAPTER V}

\section{CONCLUSIONS}

All four of the decomposition products tested for in this study were detectable by ATR-FTIR methods in samples to which they had been added, however only the two fatty acids were detectable in samples collected from human burial analogues. Particle size and organic matter content did not have any major control over the detection limits

of the four decomposition products. Although leucine detection had a slight relationship with particle size and with organic matter, suggesting better detection with lower clay content and lower organic matter content, neither trend was statistically significant. Calcium pyrophosphate had such high detection limits that it was difficult to determine a relationship between its detection and the different soil conditions. While there was no strong trend between either of the soil conditions and fatty acid detection, there was some similarity between the plots of fatty acid detection limits against particle size (clay content) and fatty acid detection limits against organic matter content. This may be attributed to the way in which the FTIR method collects information solely from the surface of the sample, therefore relying on the size of the individual mineral and organic matter particles.

The detection limits of leucine and calcium pyrophosphate $(0.4 \%$ and $4.0 \%$ respectively) were too high to adequately distinguish the presence of either product in samples containing only trace amounts. Nitrogen-based leucine leaves the carcass in an early stage of decomposition and has a short residence time in the soil column due to its solubility in water; any leucine left behind in the samples from the human burial 
analogues of this study would presumably have only been in trace amounts. Phosphorousbased calcium pyrophosphate is not released from the bones of a carcass until the end stage of decomposition; any trace amounts of calcium pyrophosphate that may have been present in the human burial analogue samples of this study were most likely less than 4.0\%, and therefore undetectable by these methods.

Both oleic and palmitic acid were detectable to much lower concentrations than the other two decomposition products, oleic acid ranging from $0.1 \%-0.01 \%$, and palmitic acid ranging from $1.0 \%-0.01 \%$. Additionally, either oleic acid or palmitic acid, or possibly both, were present in some of the samples taken from each of the human burial analogues. In the sample with visible adipocere, there were peaks in the spectra indicative of approximately $1.0 \%$ oleic acid and/or $1.0-4.0 \%$ palmitic acid. While the fatty acid peaks present were composite peaks indicative of several fatty acids, it is very likely that palmitic acid and oleic acid were among the fatty acids present, due to the shape of the peaks. The core's peak apexes were closely aligned with the palmitic acid peak apexes from the samples with known concentrations, suggesting the presence of palmitic acid; but the core's peak limbs followed more closely to the oleic acid peaks from the samples with known concentrations, suggesting the presence of oleic acid as well.

The results from this study suggest that fatty acids will be beneficial decomposition products for further research by the S4 Initiative in their pursuit to create a geochemical instrument for subsurface prospection and characterization of soil conditions in an archaeological and forensic context. A specific area to investigate in a future project is the effect of water on the detectability of the fatty acids, or other decomposition products. All of the samples in this study were allowed to air-dry, however in situ soil has a certain amount of water present within it. As demonstrated by the calcium pyrophosphate spectra in this study, water alters the shape as well as the location of diagnostic peaks in the 
spectra. It would be beneficial to know how the spectral peaks are altered by different moisture contents in the samples.

In addition to differing water contents, it would be advantageous to study the effects of soil $\mathrm{pH}$ on the detectability of human decomposition products. The $\mathrm{pH}$ of a soil would influence the type of organisms present in the soil, therefore having an influence over the rate of decomposition and potentially the type of decomposition compounds produced. Forbes et al. (2005a) stated, "The mildly alkaline pH of the soil [used in this study] would have been ideal for the survival and proliferation of destructive bacteria which would subsequently encourage decomposition of the adipose tissue.” The three soils tested in this study were of a near-neutral pH, including the Steiner Property where the 2015 cores and subsequent adipocere in core C2 were extracted. If the soil had contained a more alkaline $\mathrm{pH}$, the results from Forbes et al. (2005a) suggest it would have allowed for a more substantial formation of adipocere, and therefore a more evident detection of fatty acids. Within a study on the effect of soil $\mathrm{pH}$ on the detectability of fatty acids, one may also want to consider the specific bacteria involved in the decomposition processes; how they differ and how they influence the entire human decomposition process.

Perhaps the most challenging area of future research for the S4 Initiative will be the effect of time over the detectability of the decomposition products. The pigs used in this study were allowed to decompose over a relatively short time span of nine months. This leaves behind questions such as: How long will the fatty acids remain detectable using this method? Will the fatty acids break down into further compounds that will be undetectable by this method? How will the results be affected by a cadaver that has been decomposing for much longer than nine months? A potential study could involve a pig burial that is revisited over a longer time span than nine months. Perhaps cores could periodically be taken in transects away from the carcass over a longer time period, such 
as a few years. This would allow the researchers to study how mobile the decomposition products are over time and how long they remain detectable within the soil. 


\section{REFERENCES}

Aleese, L.M., A. Simon, T.B. McMahon, J. Ortega, D. Scuderi, J. Lemaire, P. Maître. 2006. Mid-IR spectroscopy of protonated leucine methyl ester performed with an FTICR or a Paul type ion-trap. Mass Spectrometry 249-250, 14-20.

Anderson, J.B. 1996. Calcium, phosphorus and human bone development. The Journal of Nutrition 126, 1153S-1158S.

Beasley, M.M., E.J. Bartelink, L. Taylor, R.M. Miller. 2014. Comparison of transmission FTIR, ATR, and DRIFT spectra: Implications for assessment of bone bioapatite diagenesis. Journal of Archaeological Science 46, 16-22.

Bellon-Maurel, V. and A. McBratney. 2011. Near-infrared (NIR) and mid-infrared (MIR) spectroscopic techniques for assessing the amount of carbon stock in soils - Critical review and research perspectives. Soil Biology \& Biochemistry 43, 1398-1410.

Buol, S.W., R.J. Southard, R.C. Graham, P.A. McDaniel. 2003. "Soil Genesis and Classification $5^{\text {th }}$ ed.” Iowa State Press, Ames.

Burt, R., and S. S. Staff. 2014. "Kellogg Soil Survey Laboratory Methods Manual.” Natural Resources Conservation Services. National Soil Survey Center, Lincoln, Nebraska.

Buse, M.G. and S.S. Reid. 1975. A possible regulator of protein turnover in muscle. The Journal of Clinical Investigation 56, 1250-1261.

Carter, D.O., D. Yellowlees, M. Tibbett. 2008. Using ninhydrin to detect gravesoil. Journal of Forensic Sciences 53, 397-400.

Caswell, A., D.F. Guilland-Cumming, P.R. Hearn, M.K.B. McGuire, R. R. G. Russell. 1983. Pathogenesis of chondrocalcinosis and pseudogout. Metabolism of inorganic pyrophosphate and production of calcium pyrophosphate dehydrate crystals. Annals of the Rheumatic Diseases 42, 27S-37S.

Chang, C., D. Laird, M. Mausbach, C.R. Hurburgh Jr. 2001. Near-Infrared reflectance spectroscopy-principal components regression analyses of soil properties. Soil Science Society of America Journal 65, 480-490.

Chang, R. and J. Thoman. 2014. "Physical Chemistry for the Chemical Sciences." University Science Books, Canada. 
Chumanov, G.D., R.G. Efremov, I.R. Nabiev. 2005. Surface-enhanced Raman spectroscopy of biomolecules. Part I. - water-soluble proteins, dipeptides, and amino acids. Journal of Raman Spectroscopy 21, 43-48.

Dent, B.B., S.L. Forbes, B.H. Stuart. 2003. Review of human decomposition processes in soil. Environmental Geology 45, 576-585.

Evans, W.E.D. 1963. "The chemistry of death.” Thomas, Springfield.

Forbes, S.L., B.H. Stuart, B.B. Dent. 2005a. The effect of the burial environment on adipocere formation. Forensic Science International 154, 24-34.

Forbes, S.L., B.H. Stuart, B.B. Dent. 2005b. The effect of soil type on adipocere formation. Forensic Science International 154, 35-43.

Fuller, M.P., and P.R. Griffiths. 1978. Diffuse reflectance measurements by infrared Fourier transform spectrometry. Analytical Chemistry 50, 1906-1910.

Garlick, P.J. 2005. The role of leucine in the regulation of protein metabolism. American Society for Nutritional Sciences 05, 0022-3166.

Griffths, P.R. 1983. Fourier transform infrared spectrometry. Science, New Series 222, 297-302.

Guo, Z., W. Zhu, H. Tian. 2010. Hydrophilic copolymer bearing dicyanomethylene4H-pyran moiety as fluorescent film sensor for $\mathrm{Cu}^{2+}$ and pyrophosphate anion. Macromolecules 43, 739-744.

Higgins, I.J. and R. G. Burns. 1975. "The chemistry and microbiology of pollution.” Academic Press, London.

Janaway, R.C., S.L. Percival, A.S. Wilson. 2009. “Decomposition of Human Remains,” In Microbiology and Aging, edited by S.L. Percival, 313-334. Springer Science + Business Media, LLC.

Janik, L.J., R.H. Merry, J.O. Skjemstad. 1998. Can mid infrared diffuse reflectance analysis replace soil extractions? Aust. J. Exp. Agric. 38, 681-696.

Janitzky, P. 1986. "Particle-Size Analysis" In "Field and Laboratory Procedures Used in a Soil Chronosequence Study,” 1986, edited by Michael J. Singer and Peter Janitzky, 1116. U.S. Geological Survey Bulletin 1648.

Jenny, H. 1941. "Factors of Soil Formation: A System of Quantitative Pedology.” McGraw-Hill, New York.

Kelly, R.L. and D.H. Thomas. 2013. “Archaeology $6^{\text {th }}$ ed.” Wadsworth, Cengage Learning.

Klee, W.E. and G. Engel. 1970. I.R. spectra of the phosphate ions in various apatites. Journal of Inorganic and Nuclear Chemistry 32, 1837-1843. 
Leifeld, J. 2006. Application of diffuse reflectance FT-IR spectroscopy and partial leastsquares regression to predict NMR properties of soil organic matter. European Journal of Soil Science 57, 846-857.

Little, D.P., J.P. Speir, M.W. Senko, P.B. O’Connor, F.W. McLafferty. 1994. Infrared multiphoton dissociation of large multiply charged ions for biomolecule sequencing. Analytical Chemistry 66, 2809-2815.

Matney, T., L.R. Barrett, M.B. Dawadi, D. Maki, C. Maxton, D.S. Perry, D.C. Roper, L. Somers, L.G. Whitman. 2014. In situ shallow subsurface reflectance spectroscopy of archaeological soils and features: A case-study of two Native American settlement sites in Kansas. Journal of Archaeological Science 43, 315-324.

Morgan, C.L.S, T.H. Waiser, D.J. Brown, C.T. Hallmark. 2009. Simulated in situ characterization of soil organic and inorganic carbon with visible near-infrared diffuse reflectance spectroscopy. Geoderma 151, 249-256.

Morgan, H.E., D.C.N. Earl, A. Broadus, E.B. Wolpert, K.E. Giger, and L.S. Jefferson. 1971. Regulation of protein synthesis in heart muscle. The Journal of Biological Chemistry 246, 2152-2162.

Nelson, D.W. and Sommers, L. 1982. Total carbon, organic carbon, and organic matter. Methods of soil analysis. Part 2. Chemical and microbiological properties, (methodsofsoilan2), 539-579.

Notter, S.J., B.H. Stuart, R. Rowe, N. Langlois. 2009. The initial changes of fat deposits during the decomposition of human and pig remains. Journal of Forensic Science 54, 195-201.

PerkinElmer Life and Analytical Sciences. 2005. "FT-IR Spectroscopy Attenuated Total Reflectance (ATR) Technical Note.” Shelton, CT: PerkinElmer, Inc.

Reeves, J. B. 2010. Near- versus mid-infrared diffuse reflectance spectroscopy for soil analysis emphasizing carbon and laboratory versus on-site analysis: Where are we and what needs to be done? Geoderma 158, 3-14.

Rey, C., M. Shimizu, B. Collins, M.J. Glimcher. 1990. Resolution-enhanced Fourier transform infrared spectroscopy study of the environment of phosphate ion in the early deposits of a solid phase of calcium phosphate in bone and enamel and their evolution with age: 2. Investigations in the $\mathrm{v}_{3} \mathrm{PO}_{4}$ domain. Calcified Tissue International 49, 383388.

Raubenstraw, T. 2014. "An Investigation into the Detection Limit of Palmitic Acid in Soil using Attenuated Total Reflectance-Fourier Infrared Spectroscopy (ATR-FTIR)" Unpublished Honors Thesis. The University of Akron, Akron.

Reynold, A.E. and G.F. Cahill. 1965. "Handbook of physiology: Adipose tissue.” American Physiological Society, Washington.

Ryan, L.M. and D.J. McCarty. 1995. Understanding inorganic pyrophosphate metabolism: Toward prevention of calcium pyrophosphate dehydrate crystal deposition. Annals of the Rheumatic Diseases 54, 939-941. 
Schaetzl, R.J. and S. Anderson. 2005. “Soils: Genesis and Geomorphology.” Cambridge University Press, Cambridge.

Schoeneberger, P.J., D.A. Wysocki, E.C. Benham, and Soil Survey Staff. 2012. "Field book for describing and sampling soils, Version 3.0." Natural Resources Conservation Service, National Soil Survey Center, Lincoln, NE.

Stein, W.H. and S. Moore. 1954. The free amino acids of human blood plasma. The Journal of Biological Chemistry 211, 915-926.

Stenberg, B. 2010. Effects of soil sample pretreatments and standardised rewetting as ineracted with sand classes on Vis-NIR predictions of clay and soil organic carbon. Geoderma 158, 15-22.

Stenberg, B., R.A. Viscarra Rossel, A. Mounem Mouazen, J. Wetterlind. 2010. Visible and near infrared spectroscopy in soil science. In Donald L. Sparks, editor: Advances in Agronomy, Vol. 107, Burlington: Academic Press, 2010, pp. 163-215.

Stokes, K.L., S.L. Forbes, L.A. Benninger, D.O. Carter, M. Tibbett. 2009.

"Decomposition studies using animal models in contrasting environments: Evidence from temporal changes in soil chemistry and microbial activity,” In Ritz, K., L. Dawson, D. Miller, Criminal and Environmental Soil Forensics (pp. 357-377). Springer Science + Business Media B.V.

Stuart, B.H., S. Forbes, B.B. Dent, G. Hodgson. 2000. Studies of adipocere using diffuse reflectance infrared spectroscopy. Vibrational Spectroscopy 24, 233-242.

Swann, L.M., S.L. Forbes, S.W. Lewis. 2010. Analytical separations of mammalian decomposition products for forensic science: A review. Analytica Chimica Acta 682, $9-22$.

Thermo Fisher Scientific. 2016. iD5 ATR Accessory for the NicoletTM iS5 Spectrometer. Thermo Fisher Scientific Inc. $<<$ https://www.thermofisher.com/order/catalog/product/ IQLAADGAAGFAJAMAYY>> Accessed July 1, 2016.

Tibbett, M. and D.O. Carter. 2009. "Research in forensic taphonomy: A soil-based perspective,” In Ritz, K., L. Dawson, D. Miller, Criminal and Environmental Soil Forensics (pp. 317-332). Springer Science + Business Media B.V.

Ubelaker, D.H. and K.M. Zarenko. 2011. Adipocere: What is known after over two centuries of research. Forensic Science International 208, 167-172.

Van Slyke, D.D. and G.M. Meyer. 1912. The amino-acid nitrogen of the blood. Preliminary experiments on protein assimilation. The Journal of Biological Chemistry 12, 399-410.

Viscarra Rossel, R.A., D.J.J. Walvoort, A.B. McBratney, L.J. Janik, J.O. Skjemstad. 2006. Visible, near infrared, mid infrared or combined diffuse reflectance spectroscopy for simultaneous assessment of various soil properties. Geoderma 131, 59-75.

White, E., and L. Hannus. 1983. Chemical weathering of bone in archaeological soils. American Antiquity 48, 316-322. 
APPENDICES 


\section{APPENDIX A}

\section{FAT_ABS ROUTINE}

Macro Routine: Fat_abs

\#include $<$ Multi-peak fitting 1.4>

Function Fat_abs (spec)

// The function assumes that data are in the wave "spec" SCALED in wavenumbers (cm-1) and that

// another similarly scaled wave "mask_wave" contains 1's in the regions to be fit to a baseline and zeros elsewhere.

// The waves "wfrom" and "wto" contain the beginning and ending wavenumbers of the peaks to be integrated.

// The output peak areas are put into a new row of the 2-D array "peakareas". The columns of "peakareas" correspond to the spectral

// intervals defined in the rows of "wfrom" and "wto".

// The wave "spec_names" contains the wave names corresponding to the row of "peakareas" and also the time and date at which the peakareas were computed..

wave spec //input wave name with spectrum to be analyzed, The wave scaling for "spec" must be set appropriately. NO x/y data!

string b1, b2, b3

wave wfrom, wto, peakareas, mask_ave

wave /T spec_names

variable npeaks, index,i,xfrom,xto

npeaks $=$ numpnts $($ wfrom $)$

If (npeaks!=numpnts(wfrom))

// number of peaks to be measured

endif

print "mERROR: mismatch in dimensions of wfrom and wto"

// This section prepares the waves that will contain the results.

If (WaveExists(peakareas))

index=DimSize(peakareas, 0 )

// index $=$ index +1

//print "index", index

redimension/ $\mathrm{N}=($ index $+1,-1)$ peakareas // add an extra row to "peakareas"

for the current spectrum.

redimension/ $\mathrm{N}=($ index +1$)$ spec_names

else

make $/ \mathrm{N}=(1$,npeaks) peakareas

// create the 2-D wabe "peak- 
areas" if it does not already exist

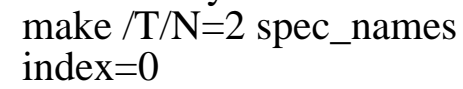
index $=0$

Endif

spec_names[index]=NameOfWave(spec)+" "+time()+", "+date() // add the name of the current spectrum to the list of analyzed sprectra

// print "index", index

// The following parts prepare the wave that will contian the intermediate results.

b1=NameOfWave(spec)+"_baseline" // set up a wave for the fitted baseline with name "spec_baseline"

Duplicate/O spec \$b1

Wave $\mathrm{wb} 1=\$ \mathrm{~b} 1$

$\mathrm{wb} 1=0$

b2=NameOfWave(spec)+" flat" // set up a wave for the baseline-flattened spectrum with name "spec flat"

Duplicate/O spec $\$ \bar{b} 2$

Wave wb2 $=\$ b 2$

$\mathrm{wb} 2=0$

b3=NameOfWave(spec)+"_integral" // set up a wave for the integrated

spectrum with name "spec_integral"

Duplicate/O spec \$b3

Wave $\mathrm{wb} 3=\$ \mathrm{~b} 3$

$\mathrm{wb} 3=0$

//print NameOfWave(spec), b1, b2, b3

// The following lines comprise the actual calculations. nomial

CurveFit /Q poly 10, spec /M=mask_ave // fit the baseline to a 10th order poly-

$\mathrm{wb} 1=\mathrm{K} 0+\mathrm{K} 1{ }^{*} \mathrm{x}+\mathrm{K} 2{ }^{*} \mathrm{x}^{\wedge} 2+\mathrm{K} 3{ }^{*} \mathrm{x}^{\wedge} 3+\mathrm{K} 4{ }^{*} \mathrm{x}^{\wedge} 4+\mathrm{K} 5{ }^{*} \mathrm{x}^{\wedge} 5+\mathrm{K} 6{ }^{*} \mathrm{x}^{\wedge} 6+\mathrm{K} 7{ }^{*} \mathrm{x}^{\wedge} 7+\mathrm{K} 8 * \mathrm{x}^{\wedge} 8$

$+\mathrm{K} 9 * \mathrm{x}^{\wedge} \mathrm{9} / /$ calculate the baseline $\mathrm{wb} 2=\operatorname{spec}(\mathrm{x})-\mathrm{wb} 1(\mathrm{x}) / /$ compute spectrum with flattened baseline

line integrate $w b 2 / D=\$ b 3 / /$ compute the integral of the spectrum with flattened base-

$\mathrm{i}=0$

Do

xfrom $=$ wfrom $[\mathrm{i}]$

xto $=$ wto[i $]$

//print i, xfrom, xto,wb3(xfrom),wb3(xto),wb3(xto)-wb3(xfrom)

peakareas[index][i]=wb3(xto)-wb3(xfrom) // calc the area of each peak

as difference between relevant points in "spec_integral"

$\mathrm{i}+=1$

while $(\mathrm{i}<$ npeaks)

end 


\section{APPENDIX B}

\section{LEUCINE PEAKS}
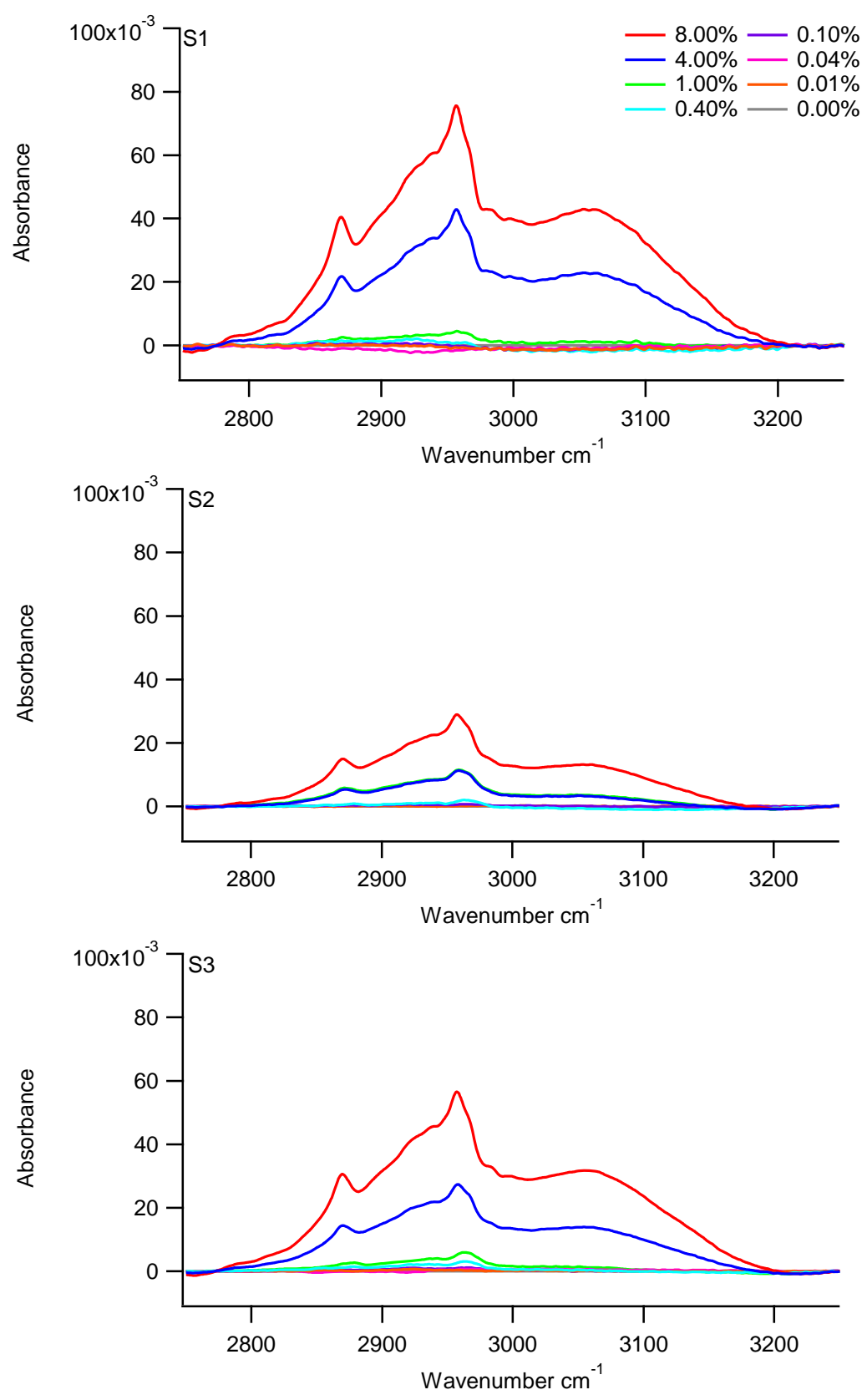

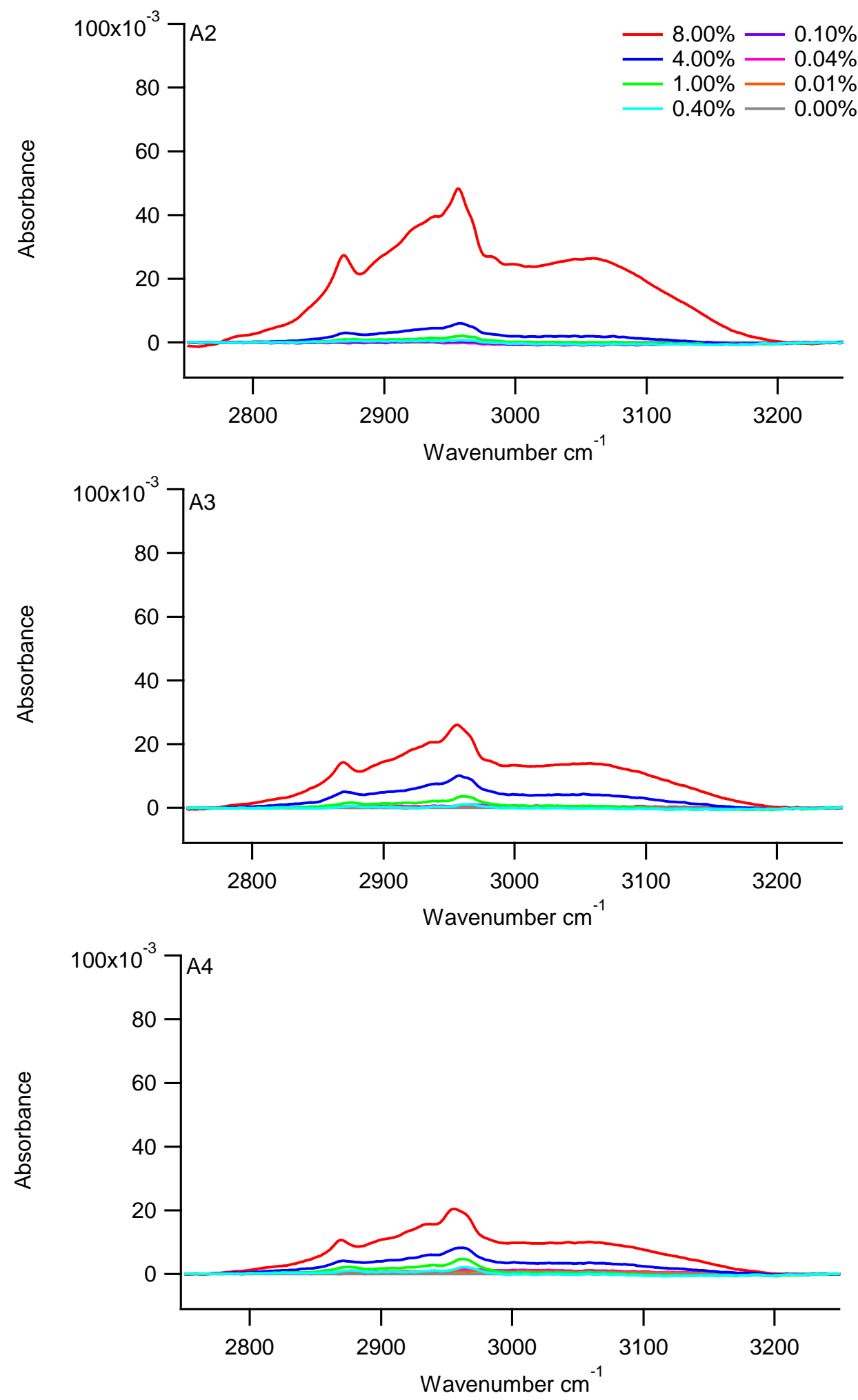

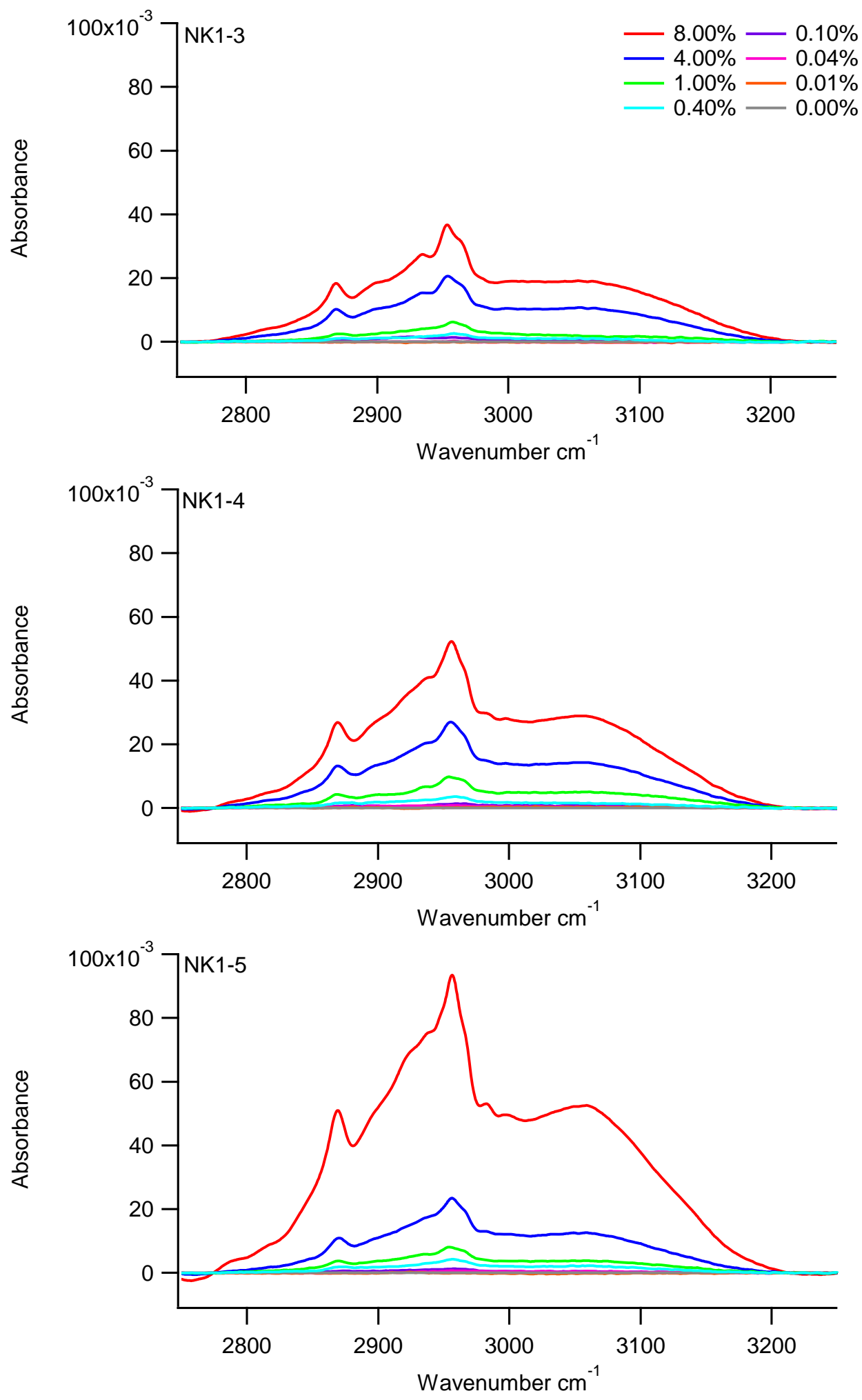


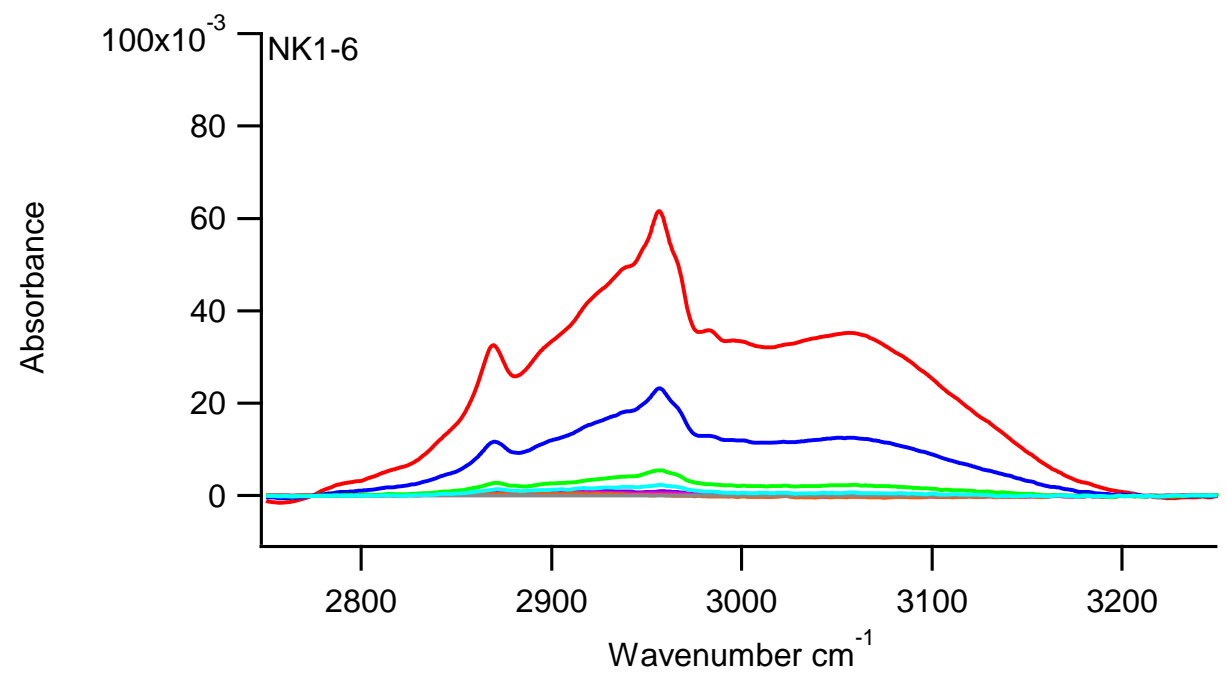




\section{APPENDIX C}

\section{CALCIUM PYROPHOSPHATE PEAKS}
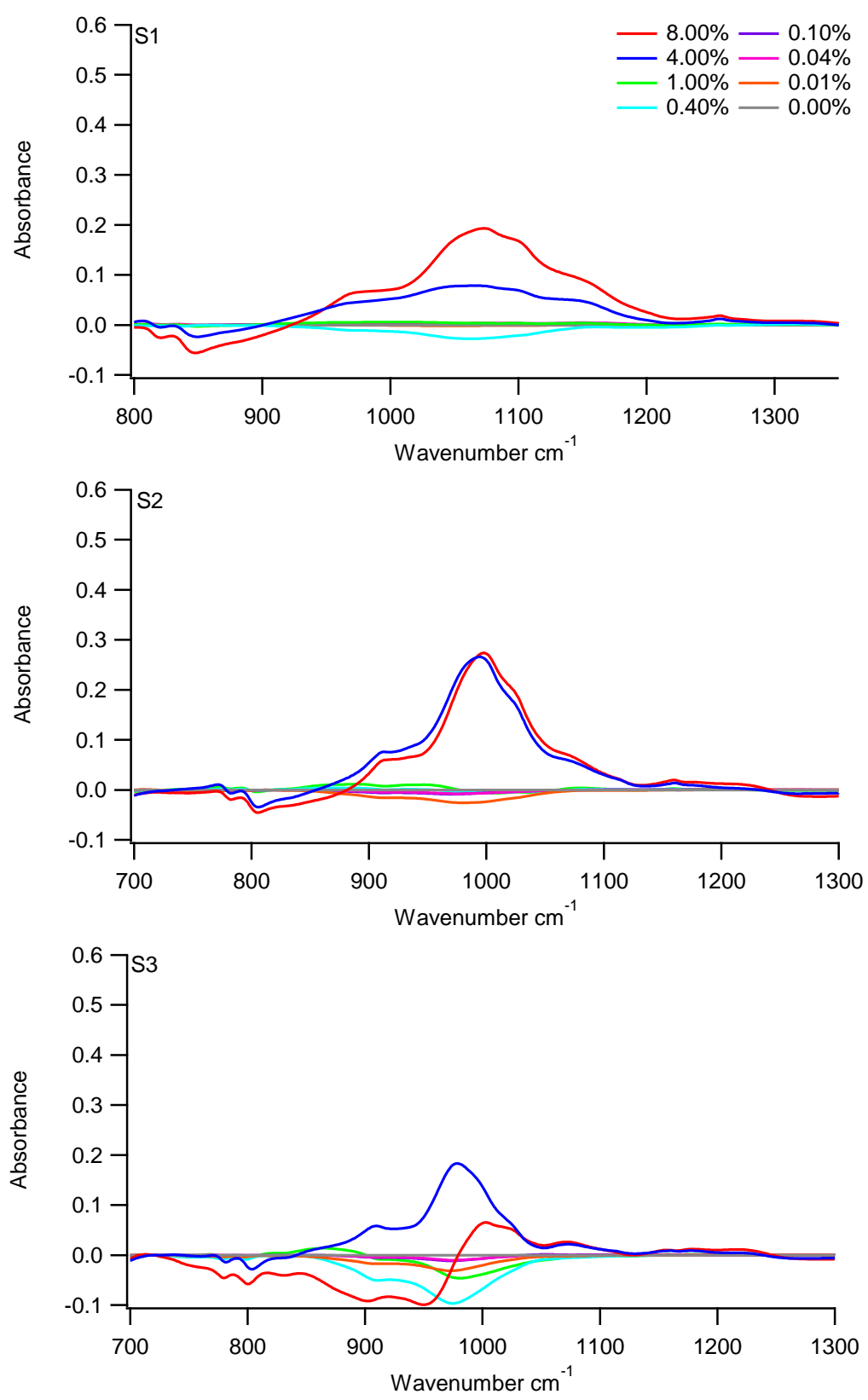

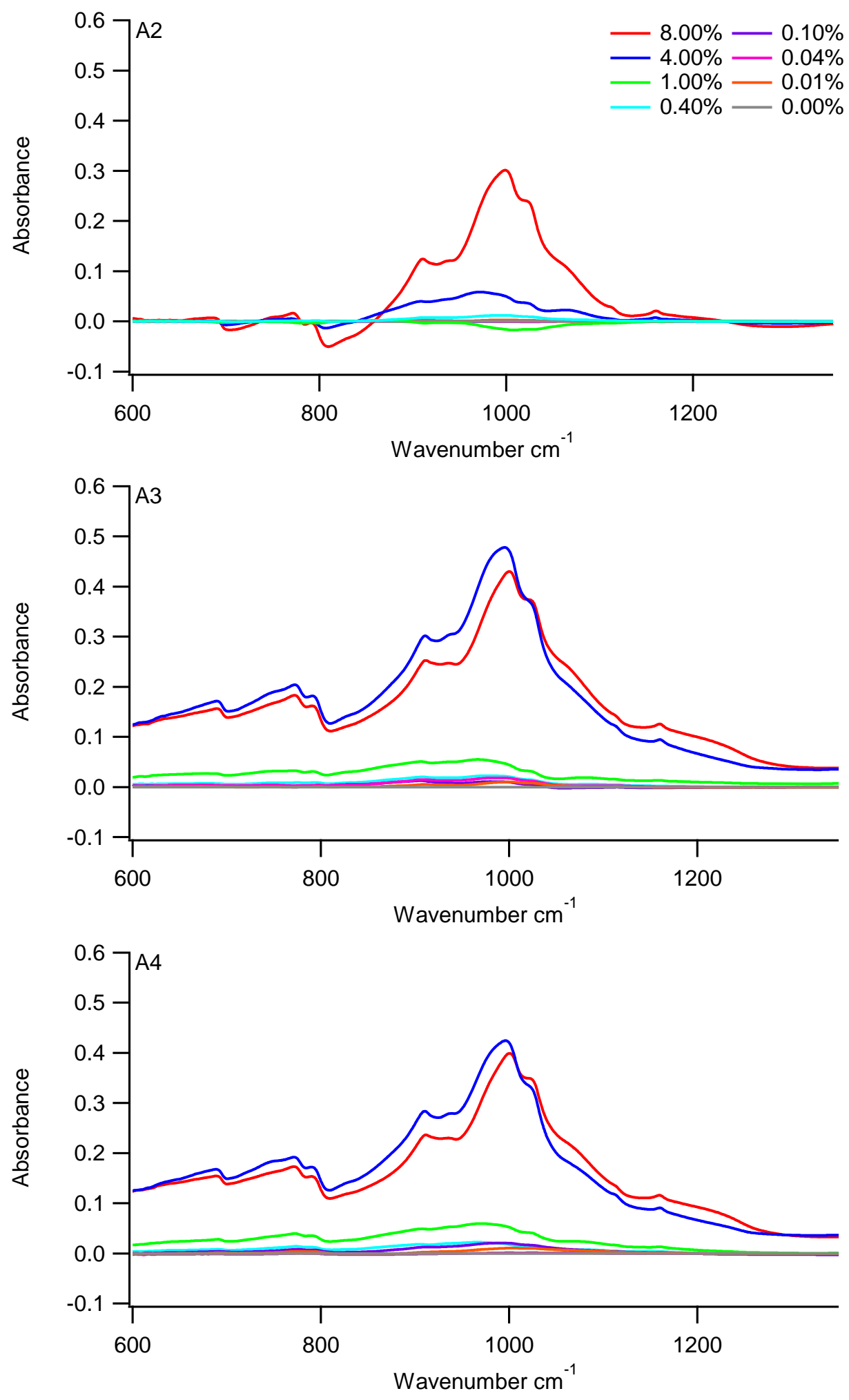

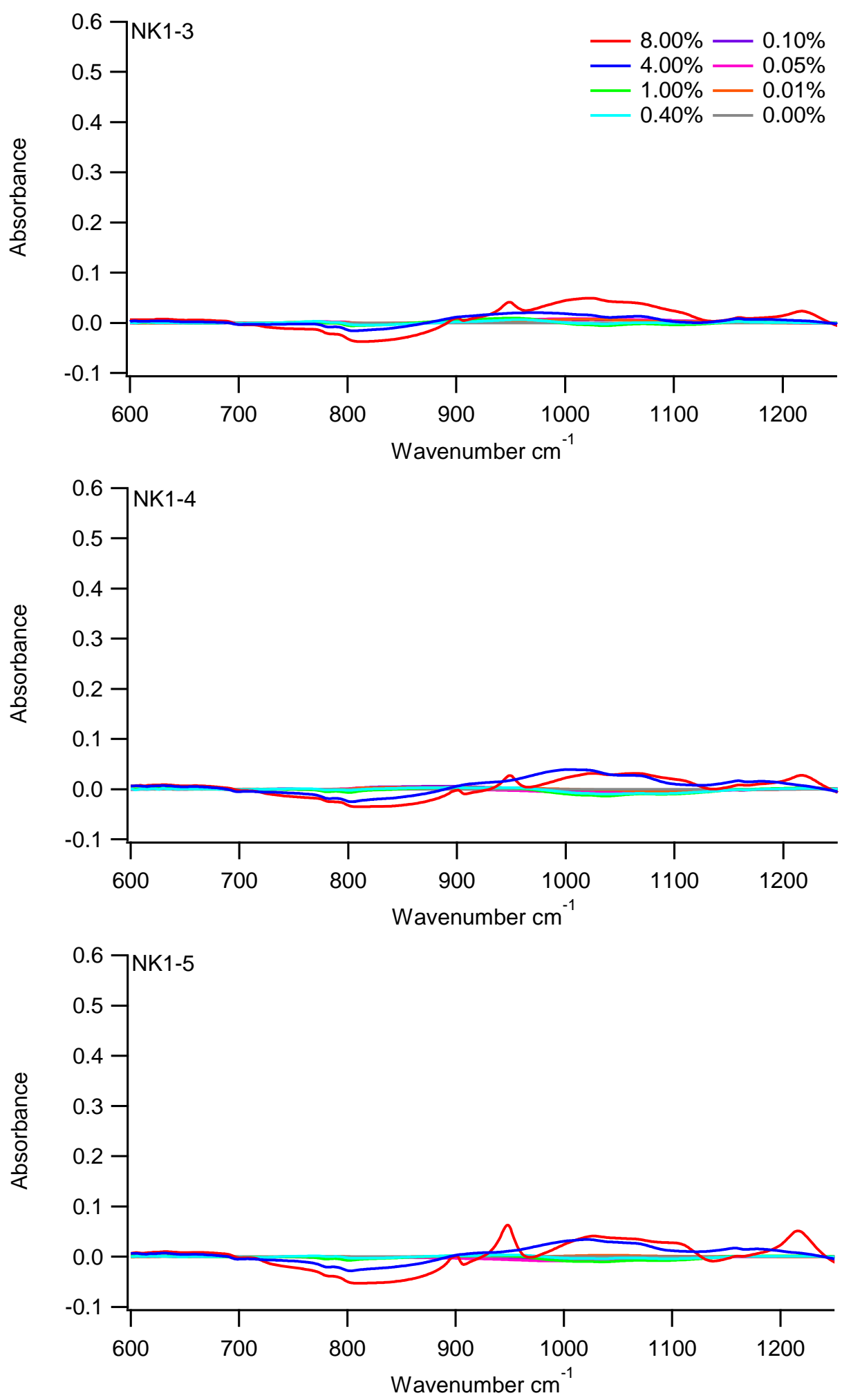


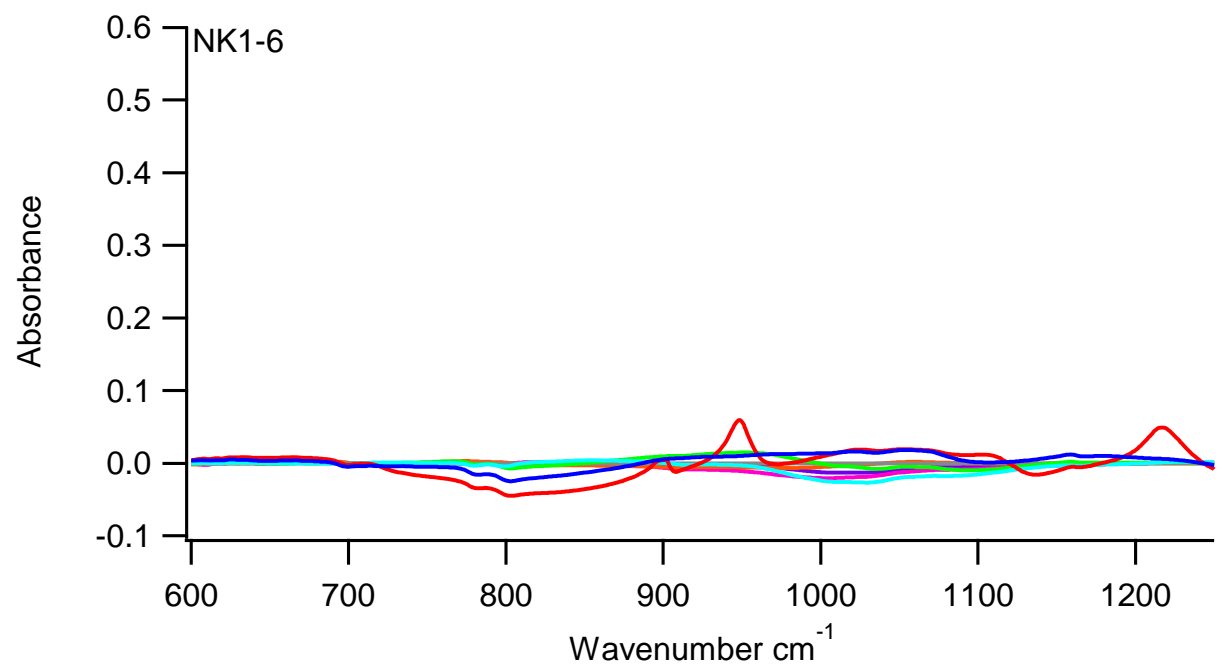




\section{APPENDIX D}

\section{OLEIC ACID PEAKS}
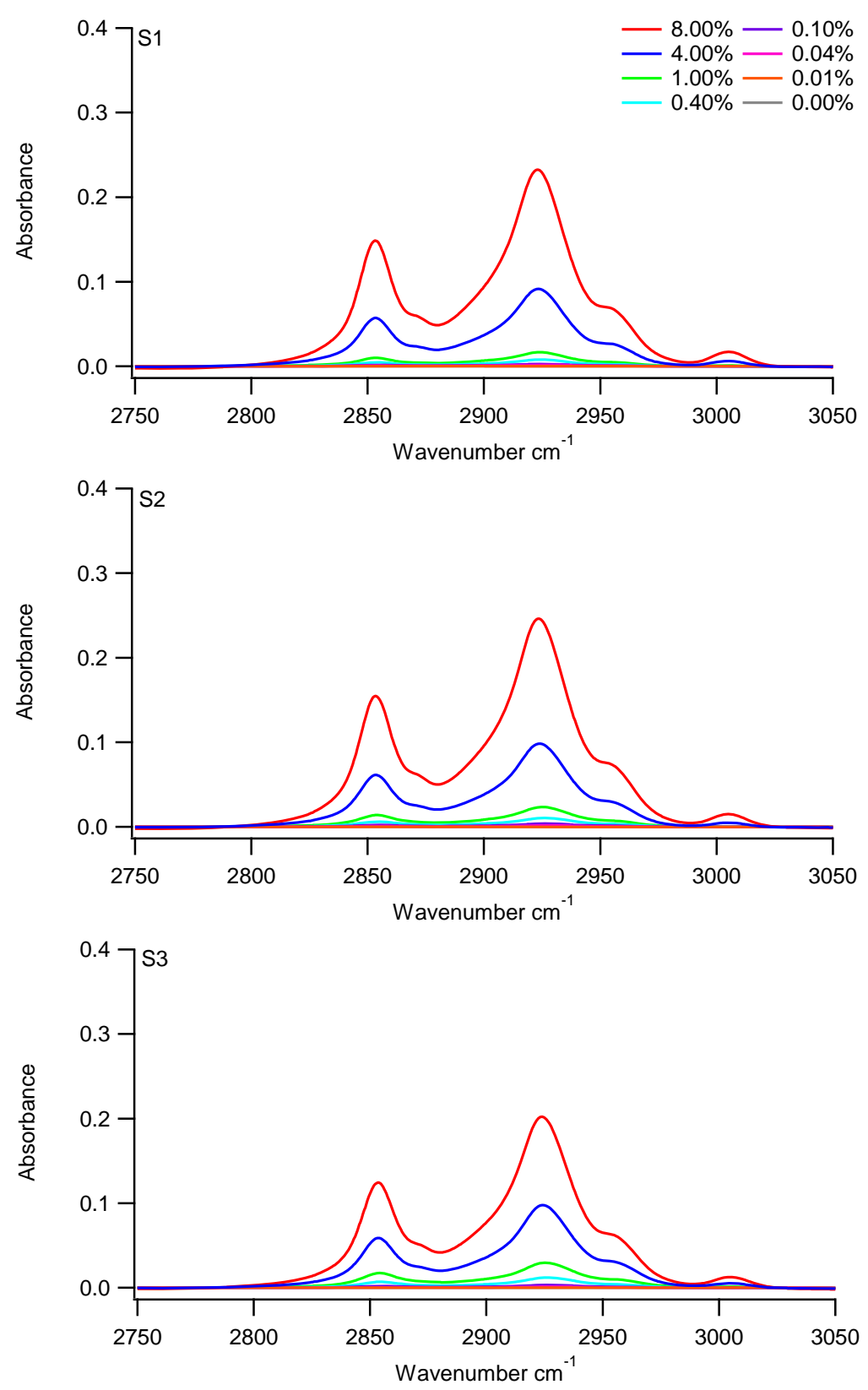

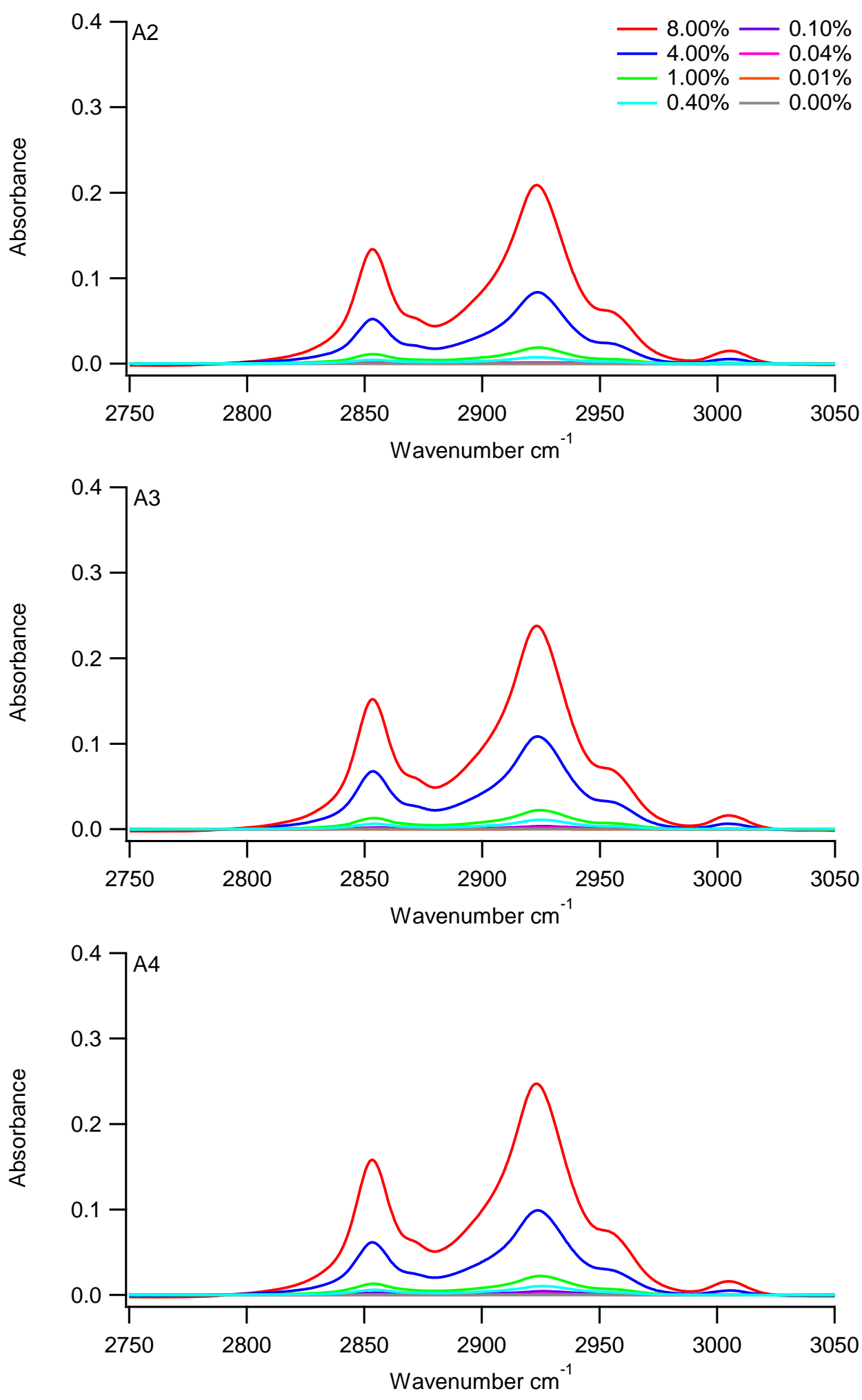

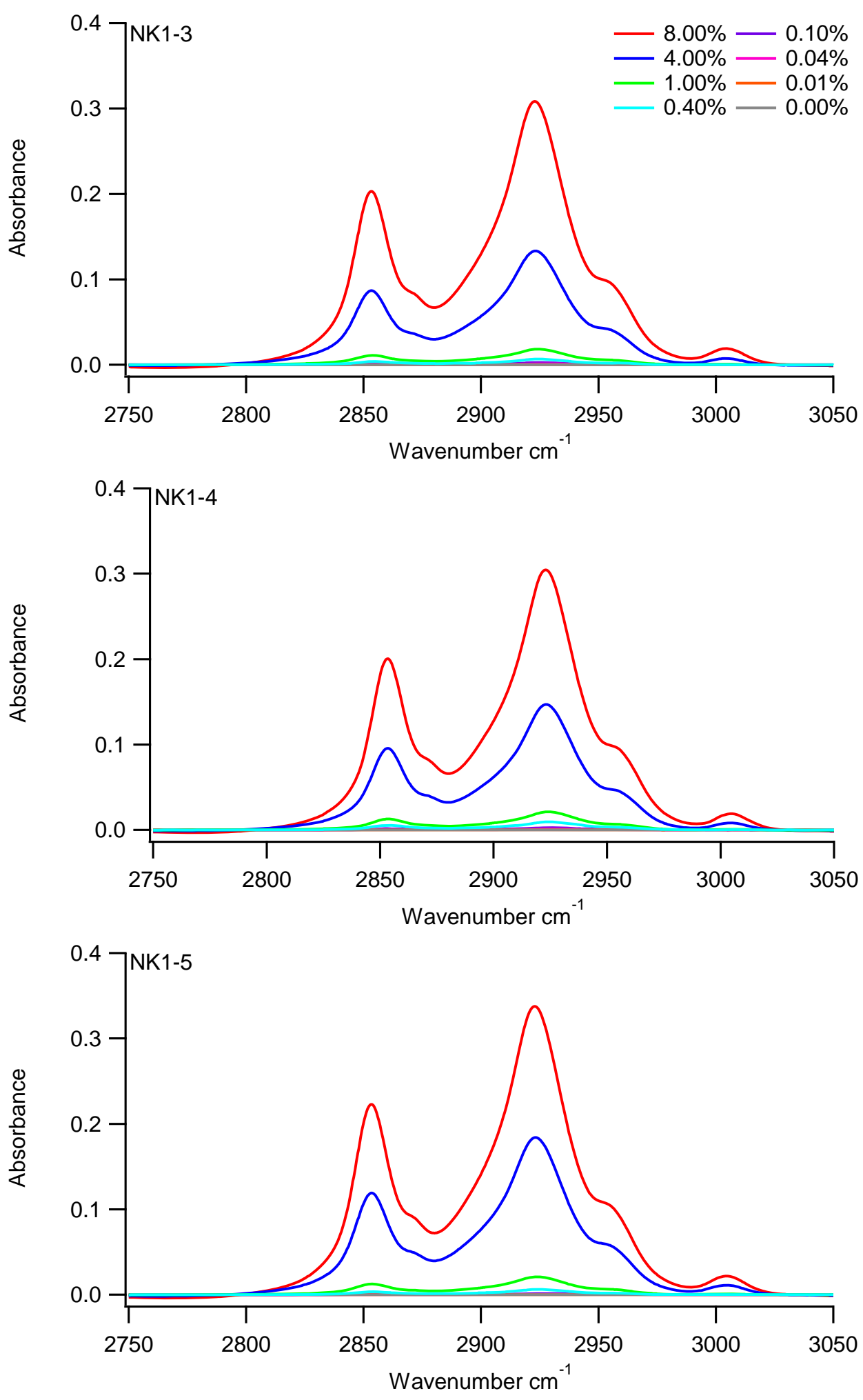


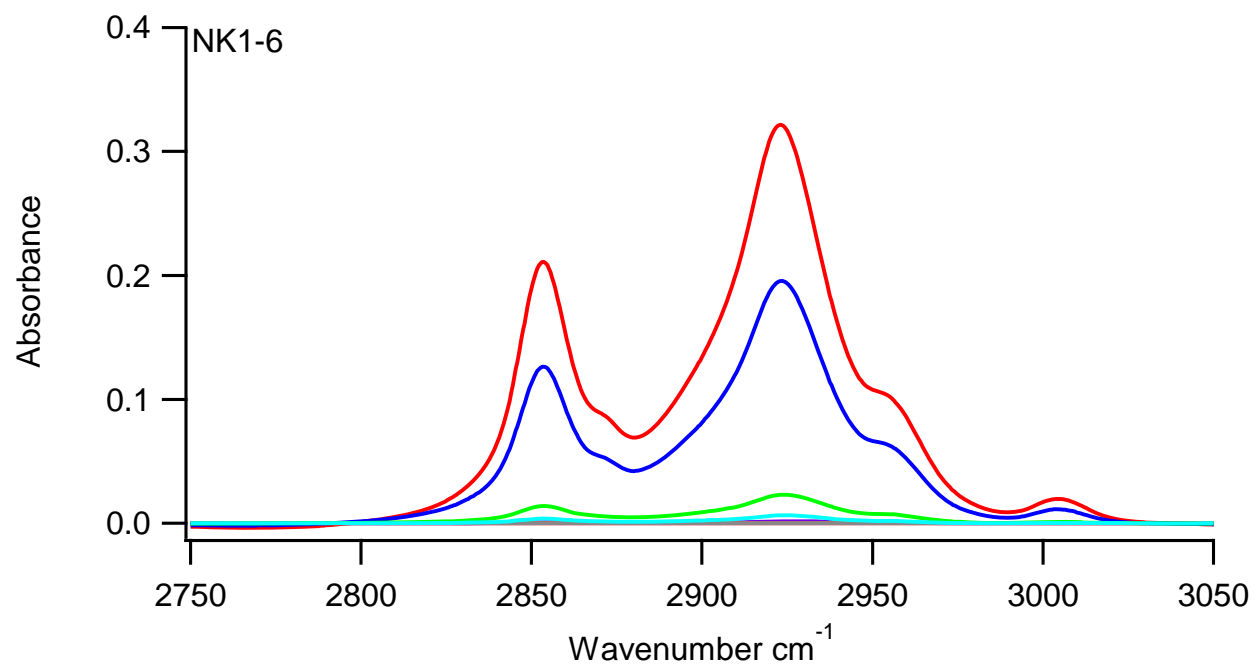




\section{APPENDIX E}

\section{PALMITIC ACID PEAKS}
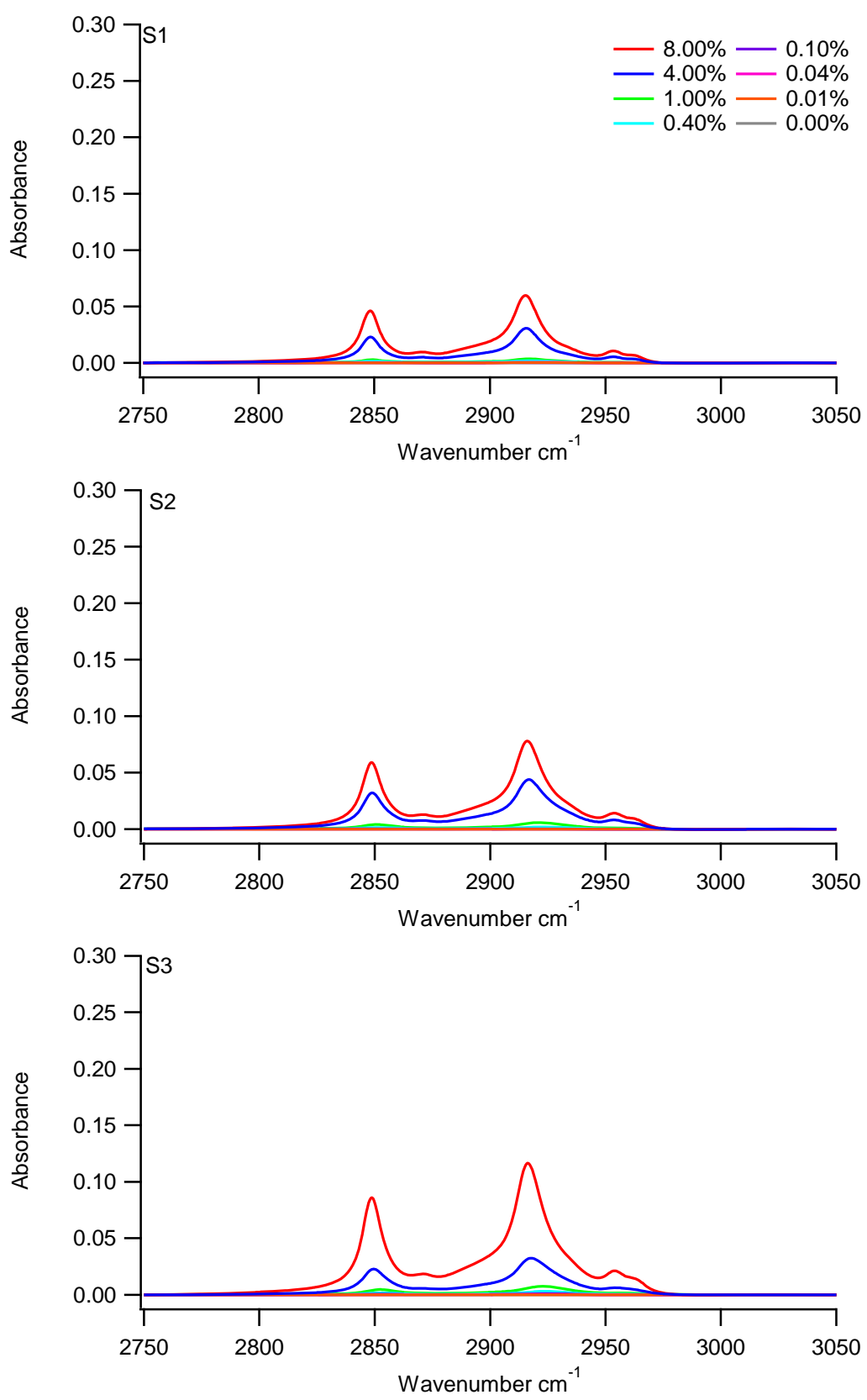

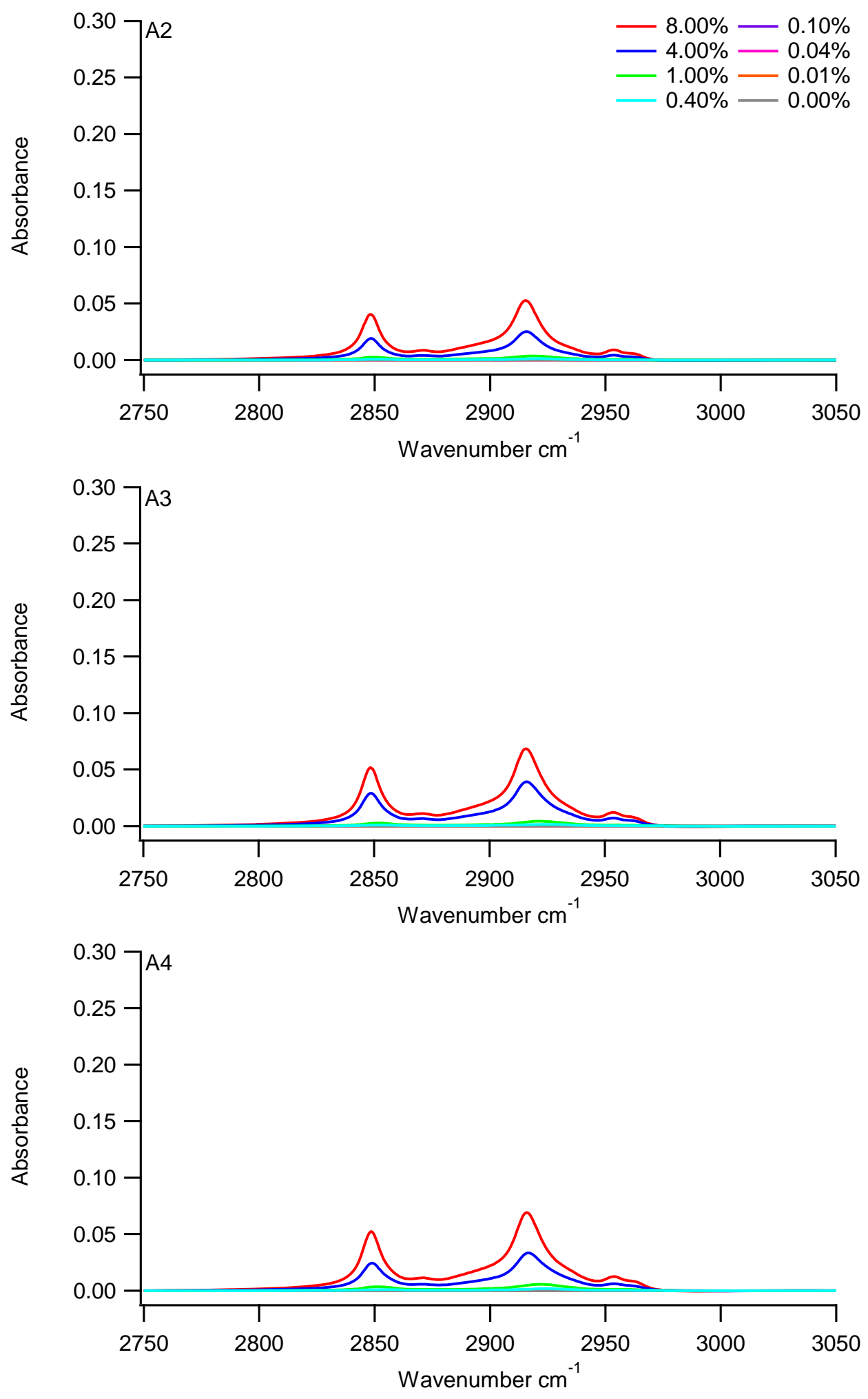

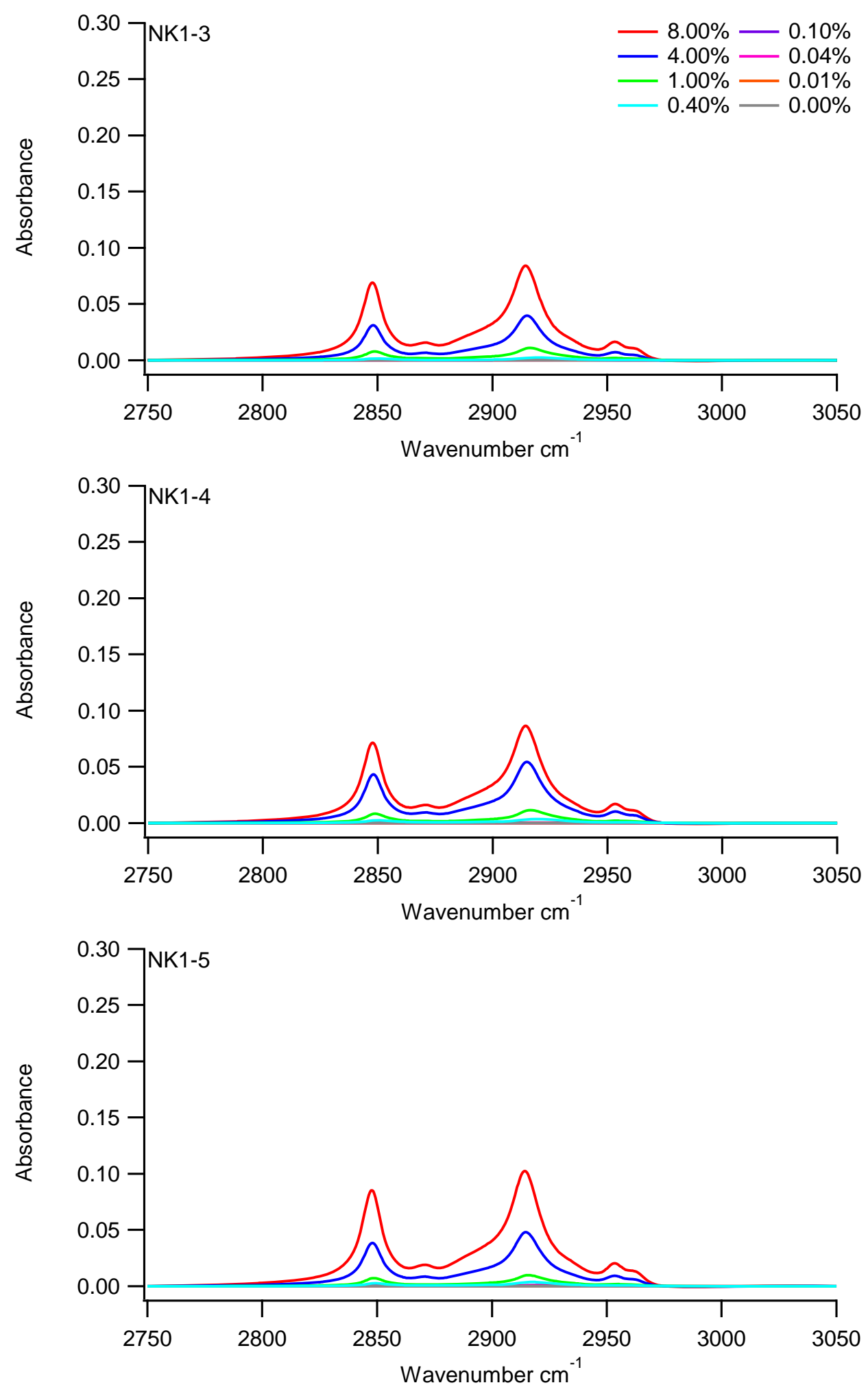


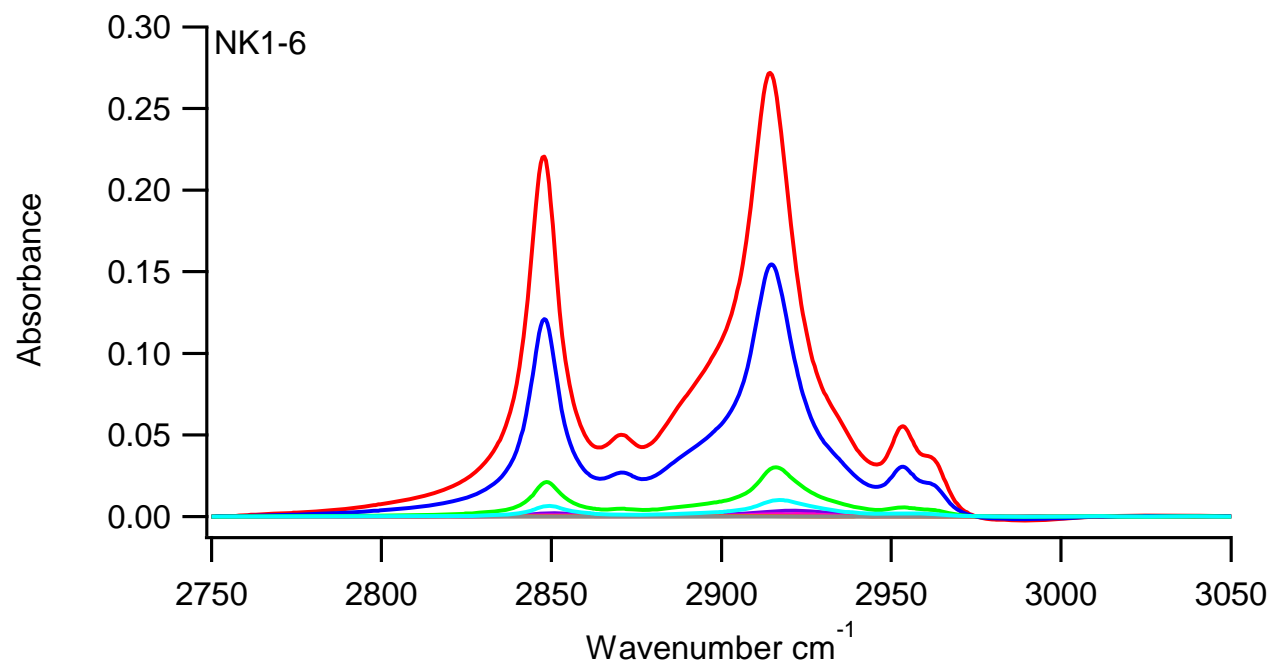

